\title{
Cavity Ring-Down Spectroscopy
}

in

\section{Combustion Environments}




\section{Pulsed Cavity Ring-Down Spectroscopy}

IN

COMbUSTION ENVIRONMENTS 
Pulsed Cavity Ring-Down in Combustion Environments

Rogier Evertsen

Thesis Katholieke Universiteit Nijmegen - Illustrated

With references - With summary in Dutch

ISBN 90-9016163-5

NUR 910

Subject headings: combustion diagnostics / laser spectroscopic techniques / cavity ring-down spectroscopy / flames

Cover by R. Evertsen 


\title{
Pulsed Cavity Ring-Down Spectroscopy
}

IN

\section{COMBUSTION ENVIRONMENTS}

EEN WETENSCHAPPELIJKE PROEVE OP HET GEBIED VAN DE NATUURWETENSCHAPPEN

\section{PROEFSCHRIFT}

\author{
TER VERKRIJGING VAN DE GRAAD VAN DOCTOR \\ AAN DE KATHOLIEKE UNIVERSITEIT NIJMEGEN \\ OP GEZAG VAN DE RECTOR Magnificus PRof. DR. C.W.P.M. Blom \\ VOLGENS BESLUIT VAN HET COLLEGE VAN DECANEN \\ IN HET OPENBAAR TE VERDEDIGEN \\ OP DINSDAG 12 NOVEMBER 2002, \\ DES NAMIDDAGS OM 3.30 UUR PRECIES
}

DOOR

\section{ROGIER EVERTSEN}

GEBOREN OP 1 AUGUSTUS 1972

TE HAARLEM 
Promotores

Co-promotor

Maunscriptcommissie
: Prof. Dr. J.J. ter Meulen

Prof. Dr. L.P.H. de Goey

: Dr. N.J. Dam
: Mevr. Dr. P. Desgroux

Université des Sciences et Technologies de Lille

Prof. Dr. H.B. Levinsky

Universiteit Groningen

Prof. Dr. D.H. Parker

\section{Gtw}

This research was supported by the Technology Foundation STW, applied science division of NWO and the technology programme of the Ministry of Economic Affairs. 
Voor Oma 



\section{VOORWOORD}

Van deze ontdekkingsreis met opdrachten, moeilijk begaanbare wegen en vol gevaren en valkuilen ligt hier een reisverslag in de vorm van een proefschrift. Het is een reis geweest naar nieuw te ontdekken plaatsen en met bezoeken aan bekende, maar niet eerder bezochte gebieden. Dit reisje maak je gelukkig niet alleen en in het bijzonder wil ik de mensen bedanken die direct met de tot standkoming van dit werk te maken gehad hebben:

Mijn promotor Hans ter Meulen die mij de mogelijkheid geboden heeft om aan dit onderzoek in Nijmegen te kunnen beginnen en het ook af te ronden. Uit Eindhoven mijn promotor Philip de Goey die het project waarbinnen dit onderzoek valt in goede banen geleid heeft, ondanks de tegenspoed. Nico Dam, die gelukkig mijn co-promotor is en ondanks de fysieke afstand door zijn kamer in de Graalburcht in ieder geval altijd telefonisch te bereiken was voor raadselachtig commentaar. De leden van de manuscript commissie prof. Levinsky, Mevr. dr. Desgroux en prof. Dave Parker voor het nauwkeurig bestuderen van het manuscript.

Natuurlijk wil ik alle collega's van de afdelingen bedanken, niet alleen voor raad maar ook voor de collegialiteit, gezelligheid en natuurlijk de taart.

In het bijzonder de oorspronkelijke 'vaste' kamerbewoners die de goede sfeer maakten: Michiel van Beek voor de vele verhelderende discussies, Robert Stolk voor de vlammende start en Mr. Diamond Ivan Buijnsters voor zijn onderricht in blues en jazz en het gebruik van zijn computer.

De bewoners van de Graalburcht, waar ik altijd een beetje een 'gast' ben gebleven maar waar ik in ieder geval wel een voorname plaats op de leenlijst bezette: Thijs Elenbaas, Marianna Sijtsema, Robert Klein-Douwel, Bas Bougie, Kasper Verbiezen, René Tolboom voor zijn heldere (beleids)inzichten, Erik-Jan van den Boom die als ik binnenkwam altijd met eetstokjes in de weer was, Charles Spaanjaars die op de valreep de lage-druk brander vorm gaf en Arjan van Vliet voor zijn (ongezonde) ondersteuning bij de hernieuwde dieselmotormeetpogingen.

De cavity ring-down mannen van Gerard Meijer van het eerste uur Richard Engeln en Giel Berden die mij op weg hielpen en ook hielden en natuurlijk Rudy van de Werken: na jouw 
vertrek werd het wel erg stil op het lab. Verder zou ik alle (oud)leden van de afdeling en de 'Nieuwegein'-groep willen bedanken en bij naam willen noemen: Tim Groot, Martina Kunze, Leo Meerts, Rik Berkelmans en voor de technische en secretariële ondersteuning Cor Sikkens, motorrijder Leander Gerritsen, Chris Timmer, Peter Claus, de saxofoonspecialist Eugene van Leeuwen, Harry van Brakel, Magda Speijers, Erna Gouwens en natuurlijk Ine Meijer.

Gelukkig kon ik ook werken met twee afstudeerders: de globetrotter Jan Matthijs ter Meulen, die naar de vlammen luisterde, maar wat verwarrende berichten ontving en die er spannende ontstekingsmethoden op na hield, en Gijs Franssen die nu hopelijk al een vlot woordje Pools kan wisselen met Iza en die ik succes wens met zijn promotieonderzoek. Joris Mooij bedankt voor de wiskundige hulp. Of course, I would also like to mention Angela Staicu, who visited us again and again and probably will also visit the department successfully in the future, and Angelica, Ralucca and Dragana, with whom I performed some of the final experiments.

In Eindhoven heb ik mij ook altijd op mijn gemak gevoeld en ik wil met name Jeroen van Oijen en Roy Hermanns danken voor hun hulp als ik weer eens een dringende vraag had of een probleem met datafiles in Windows en Karel-Joop Bosschaart voor de muziek/drink ervaringen en natuurlijk het experimentele werk.

Tot slot: natuurlijk was het totaal niet mogelijk geweest zonder de stimulans van mijn vrienden, studiegenoten en docenten. Maar in het bijzonder ben ik gelukkig met de nietaflatende steun van mijn vader, moeder en mijn zus(je) bij al mijn keuzes en beslissingen. En mijn lieve Barbara, die met mij hobbels en diepe dalen genomen heeft en met wie het samen nog mooier zal worden.

Rogier Evertsen

Nijmegen, Juli 2002 
Chapter 1: Introduction $\quad 1$

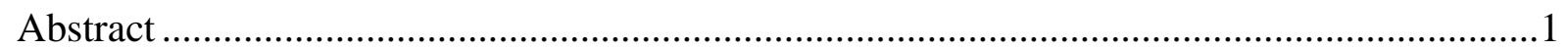

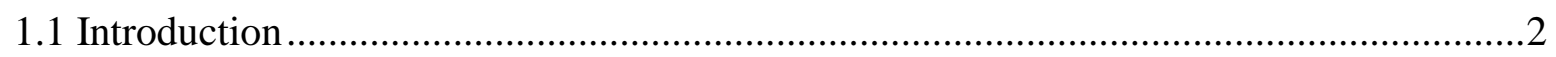

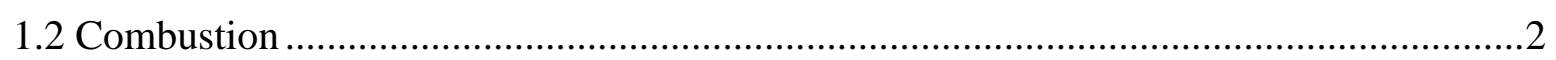

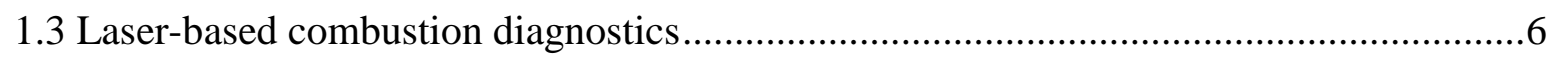

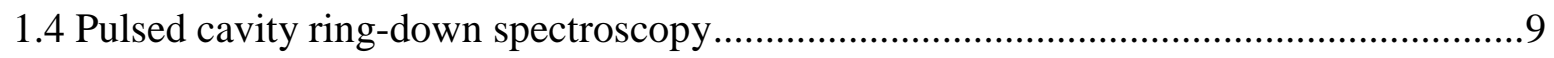

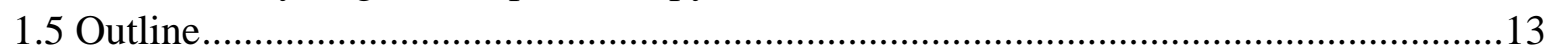

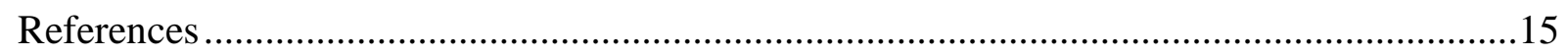

Chapter 2: Cavity Ring-Down Spectroscopy and Combustion Science 19

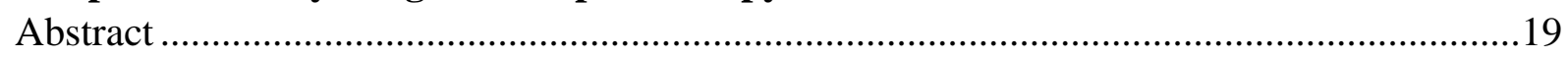

2.1 Application of cavity ring-down spectroscopy in combustion science..........................20

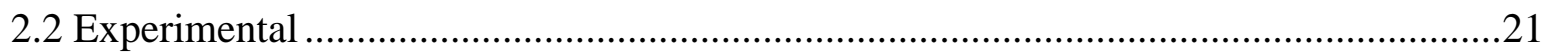

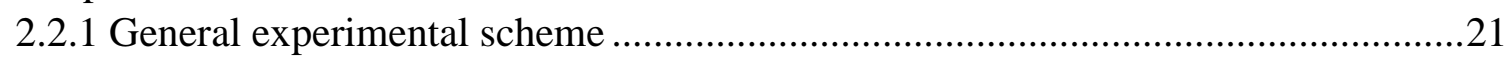

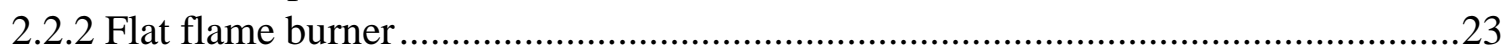

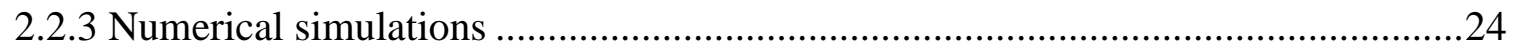

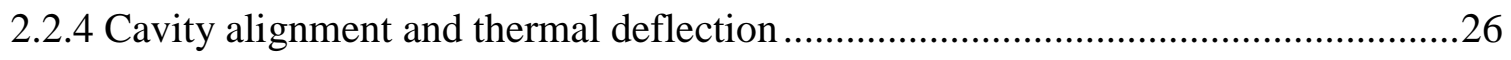

2.3 Temperature and density: the hydroxyl radical as an example ..................................29

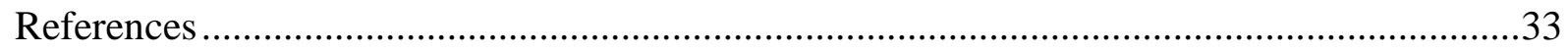

Chapter 3: Absolute CH Concentration Measurements in Premixed $\begin{array}{ll}\text { Atmospheric Flat Flames } & 37\end{array}$

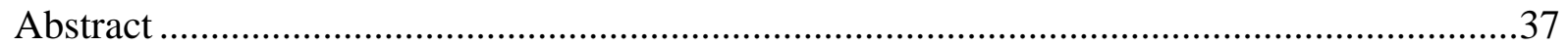

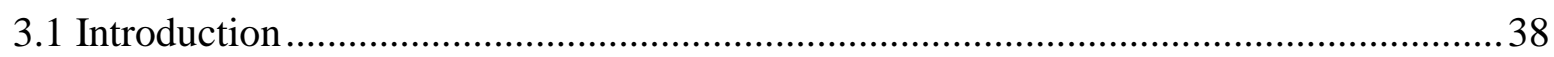

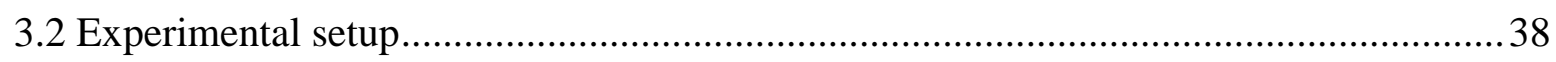

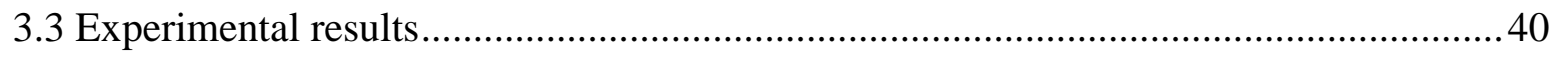

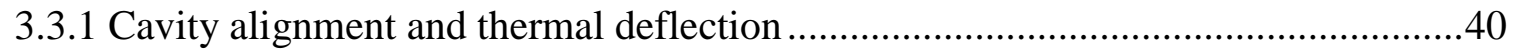

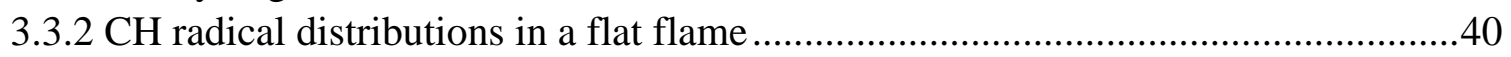

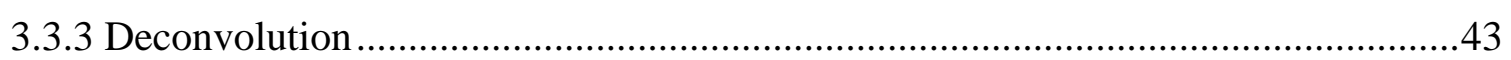

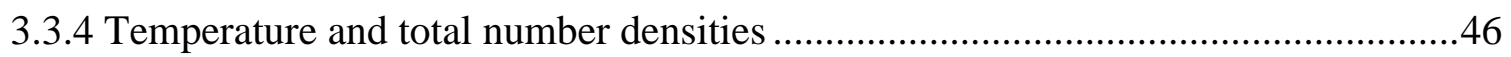

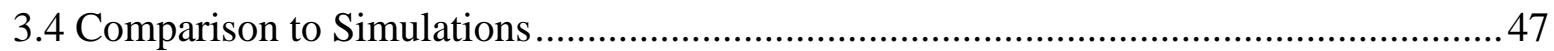

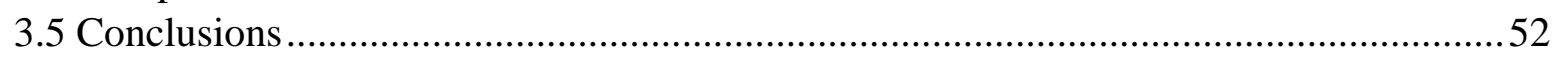

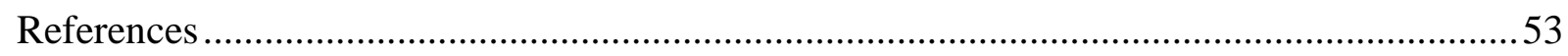


Chapter 4: Absolute $\mathrm{HCO}$ and ${ }^{1} \mathrm{CH}_{2}$ Concentration Measurements in a Premixed Atmospheric Flat Flame

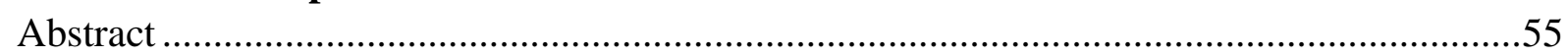

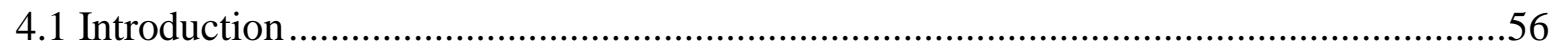

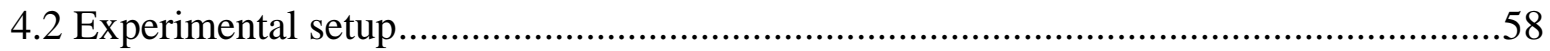

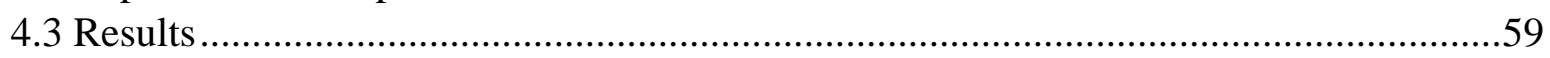

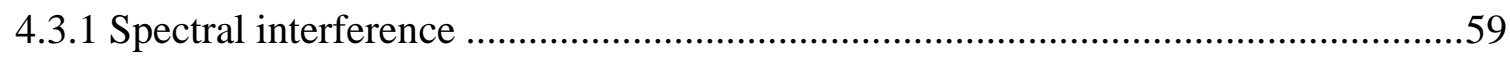

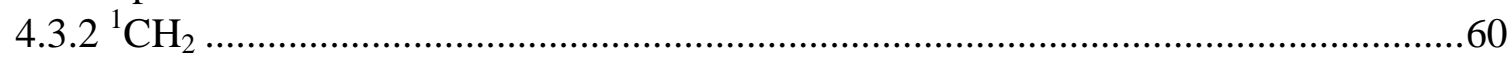

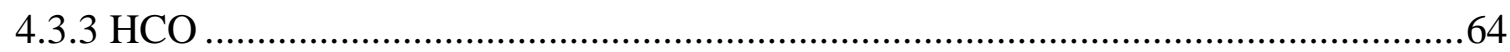

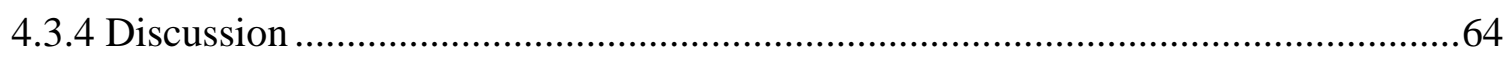

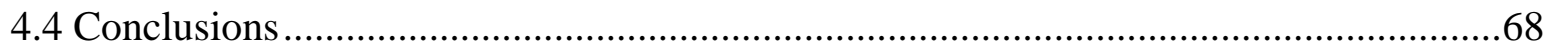

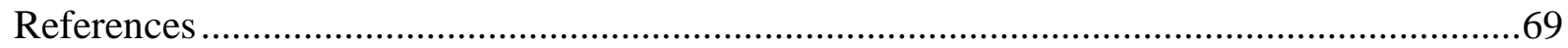

Chapter 5: Cavity Ring-Down Spectroscopy of $\mathrm{NO}$ and $\mathrm{NO}_{2}$ for Pollution

Analysis $\quad 71$

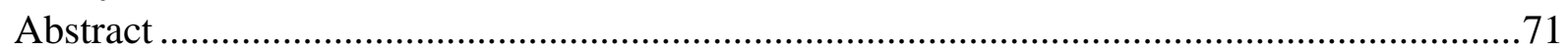

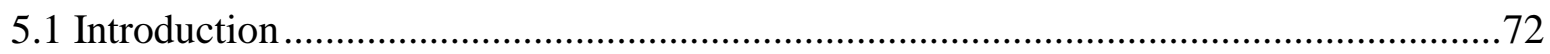

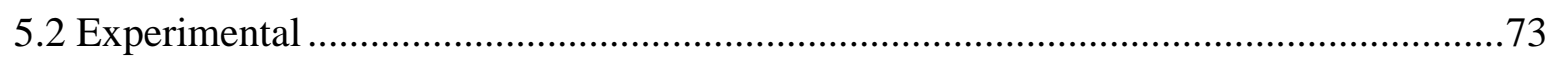

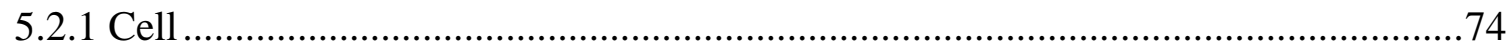

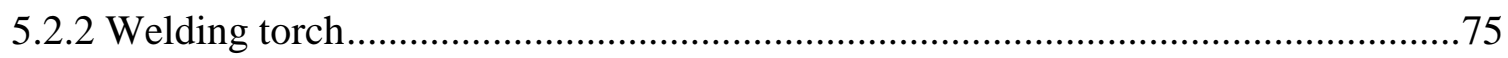

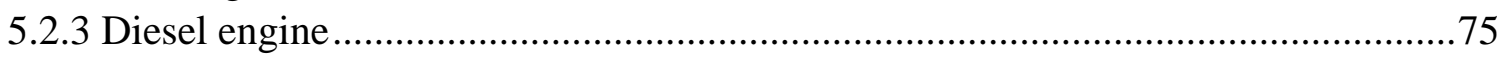

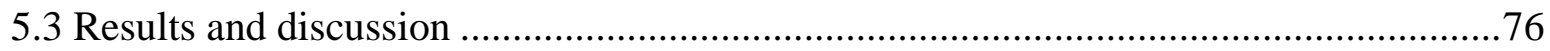

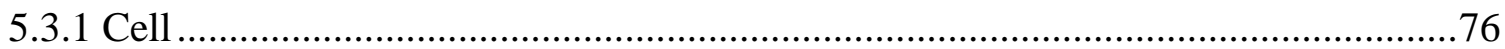

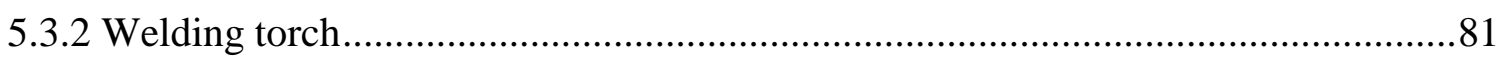

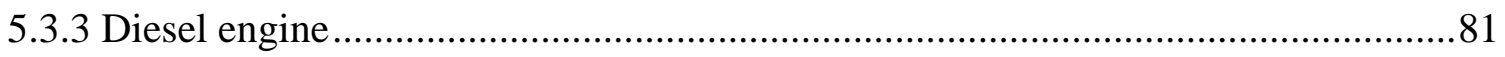

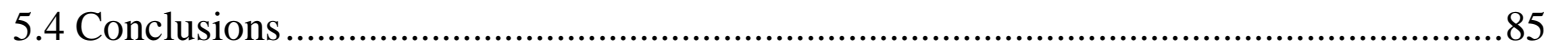

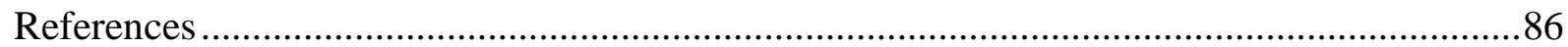

Chapter 6: Cavity Ring-Down Spectroscopy of a Low-Pressure Flat Flame 89

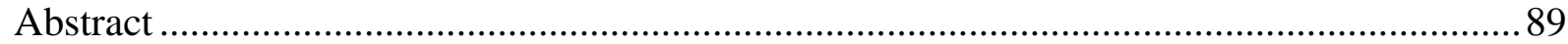

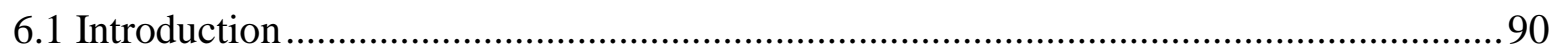

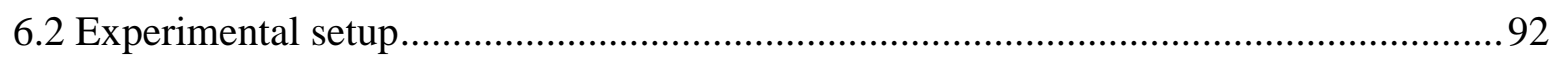

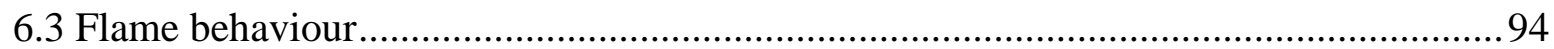

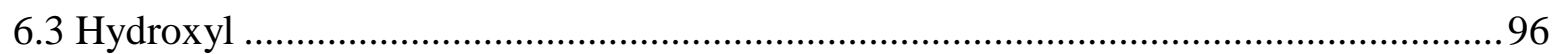

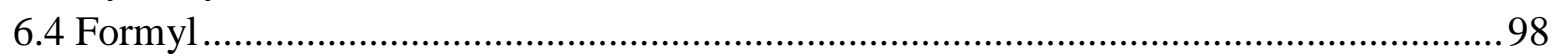

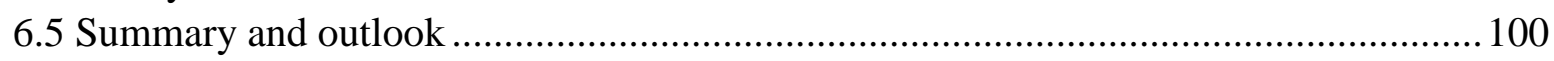

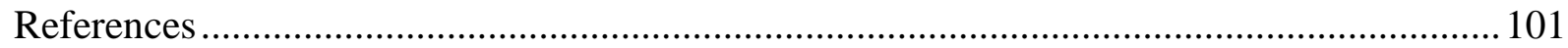

Chapter 7: Summary and Outlook $\quad 103$

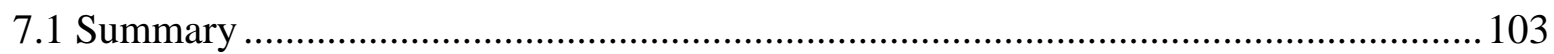

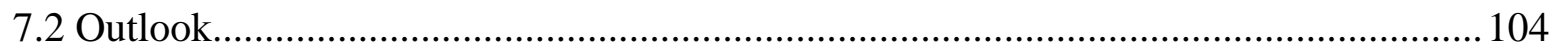

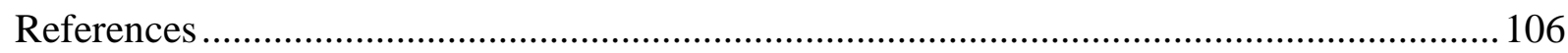

$\begin{array}{ll}\text { Samenvatting } & 107\end{array}$

Curriculum Vitae $\quad 113$

$\begin{array}{ll}\text { Publications } & 115\end{array}$ 


\title{
CHAPTER 1
}

\section{INTRODUCTION}

\begin{abstract}
The application of cavity ring-down spectroscopy to study species and temperature in flames and combustion gases is presented. This introductory chapter starts with a background to the research presented in this thesis. A few basic concepts in combustion and combustion processes are introduced, particularly with regard to premixed laminar flames. The most common laser-based diagnostic techniques for species and temperature in combustion research are reviewed and discussed briefly. The fundamentals of pulsed cavity ring-down absorption spectroscopy as a laser-based non-intrusive diagnostic tool are introduced and its advantages, disadvantages and possible pitfalls are discussed. Finally, the outline of this thesis is given.
\end{abstract}




\subsection{Introduction}

Combustion has made a major contribution to the development of human civilization. Thousands of years ago, mankind learned to handle fire, having first received it from nature, through vulcanoes or strokes of lightning. Eventually, this fire developed into advanced technological and scientific combustion methods, as can nowadays be found in everyday modern life [1]. Fire has often been represented as a gift from the gods, e.g. Prometheus delivering fire to the world, and has played both practical and religious roles, as in cooking, warfare and the visualisation of hell. Nowadays, combustion processes can be found almost everywhere. They are commonplace in many settings, for example in cars, gas turbines for electrical power generation, cooking stoves and central heating devices and boilers in households. Despite the efforts put into solar and wind energy production, combustion is still by far the predominant source of energy and will most likely stay so for at least the next 50 years [2]. As a result, the modern, industrial economy is a fuel economy with a growing energy consumption rate, depending heavily on the continuous supply of fossil fuels, such as oil and gas. A side effect of combustion processes is the formation of pollutants, which cause acid rain, smog, ozone layer depletion and global warming. To reduce these effects and to develop efficient combustion models, a good insight into the physics and chemistry of all processes involved is needed. To this end, various diagnostic tools have been developed to probe the, often hostile, combustion systems, which will be concisely reviewed below after a short introduction to combustion.

\subsection{Combustion}

Combustion processes can be classified according to the type of fuel: a distinction can be made between solid, gas or liquid combustion. The research presented in this thesis will be restricted to gas phase combustion and gaseous combustion products. In gas phase combustion, a further division can be made on the basis of the mixing of fuel and oxidizer, e.g. methane gas and air. When the fuel and oxidizer are mixed before combustion occurs, the flame is premixed, for example the blue flame of a well-aerated Bunsen burner, and in the other, extreme, case it is a totally non-premixed type of flame, e.g. the yellow, sooting flame of a candle. In addition, flames can be divided in classes depending on the flow speed and the structure of the flame. If the gas flow is laminar, the flames are laminar. In the other case, when the flow is turbulent (Reynolds number larger than approx. 2000), the flames can also be considered turbulent.

To describe the proportion to which the fuel and oxidizer are mixed we use the fuel equivalence ratio, $\phi$. This parameter is defined as the ratio of the mass fractions of fuel and oxidizer divided by the stoichiometric fuel/oxidizer ratio. A flame is said to be stoichiometric 
when the oxidizer and the fuel are both consumed completely during combustion with the formation of only carbon dioxide and/or water, and by definition $\phi=1$. If there is an excess of fuel, the system is called rich and $\phi>1$. In the other case, if there is an excess of oxidizer, the system is called lean and $\phi<1$.

The general structure of a premixed flame is given in Figure 1.1. The figure shows the change of the temperature and the fuel and oxidizer concentrations in a premixed flame as a function of the direction of progress of the combustion along the x-axis. The fuel and the oxidizer, in this case oxygen, are consumed during the progress of the reactions and combustion products are being formed. In Figure 1.1, the situation of a lean flame is sketched: the fuel is completely depleted whereas some oxygen is still present afterwards. The total process leads to an increase in temperature and the formation of products in the so-called reaction zone, with thickness $\delta$. Thermal conductivity leads to a heat flux upstream of the flame reaction zone and an increase in temperature in the so-called preheating zone.

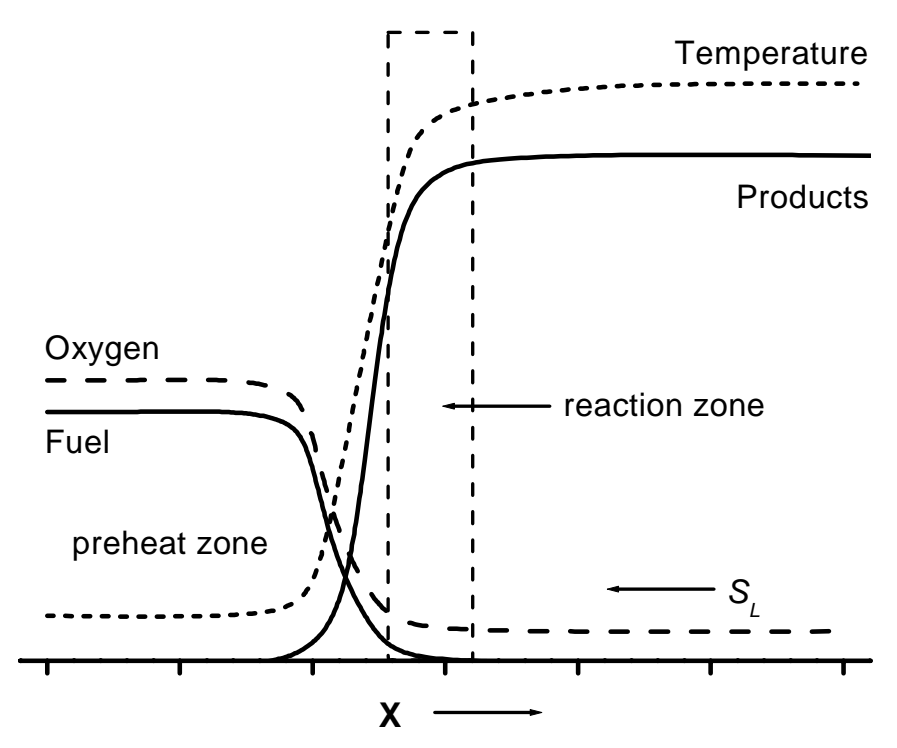

Figure 1.1: Global flame structure of a lean premixed flame with the burning velocity along the $x$-coordinate. The so-called reaction zone is presented as a dashed rectangle. The burning velocity is directed opposite to the flow direction of the unburned gases.

Premixed laminar flames, the subject of research in this thesis, can be characterized by the laminar burning velocity. The burning velocity is the velocity at which the flame front, roughly the bluish, visible part of the flame, travels through the unburned gases. Consider a static mixture of fuel and oxidizer inside a tube closed at one end. When the mixture is ignited at the other end of the tube, the flame front, which, except for wall effects, takes on the shape 
of a disk perpendicular to the tube axis, will propagate along the axis of the tube with a fixed velocity, i.e. to the flame front. The adiabatic burning velocity $S_{L}$ is the burning velocity of a freely propagating flame. For a given gas composition, the adiabatic burning velocity $S_{L}$ and the final temperature are only dependent on the initial conditions of the mixture: the unburned gas temperature, the equivalence ratio $\phi$ and the pressure. A flame is adiabatic when the heat generated by the chemical reactions is transferred completely to the gas mixture, i.e. there are no additional heat losses. In case of a premixed laminar flat flame burner, the direction of the burning velocity $S_{L}$ is opposite to the direction of the flow of the unburned gas mixture. If the burning velocity is larger than the velocity of the unburned gases the flame flashes back or stabilizes on the burner surface. If the burning velocity of a flat flame is less than the velocity of the unburned gases, the flame blows off. The reaction zone thickness $\delta$ and the flame thickness $\delta_{L}$, which includes both the preheating and the reaction zone, are for a laminar premixed flame related by $\delta_{L}=\beta \delta=D_{f} / S_{L}$, with $\beta$ the Zeldovich number and $D_{f}$ the thermal diffusivity [3]. The reaction zone thickness is roughly a factor of 10 smaller than $\delta_{L}$ and is for a premixed laminar flat flame at atmospheric pressure less than one-tenth of a millimeter wide.

Combustion processes can basically be regarded as chemically reacting flows. In principle, all types of flames can be described by a fixed set of equations: the equations for conservation of mass, species mass fractions, energy and momentum, including models for transport and radiation processes and a set of chemical reactions and reaction rate parameters. The overall reaction of the complete oxidation of methane by oxygen:

$$
\mathrm{CH}_{4}+2 \mathrm{O}_{2} \rightarrow 2 \mathrm{H}_{2} \mathrm{O}+\mathrm{CO}_{2}
$$

consists in reality of a large set of elementary chemical reactions. In order to model combustion accurately, the elementary steps and their reaction parameters must be known. In case of methane combustion, these are being heavily investigated. Complex reaction mechanisms for methane and air may comprise more than 300 elementary chemical reactions with 53 different species [4] as derived from experimental data from different fields of research. The reaction pathway for methane (or natural gas) combustion with its most important intermediates is schematically depicted in Figure 1.2 [5]. As can be seen from the figure, the conversion of methane to carbon monoxide proceeds via a specific number of reactants. The dominant pathway is called the $\mathrm{C}_{1}$-pathway, but the formation and oxidation of ethane $\left(\mathrm{C}_{2} \mathrm{H}_{6}\right)$ also plays a role and this $\mathrm{C}_{2}$-pathway should be considered as well if $\phi>1$. Under very fuel rich conditions, also $\mathrm{C}_{3^{-}}$and $\mathrm{C}_{4}$-pathways become important. The process develops via a complex sequence of chain initiating, propagating, branching and terminating reactions [6]. Comprehensive tabulations of the reactions and reaction parameters related to the combustion of methane and other fuels can be found in references $[3,5,6]$. 


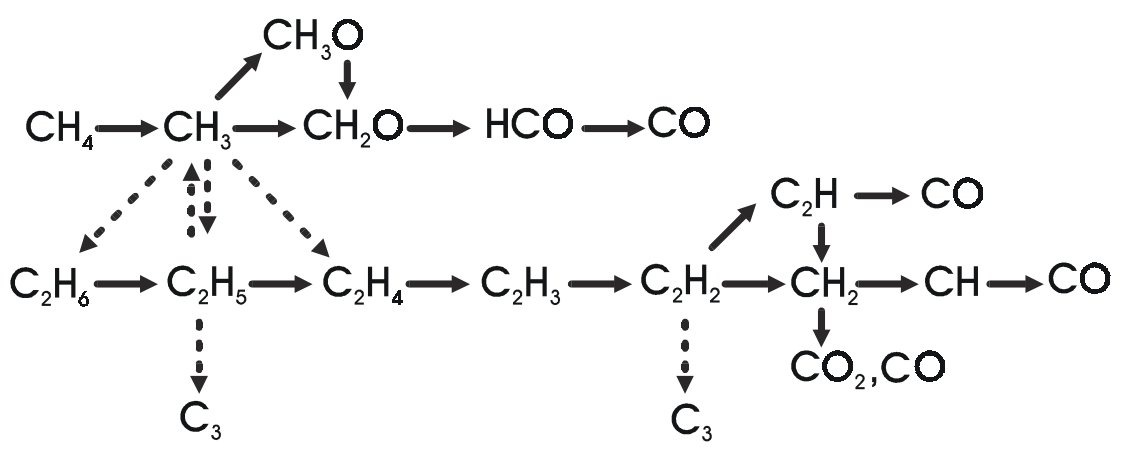

Figure 1.2: Schematic representation of the main reaction pathways with the central species in methane/air combustion under slightly fuel-rich conditions with the $C_{1^{-}}$(top) and $C_{2^{-}}$-chains (bottom) [5].

The continuous evaluation, improvement and extension of current reaction mechanisms is necessary to gain a good insight into combustion processes. It should be born in mind that computational approaches to model combustion can only be as accurate as the thermochemical and reaction rate values that form their input. The mechanism of methane combustion is fairly complete but still not firmly established or definitive, and many rate constants are still not accurately known in the relevant temperature ranges. The achievements of comprehensive theories on combustion can be evaluated using experimental research. Therefore, numerous experiments have been conducted to obtain temperature information and quantitative, spatially resolved, data on species densities. In particular, information on intermediate, minority species and radicals, sensitive to changes in the reaction mechanism, is indispensable to validate reaction mechanisms and numerical approaches.

\subsection{Laser-based combustion diagnostics}

A good diagnostic tool is needed to conduct experimental research in order to gain more detailed insight into combustion processes and to evaluate, improve or extend the currently available reaction mechanisms. It should be non-intrusive in nature to avoid any disturbances of the process under study and should be able to provide quantitative and unambiguous experimental data.

Optical emission spectroscopy is one of the oldest techniques that have been used to study flames $[7,8]$. As a result of chemical reactions, excited state species can be formed, which can relax to their ground state by the emission of a photon. The wavelength of the emitted light is species-specific and can be used for identification and for spatially resolving the flame structure. For example, excited $\mathrm{CH}$ is mainly responsible for the blue emission of methane/air 
flames. Although recently progress was made in the prediction and quantification of excited state species $[9,10]$, little quantitative work has been published using emission spectroscopy up to now. Its usefulness for flame studies is limited since no information about ground state species can be obtained.

Various laser-based diagnostic techniques have been applied to or developed in the field of combustion science [11]. The advantages of using laser-based techniques lie in their nonintrusive character and in the high spatial and temporal resolution that can in principle be achieved. A disadvantage may lie in the optical access, which is a prerequisite. Well-known, and less well-known, laser-based methods like laser Doppler-anemometry (LDA), phase-shift Doppler-anemometry (PDA), particle imaging velocimetry (PIV) and molecular tagging methods are currently used to measure flow field parameters in flames. Others, such as laserinduced incandescence (LII) are focussed on the measurement of soot. Such techniques fall outside the scope of this thesis, and will not be discussed further. Instead, we will focus on a number of laser-based methods with which absolute species densities and temperatures can be determined. A more comprehensive and complete discussion of the methods and their applications can be found in reference [11]. Below, a short description of some of these will be given, particularly in relation to combustion research.

\section{Absorption spectroscopy}

Absorption spectroscopy has long been used in combustion science [7]. It provides a direct method to obtain absolute species densities by measuring the transmitted intensity of a laser beam through the medium. Atoms and molecules can absorb electromagnetic radiation of specific frequencies. These frequencies are unique and present a 'fingerprint', which enables identification of the absorbing species, and through the spectral intensities quantification and determination of the temperature. The spectral intensity $I$ in the presence of absorption can be described according to Lambert-Beer's law [12]:

$$
I(v)=I_{0}(v) \exp \left(-\sum_{i} \sigma_{i}(v) \int_{0}^{l} N_{i}(x) \mathrm{d} x\right)=I_{0}(v) \exp (-\alpha(v) l)
$$

with $I_{0}$ the spectral intensity of the light incident on the sample containing the absorbing species $i, \sigma_{l}$ the frequency-dependent absorption cross-section, $N_{i}$ the number density of the absorbing species $i, l$ the absorption path length and $\alpha$ the effective absorption coefficient. Both broad-band light sources like high-pressure Hg-lamps in combination with dispersive elements like a grating or prism, and lasers can be used to irradiate a sample to determine the absorbance.

The method can be applied to stationary laminar flames. However, the absorbances result from the integration along the absorption path length as it is a line-of-sight technique and local densities can only be obtained by the application of tomographic techniques or in case of 
cylindrically symmetric flames with techniques like Abel inversion [13, 14]. The sensitivity in conventional absorption spectroscopy is limited, as a small intensity change has to be recorded on top of a large signal and intensity fluctuations of the light source add to the noise. In combination with light sources having stable output intensity, like continuous wave lasers such as diode lasers or tunable cw dye lasers, absorption ratios $\Delta I / I$ in the order of $10^{-5}$ can be reached. The versatile pulsed dye lasers used in many flame studies usually show large pulse-topulse intensity fluctuations, typically $10 \%$, which make them, in spite of their large spectral range, unsuitable for standard absorption measurement techniques. A way to lower the detection limit is by elongation of the absorption path length using multi-pass configurations like Herriott and White cells [15]. In such configurations, the light beam travels repeatedly through the sample medium using two or more mirrors. A disadvantage is that each time a different optical path through the medium is followed, resulting in a decreasing spatial resolution of the measurement. A further increase in sensitivity requires more sophisticated techniques such as frequency modulation [15]. High sensitivities can also be reached using the absorption-based technique cavity ring-down spectroscopy (CRDS), which has been explored in the research described in this thesis and will be considered in more detail in the next section.

\section{Intracavity laser absorption spectroscopy}

Intracavity laser absorption spectroscopy (ICLAS) is an enhancement of conventional absorption spectroscopy [16]. It is based on the change in the gain profile of a broad-band laser by placing the absorbing medium, i.e. the flame, inside a laser resonator. The light coupled out of the resonator is dispersed to obtain the absorption spectrum. Depending on the time evolution of the radiation inside the cavity, long absorption path lengths can be achieved. The sensitivity limits in combustion applications are comparable to those of pulsed cavity ring-down techniques [17]. However, the method requires a custom-built laser system, is not particularly flexible and difficult to employ in the UV-range.

\section{Laser induced fluorescence}

Laser induced fluorescence (LIF) is the most widely used technique in combustion because of its sensitivity, selectivity and high temporal and spatial resolution [11]. In short, a (laser) photon excites the species to a higher state, which is followed by the spontaneous decay back to a lower state under the emission of a photon. The technique is usually background free, though in case of flames a strong interference due to natural emission can occur. Twodimensional imaging is possible and planar LIF (PLIF) [18] can also be applied to unsteady combustion processes [19]. However, LIF is limited to the detection of fluorescing species. In addition, quantification in terms of absolute number densities is usually difficult. Due to the finite time it takes before radiative decay occurs after excitation, quenching of the electronically excited species by intermolecular collisions may take place. Particularly for combustion processes, with a large variation of species densities and temperatures, these 
quenching parameters are unknown or not completely known and calibration techniques can not always be applied. To circumvent these problems, several more complicated, and often less sensitive schemes have been developed, including predissociative LIF (LIPF) [20], picosecond LIF and bidirectional LIF [21].

\section{Raman Scattering}

In Raman spectroscopy, quenching problems are avoided. Raman scattering is based on the inelastic scattering of light in an essentially instantaneous process. However, signals are relatively weak due to very low scattering cross sections. This makes Raman-based detection schemes primarily applicable to the determination of majority species densities.

Coherent anti-Stokes Raman scattering (CARS) is a related, but non-linear technique. In the common detection scheme, two laser beams with frequency $\omega_{1}$ and a Stokes beam with frequency $\omega_{2}$ are crossed in a small probe section to generate the fourth, anti-Stokes Raman signal beam $\omega_{3}=2 \omega_{1}-\omega_{2}$. The technique is widely used to measure temperatures using majority species in flames with a high accuracy (typically $\pm 40 \mathrm{~K}$ ) [22, 23]. The configuration is quite complex and in addition, interference by other scattering mechanisms, notably fluorescence, may occur.

\section{Degenerate Four-Wave Mixing}

Degenerate four-wave mixing techniques are also based on non-linear processes, in which three laser beams intersect to produce a fourth, coherent, signal beam. The FWM grating techniques are dependent on absorption processes and have been applied for point measurements of temperature and species densities [24] and imaging of species in flames [25]. The experimental configuration is complex, but due to the coherent nature of the process the signal beam is virtually background free [11].

\section{Photoacoustic spectroscopy}

Photoacoustic absorption spectroscopy (PAS) is a technique that, in a sense, is complementary to LIF. It is based on the absorption of a (laser) photon by the species of interest. Rather than relaxation by fluorescence, the energy can be dissipated to the surroundings through collisions with the production of a sound wave. However, the sensitivity of PAS applied to open combustion systems seems to be limited [26, 27]. More successful results were reported using optoacoustic deflection schemes. In this scheme, the deflection of a laser beam is used to record changes in the medium after absorption [28-30]. Investigations with these techniques are limited to stable flames and to areas without steep temperature gradients. The spatial resolution is limited due to the small deflection angles. 


\subsection{Pulsed cavity ring-down spectroscopy}

In 1988, an absorption technique was introduced based on the time-dependent attenuation of the intensity of a laser pulse injected in an optical cavity containing the absorbing medium [31]. Originally developed to characterize coatings on mirror surfaces [32], this so-called cavity ring-down technique could accurately determine the reflectivity $R$ of the mirrors of the optical resonator. The method is based on the intensity change of light leaking out of the optical cavity as a function of time, instead of the absolute intensity change before and after absorption as measured in conventional absorption techniques. A comprehensive overview of the development and background of CRDS is given in references [33-36].

The general scheme is depicted in Figure 1.3 and consists basically of a stable optical cavity formed by two highly reflective concave mirrors between which the absorbing medium is placed, and a fast detector. A pulse of light is injected into the optical cavity which, for the moment, we will consider to be empty and composed of two identical mirrors, with reflectivities $R_{1}=R_{2}=R$ and radii of curvature $r$. The intensity of the pulse exiting the cavity after $n$ round-trips depends on the intensity $I_{0}$ initially coupled out of the cavity and the reflectivity $R$, and can be described by:

$$
I_{n}=I_{0} R^{2 n}
$$

The time it takes to traverse the cavity once is called the round-trip time $t_{r}$ and is given by $t_{r}=$ $2 d / c$, with $d$ the distance between the two mirrors and $c$ the speed of light. With a cavity shorter than the length of the light pulse, subsequent output pulses will overlap. Assuming limited detector response times (say on the order of the laser pulse duration), the timedependent intensity at the detection side can be described by an exponentially decaying function:

$$
I(t)=I_{0} \exp \left(\frac{-c|\ln R| t}{d}\right)=I_{0} \exp \left(\frac{-t}{\tau_{0}}\right)
$$

in which $\tau_{0}$, the $1 /$ e decay time of an empty cavity, is given by

$$
\tau_{0}=\frac{d}{c|\ln R|}
$$

Additional losses inside the cavity, for example after insertion of a flame and due to absorption of molecules and radicals, will result in a faster decay. When taking into account 


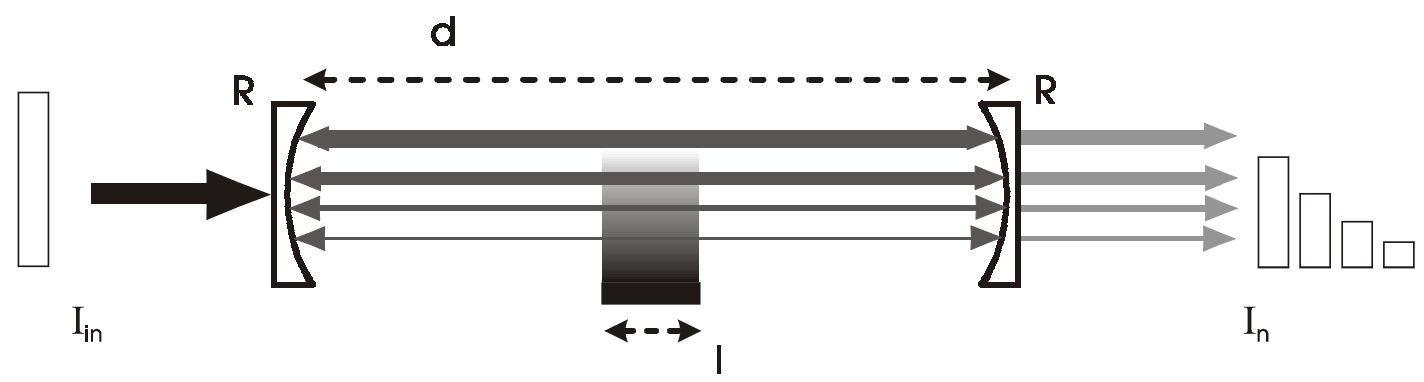

Figure 1.3: Principle of the cavity ring-down technique. A pulse of light with intensity $I_{\text {in }}$ is injected into a cavity composed of two highly reflective mirrors. Upon each reflection, part of the light is transmitted out of the cavity. This signal is recorded and will show a decaying intensity in time. Absorption of light by species inside the cavity will induce additional losses and a faster decay of the intensity of the train of pulses exiting the cavity.

the finite bandwidth of the laser radiation, a general expression for the time dependence of the light intensity transmitted through the cavity end mirror can be given as:

$$
I(t)=\int_{0}^{\infty} I(v) \exp \left(\frac{-t}{\tau(v)}\right) \mathrm{d} v
$$

with the cavity ring-down time $\tau(v)$ :

$$
\tau(v)=\frac{d}{c\left[|\ln R(v)|+\sum_{i} \sigma_{i}(v) \int_{0}^{d} N_{i}(x) \mathrm{d} x+\sum_{j} S_{j}(v)\right]}
$$

where the first summation includes losses due to all absorbing species $i$ with cross sections $\sigma_{i}(v)$ at frequency $v$ and number densities $N_{i}$ in the energy states from which the transitions take place, and the summation over $S_{j}$ includes all other scattering and broad-band absorption losses including Mie/Rayleigh scattering at frequency $v$ for the species $j$ or losses due to thermal deflection. From a measurement of the ring-down time versus frequency, both spectral and density information on absorbing species inside the cavity is obtained. In principle, the path-integrated species number density can be found if a single transition with a well-known absorption cross section $\sigma$ is induced, by measuring the on- and off-resonance decay times. Since $R(v) \approx 1,|\ln R(v)|$ can be approximated by $(1-R)$. To simplify the overall expression, all losses other than due to the absorption can be included in an effective reflectivity term $R_{\text {eff }}$, as normally only a narrow wavelength range is investigated and Rayleigh and Mie scattering 


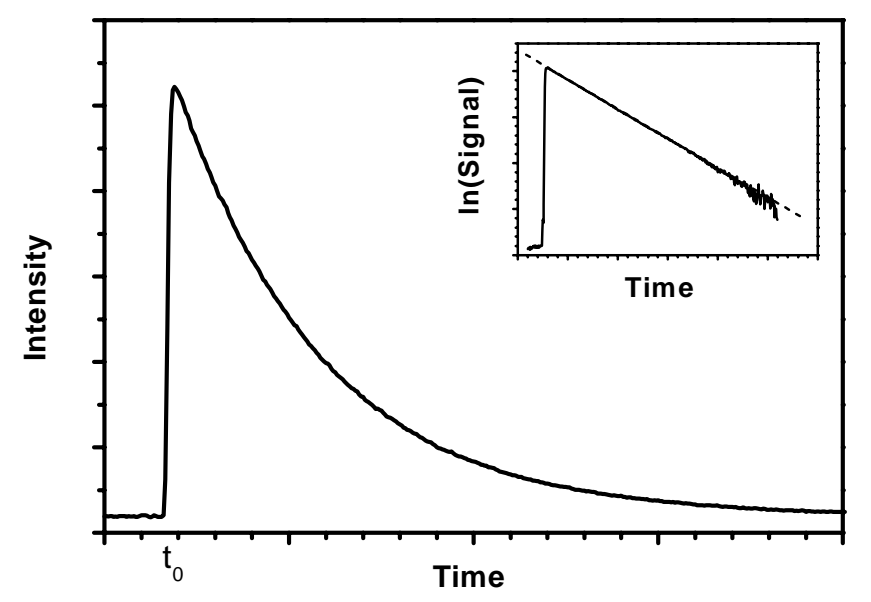

Figure 1.4: Typical cavity ring-down signal. The insertion shows a linear fit to the natural logaritm of the data as a function of the time.

cross-sections can then be assumed independent of frequency. Defining the non-resonant cavity ring-down time $\tau_{0}$ at frequency $v$ during an experiment as:

$$
\tau_{0}(v)=\frac{d}{c\left[1-R_{e f f}(v)\right]},
$$

the extinction coefficient, in this case given as $\kappa(v)=\sigma(v) N$ with $N$ taken constant over the absorption path length $l$, is obtained from the difference between the on- and off-resonance ringdown times:

$$
\kappa(v)=\frac{d}{c l}\left[\tau(v)^{-1}-\tau_{0}(v)^{-1}\right]
$$

\section{Detection limits}

The detection limit in CRDS depends on the reflectivity $R$ of the mirrors and on the accuracy with which the decay curve can be recorded and the ring-down time $\tau$ can be determined [37]:

$$
\kappa(v) l=\left(1-R_{\text {eff }}\right)\left(\frac{\Delta \tau(v)}{\tau(v)}\right)
$$

with $\Delta \tau(v)=\tau_{0}(v)-\tau(v)$. In addition to the insensitivity to pulse-to-pulse intensity fluctuations, the advantage of the technique clearly lies in the long absorption path lengths, 
which can be achieved using mirrors with a high reflectivity $R$. For example, a 1-m cavity with $R=0.9999$ results in a 1/e ringdown time of about $30 \mu \mathrm{s}$ and an absorption path length of about $10 \mathrm{~km}$. The accuracy in the determination of $\tau$ is in simple pulsed cavity ring-down experiments on the order of a few percent and is governed by the detection scheme and apparatus and the procedure to determine the ring-down time. Absorbance detection limits reported in pulsed CRDS applications are typically $10^{-6}$ to $10^{-10} \mathrm{~cm}^{-1}$.

\section{Bandwidth effects and cavity modes}

In order to be able to extract accurate quantitative data from cavity ring-down measurements, the influence of the absorption linewidth of the species, due to Doppler- and pressurebroadening, and of the finite bandwidth of the probe laser should be accurately known, just as in normal absorption spectroscopy. In general, it is assumed that the signal behaves as a single-exponential decaying function. However, particularly when the probe beam has a bandwidth larger than the linewidth of the transition and in case of strong absorptions [37-40], the signal may be composed of multiple exponentially decaying functions resulting in a multiexponential time dependence. Without careful consideration of this problem, an underestimation of the extinction coefficient $k(v)$ and thus of the species density occurs. The issue can be solved by (i) using narrow bandwidth lasers as compared to the linewidth of the transition, (ii) using only the first part of a cavity ring-down curve to determine the ring-down times, (iii) maintaining the absorptions losses small as compared to the cavity losses, and (iv) using the area below an absorption line (integrated absorption) of a spectral feature instead of the maximum and minimum, on- and off-resonance, ring-down values [37].

When considering the bandwidth of the laser and the linewidth of the absorption features, it should also be noted that the resonator itself has a mode structure. The cavity modes of the optical cavity, using Fabry-Pérot theory, are given by [12, 41]:

$$
v_{q n m}=\left[q+(n+m+1) \frac{\arctan (g)}{\pi}\right] \frac{c}{2 d}
$$

with the $g$-parameter of the cavity $g=1-d / r, q$ the longitudinal mode index, and $n, m$ the transversal mode indices. A cavity mode can be presented by $\mathrm{TEM}_{\mathrm{qmn}}$, where the $q$ is often omitted. As can be seen from (1.9), depending on the geometry of the cavity, the resonator has longitudinal and transversal modes at selected frequencies. A problem will occur when the cavity modes are not in resonance with the laser frequency and the linewidth of the laser is smaller than the frequency difference, i.e. spacing, between successive modes [37, 42]. In this case, absorption features can be missed. To avoid this, a stable, non-confocal resonator should be employed with a near-continuum mode spectrum [43], satisfying $0<d<r$ or $r<d<2 r$ [41]. In practice, the bandwidth of the pulsed laser source is larger than the mode spacing of the cavity and multiple modes are excited. Mode-beating occurs as a result of multi-mode 
excitation [44], but can be minimised using a mechanically unstable cavity, by the excitation of multiple modes without using mode-matching optics [45] and averaging over several laser pulses. In the case of multi-mode excitation, the light from all the cavity modes should be carefully collected for detection, either by placement of the detector directly behind the cavity mirror or by using a lens to focus the signal beams.

\section{Applications}

Pulsed cavity ring-down spectroscopy is a relatively simple method, and quantitative data can, apart from the careful consideration of the bandwidth, be easily obtained. However, it is clear that CRDS is a line-of-sight absorption technique and cavity losses are obtained from integration along the path length of the cavity and the absorber. Local absolute densities can be obtained in case of cylindrical symmetry from a series of longitudinal measurements by applying Abel inversion or onion-peeling techniques $[13,14]$. In addition, due mainly to the low duty-cycle of commercial pulsed laser systems, the temporal resolution tends to be poor, particularly when multiple pulses have to be averaged to obtain good signal-to-noise ratios.

The applicability, versatility and sensitivity of the method have been established in numerous publications, including applications to the field of trace gas detection [38], molecular beam studies [35, 46], spectroscopic studies [46, 47], combustion research [48, 49], and plasma research $[50,51]$; see $[36,52]$ for a recent review. Up to now, the number of papers per year is still growing. In the next chapter the application of CRDS to combustion research is shortly reviewed.

\subsection{Outline}

In this thesis, a study of the application of cavity ring-down spectroscopy to detect minority species in flames and combustion gases is presented. This introductory chapter provides a framework as a reference for the experiments described in the following chapters, with a concise introduction to premixed laminar combustion and laser-based non-intrusive diagnostic techniques and, in particular, pulsed cavity ring-down spectroscopy. In Chapter 2, a short section on recent applications of CRDS to combustion science is followed by a general outline of the experimental setup, details on the burner design and experimental aspects regarding the alignment procedure and beam steering. The chapter concludes with some results of the CRDS and direct absorption detection of the $\mathrm{OH}$ radical in a flat flame to determine temperature and absolute densities. Chapters 3 and 4 present the results of the application of CRDS to investigate minority species in a burner-stabilised methane/air flat flame. In Chapter 3 , a detailed investigation of the occurrence of $\mathrm{CH}$ in the flat flame at different conditions is presented. The experimental results are compared to numerical simulations, and possible causes for differences are discussed. Chapter 4 presents the results for the detection of HCO 
and ${ }^{1} \mathrm{CH}_{2}$ radicals under the same experimental conditions. This chapter also shows the difficulties and problems that are encountered and have to be tackled in combustion research at atmospheric pressures. Chapter 5 presents the application of CRDS for the monitoring of $\mathrm{NO}$ and $\mathrm{NO}_{2}$, collectively called $\mathrm{NO}_{x}$, in combustion gases. These environmentally important species are studied in the combustion gas of an oxyacetylene flame and in the exhaust gas of a diesel engine. In Chapter 6, CRDS experiments conducted in a low-pressure flat flame setup are described. The resulting density profiles of the $\mathrm{OH}$ and the $\mathrm{HCO}$ radical are presented and compared with numerical simulations. Finally, Chapter 7 presents a short outlook on future developments in the field of combustion diagnostics and cavity ring-down spectroscopy. 


\section{References}

1. Goudsblom, J.: Fire and civilization, The Penguin Press, London, 1992.

2. Global Business Environment: Energy needs, choices and possibilities, scenarios to 2050, Shell International, 2001.

3. Glassman, I.: Combustion, Academic Press, San Diego, CA, 1996.

4. Smith, G.P., Golden, D.M., Frenklach, M., Moriarty, N.W., Eiteneer, B., Goldenberg, M., Bowman, C.T., Hanson, R.K., Soonho Song, Gardiner Jr., W.C., Lissianski, V.V., Qin, Z., GRI-Mech 3.0. http://www.me.berkeley.edu/gri_mech/ (2000).

5. Warnatz, J., Maas, U., Dibble, R.W.: Combustion, Springer Verlag, Berlin, 1996.

6. Westbrook, C.K., Dryer, F.L., Chemical kinetic modeling of hydrocarbon combustion. Proc. Energy Combust. Sci. 10:1-52 (1984).

7. Gaydon, A.G., Wolfhard, H.G.: Flames, their structure, radiation and temperature, Chapman and Hall, London, 1979.

8. Pearse, R.W.B., Gaydon, A.G.: The identification of molecular spectra, 4th ed., Chapman and Hall, London, 1976.

9. Luque, J., Jeffries, J.B., Smith, G.P., Crosley, D.R., Walsh, K.T., Long, M.B., Smooke, M.D., $C H(A-X)$ and $\mathrm{OH}(\mathrm{A}-\mathrm{X})$ optical emission in an axisymmetric laminar diffusion flame. Combust. Flame 122:172175 (2000).

10. Walsh, K.T., Long, M.B., Tanoff, M.A., Smooke, M.D., Experimental and computational study of $C H$, $\mathrm{CH}^{*}$, and $\mathrm{OH}^{*}$ in an axisymmetric laminar diffusion flame. Proc. Combust. Inst. 27:615-623 (1998).

11. Eckbreth, A.C.: Laser Diagnostics for combustion temperature and species, 2nd ed., Gordon and Breach Publishers, Amsterdam, 1996.

12. Demtröder, W.: Laser spectroscopy, 2nd. ed., Springer Verlag, Berlin, 1998.

13. Zalicki, P., Ma, Y., Zare, R.N., Wahl, E.H., Owano, T.G., Kruger, C.H., Measurement of the methyl radical concentration profile in a hot-filament reactor. Appl. Phys. Lett. 67:144-146 (1995).

14. Stolk, R.L., Ter Meulen, J.J., Laser diagnostics of CH in a diamond depositing flame. Diamond Relat. Mater. 8:1251-1255 (1999).

15. Werle, P., A review of recent advances in semiconductor laser based gas monitors. Spectrochim. Acta A 54:197-236 (1998).

16. Baev, V.M., Latz, T., Toschek, P.E., Laser intracavity absorption spectroscopy. Appl. Phys. B 69:171202 (1999).

17. Cheskis, S., Quantitative measurements of absolute concentrations of intermediate species in flames. Prog. Energy Combust. Sci. 25:233-252 (1999).

18. Bombach, R., Kappeli, B., Simultaneous visualisation of transient species in flames by planar-laserinduced fluorescence using a single laser system. Appl. Phys. B 68:251-255 (1999).

19. Paul, P.H., Najm, H.N., Planar laser-induced fluorescence imaging of flame heat release rate. Proc. Combust. Inst. 27:43-50 (1998).

20. Spaanjaars, J.J.L., Ter Meulen, J.J., Meijer, G., Relative predissociation rates of $O H\left(A^{2} \Sigma\right.$, $\left.v^{\prime}=3\right)$ from combined cavity ring down-laser-induced fluorescence measurements. Chem. Phys. 107:2242-2248 (1997).

21. Schreel, K.R.A.M., Versluis, M., De Goey, L.P.H., The quantitative detection of OH densities in reactive flows using bi-directional LIF. Proc. Combust. Inst. 29:submitted (2002). 
22. Bosschaart, K.J., Versluis, M., Knikker, R., Van der Meer, Th. H., Schreel, K.R.A.M., De Goey, L.P.H., Van Steenhoven, A.A., The heat flux method for producing burner stabilized adiabatic flames: an evaluation with CARS thermometry. Combust. Sci. and Techn. 168:1-19 (2001).

23. Hancock, R.D., Bertagnolli, K.E., Lucht, R.P., Nitrogen and hydrogen CARS temperature measurements in a hydrogen/air flame using a near-adiabatic flat-flame burner. Combust. Flame 109:323-331 (1997).

24. Farrow, R.L., Rakestraw, D.J., Analysis of degenerate four-wave mixing spectra of $\mathrm{NO}_{\text {in }}$ a $\mathrm{CH}_{4} / \mathrm{N}_{2} / \mathrm{O}_{2}$ flame. Appl. Phys. B 68:741-747 (1999).

25. Hall, G., Whitaker, B.J., Laser-induced grating spectroscopy. J. Chem. Soc. Faraday Trans. 90:1-16 (1994).

26. Allen, J.E., Anderson, W.R., Crosley, D., Optoacoustic pulses in a flame. Opt. Lett. 1:118-120 (1977).

27. Ter Meulen, J.M., Photoacoustics in flames, Internal report, University of Nijmegen, 1999.

28. Tennal, K., Salamo, G.J., Gupta, R., Minority species concentration measuments in flames by photoacoustic techniques. Appl. Opt. 21:2133-2140 (1982).

29. Smith, G.P., Dyer, M.J., Crosley, D.R., Pulsed laser optoacoustic detection of flame species. Appl. Opt. 22:3995-4003 (1983).

30. Kizimis, S.W., Brecha, R.J., Ganguly, B.N., Goss, L.P., Gupta, R., Hydroxyl distributions and temperature profiles in a premixed propane flame obtained by laser deflection techniques. Appl. Opt. 23:3873-3881 (1984).

31. O'Keefe, A., Deacon, D.A.G., Cavity ring-down optical spectrometer for absorption measurements using pulsed laser sources. Rev. Sci. Instrum. 59:2544-2551 (1988).

32. Anderson, D.Z., Frisch, J.C., Masser, C.S., Mirror reflectometer based on optical cavity decay time. Appl. Opt. 23:1238-1245 (1984).

33. Busch, K.W., Busch, M.A., eds., Cavity ring down spectroscopy, American Chemical Society, Washington DC, 1999.

34. Wheeler, M.D., Newman, S.M., Orr-Ewing, A.J., Ashfold, M.N.R., Cavity ring-down spectroscopy. J. Chem. Soc., Faraday Trans 94:337-3351 (1998).

35. Scherer, J.J., Paul, J.B., O'Keefe, A., Saykally, R.J., Cavity ring-down laser absorption spectroscopy: History, development, and application to pulsed molecular beams. Chem. Rev. 97:25-51 (1997).

36. Berden, G., Peeters, R., Meijer, G., Cavity ring down spectroscopy: experimental schemes and applications. Int. Rev. Phys. Chem. 19:565-607 (2000).

37. Zalicki, P., Zare, R.N., Cavity ring-down spectroscopy for quantitative absorption measurements. J. Chem. Phys. 102:2708-2717 (1995).

38. Jongma, R.T., Boogaarts, M.G.H., Holleman, I., Meijer, G., Trace gas detection with cavity ring down spectroscopy. Rev. Sci. Instrum. 66:2821-2828 (1995).

39. Hodges, J.T., Looney, J.P., Van Zee, R.D., Laser bandwidth effects in quantitative cavity ring-down spectroscopy. Appl. Opt. 35:4112-4116 (1996).

40. Newman, S.M., Lane, I.C., Orr-Ewing, A.J., Newnham, D.A., Ballard, J., Integrated absorption intensity and Einstein coefficients for the $\mathrm{O}_{2} a^{1} \Delta_{g}-X^{3} \Sigma_{g}^{-}(0,0)$ transition. J. Chem. Phys. 22:1074910757 (1999).

41. Siegman, A.E.: Lasers, University Science Books, Sausalito, 1986.

42. Lehmann, K., Romanini, D., The superposition principle and cavity ring-down spectroscopy. J. Chem. Phys. 105:10263-10277 (1996).

43. Meijer, G., Boogaarts, M.G.H., Jongma, R.T., Parker, D.H., Wodtke, A.M., Coherent cavity ring down spectroscopy. Chem. Phys. Lett. 217:112-116 (1994). 
44. Van Zee, R.D., Hodges, J.T., Looney, J.P., Pulsed, sing;e-mode cavity ringdown spectroscopy. Appl. Opt. 38:3951-3960 (1999).

45. Hodges, J.T., Looney, J.P., Van Zee, R.D., Response of a ring-down cavity to an arbitrary excitation. J. Chem. Phys. 105:10278-10288 (1996).

46. Huestis, D.L., Copeland, R.A., Knutsen, K., Slanger, T.G., Jongma, R.T., Boogaarts, M.G.H., Meijer, G., Branch intensities and oscillator strenghts for the Herzberg absorption systems in oxygen. Can. J. Phys. 72:1109-1121 (1994).

47. Naus, H., Navaian, K., Ubachs, W., The $\gamma$-band of ${ }^{16} \mathrm{O}_{2},{ }^{16} \mathrm{O}^{17} \mathrm{O},{ }^{17} \mathrm{O}_{2}$ and ${ }^{18} \mathrm{O}_{2}$. Spectrochim. Acta A 55:1255-1262 (1999).

48. Mercier, X., Therssen, E., Pauwels, J.F., Desgroux, P., Cavity ring-down measurements of OH radical in atmospheric premixed and diffusion flames. A comparison with laser-induced fluorescence and direct laser absorption. Chem. Phys. Lett. 299:75-83 (1999).

49. Cheskis, S., Derzy, I., Lozovsky, V.A., Kachanov, A., Romanini, D., Cavity ring-down spectroscopy of OH radicals in low pressure flames. Appl. Phys. B 66:377-381 (1998).

50. Miller, G.P., Winstead, C.B., Inductively coupled plasma cavity ringdown spectroscopy. J. Anal. Atom. Spectrom. 12:907-912 (1997).

51. Engeln, R., Letourneur, K.G.Y., Boogaarts, M.G.H., Van de Sanden, M.C.M., Schram, D.C., Detection of $\mathrm{CH}$ in an expanding argon/acetylene plasma using Cavity Ring Down Absorption Spectroscopy. Chem. Phys. Lett. 310:405-410 (1999).

52. Peeters, R., Cavity enhanced absorption spectroscopy, Ph.D. thesis, University of Nijmegen, Nijmegen, the Netherlands, 2001. 



\title{
CHAPTER 2
}

\section{CAVITY RING-DOWN SPECTROSCOPY AND COMBUSTION SCIENCE}

\begin{abstract}
A short overview is given of the application of cavity ring-down spectroscopy in combustion processes described in literature. The experimental setup and the practical implications of the application of the method to premixed flames are presented. As an example of the potential of the technique, the detection of $\mathrm{OH}$ found in the flame of a laminar premixed flat flame burner is described, assessing sensitivity, absolute number densities and temperature.
\end{abstract}




\subsection{Application of cavity ring-down spectroscopy in combustion science}

Cavity ring-down spectroscopy (CRDS) is becoming a widely accepted technique for applications in the field of combustion due to its clear advantages of sensitivity and absolute measurement results [1]. Since the first application in 1994 by Meijer and coworkers for the detection of $\mathrm{OH}$ at $308 \mathrm{~nm}$ and the determination of temperature in a Bunsen flame at atmospheric pressure [2], the number of reported studies has been growing steadily. However, research has mainly focussed on detection of molecules and radicals in combustion environments at reduced pressures, due to the small flame structures and the related experimental difficulties at atmospheric pressure, and applications seem to be limited to stable, non-turbulent combustion processes.

A small set of different radicals has been detected in low-pressure flame setups. The $\mathrm{OH}$ [3] and $\mathrm{HCO}$ [4] radicals have been detected in the stoichiometric $\mathrm{CH}_{4} / \mathrm{N}_{2} / \mathrm{O}_{2}$ flame of a McKenna burner. Suprisingly, the $\mathrm{OH}$ concentrations found were two times lower than were expected from numerical calculations. Lozovsky et al. studied the $\mathrm{OH}$ radical, using $\mathrm{A}^{2} \Sigma \leftarrow \mathrm{X}^{2} \Pi, \mathrm{v}^{\prime \prime}=0$ and 1 transitions, which resulted in the conclusion that, at positions close to the burner surface, deviations from thermal equilibrium can be found for the $v^{\prime \prime}=1$ state $[5,6]$. Derzy et al. measured the $\mathrm{C}-\mathrm{X}$ transition of $\mathrm{CH}$ at $330 \mathrm{~nm}$ [7] and obtained $\mathrm{CH}$ and $\mathrm{NH}$ profiles for a methane/air flame doped with $\mathrm{N}_{2} \mathrm{O}[8,9]$. Thoman and McIlroy studied $\mathrm{CH}$, $\mathrm{OH}, \mathrm{HCO}$ and ${ }^{1} \mathrm{CH}_{2}$ radicals in rich methane/oxygen/argon flames by CRDS [10-12]. A predissociation study of $\mathrm{CH} \mathrm{B}^{2} \Sigma^{-}\left(\mathrm{v}^{\prime}=0,1\right)$ levels was performed by Luque et al. using analysis of the spectral broadening [13-15]. Mercier et al. measured CH C-X and B-X and OH A-X bands in a methane/air flame [16], and detected $\mathrm{CN}$ in a premixed rich methane/air flame with and without doping with NO achieving detection limits in the ppb-range [17]. In a different study, they investigated NO and the contribution of NO in the volume surrounding the flame to the NO signal in a flame seeded with NO, and used LIF to correlate this with an unseeded flame [18]. $\mathrm{H}_{2} \mathrm{O}, \mathrm{CH}_{4}$ and $\mathrm{OH}$ have all been subject to study by CRDS in the infrared wavelength region at $1.6 \mu \mathrm{m}$ and $3.3 \mu \mathrm{m}[19,20]$. Luque et al. combined the quantitative aspect of CRDS with LIF line measurements, in an attempt to attach absolute number densities to the LIF image without elaborate calibration procedures, and constructed 2D images of species densities in studies on $\mathrm{CH}, \mathrm{CN}$ and $\mathrm{CH}_{2} \mathrm{O}[15,21]$. They found a slight curvature of their flame from the LIF images and concluded that correction of the line-of-sight CRDS data was necessary to obtain correct absolute number densities.

Thus far, the number of studies on atmospheric flames has been limited. Mercier et al. [22] compared CRDS, direct absorption spectroscopy and LIF for the quantitative analysis of $\mathrm{OH}$ radical concentrations and spatial profiles in a premixed flat flame burner and in a WolfhardParker burner. They commented on the limited dynamic range of OH CRDS measurements, which could be improved by a factor of ten when a model of the multi-exponential effect due to the finite laser bandwidth was included in the determination of the ring-down times, shown 
in practise in a low-pressure study [16]. In a different study, they reported absolute $\mathrm{CH}$ number densities in an atmospheric diffusion flame using the $\mathrm{C}-\mathrm{X}$ system for detection and made a comparison with LIF detection [23]. The overtones of $\mathrm{H}_{2} \mathrm{O}$ in the near-infrared, 810 to $820 \mathrm{~nm}$, range have been recorded by Xie et al. in both a methane/air laminar flat flame burner and a propane premixed jet [24]. Stolk and Ter Meulen studied the CH A-X transition at $430 \mathrm{~nm}$ in a diamond-depositing oxyacetylene flame, correlating the $\mathrm{CH}$ density and diamond growth rates [25-27]. In the same oxyacetylene flame, under freely burning conditions, profiles for $C_{2}$ in the $A^{1} \Pi_{u}$ excited state around $360 \mathrm{~nm}$ could be obtained [28]. Spaanjaars et al. [29] used a crossed beam experimental setup to simultaneously record CRDS and LIF of $\mathrm{OH}$ to obtain predissociation rates for the $\mathrm{A}^{2} \Sigma^{+}, \mathrm{v}^{\prime}=3$ state. Recently, Dreyer et al. reported on CRDS on weak $\mathrm{OH} A-\mathrm{X}$ transitions to calibrate $\mathrm{OH}$ LIF in a premixed methane/air flat flame [30]. They found an overprediction of $\mathrm{OH}$ with CRDS in rich flames and assigned this to spectral overlapping with other flame species.

Apart from the pulsed CRDS experiments, a number of papers based on the cavity enhancement principle has been reported in literature. Intracavity laser absorption spectroscopy (ICLAS) has been used to detect a range of radicals in flames, primarily at reduced pressures, including $\mathrm{OH}, \mathrm{HCO}[3,31,32],{ }^{1} \mathrm{CH}_{2}$ [3, 32-34], $\mathrm{HNO}$ [35], and $\mathrm{NH}_{2}$ [8]. Cavity enhanced absorption spectroscopy (CEA) was used to detect $\mathrm{OH}$ at $1.5 \mu \mathrm{m}$ in a methane/air flat flame and an oxyacetylene torch [36]. A recent, more detailed review of the application of cavity ring-down spectroscopy in combustion research can be found in reference [1].

\subsection{Experimental}

\subsubsection{General experimental scheme}

The general scheme for cavity ring-down experiments as described in this thesis is given in Figure 2.1. The output of a dye laser, pumped by a frequency-doubled Nd:YAG laser with a repetition rate of $10 \mathrm{~Hz}$ and a pulse duration of $7 \mathrm{~ns}$ is used as the light source. The laser beam can be narrowed by a diaphragm and spatially filtered by a lens-pinhole-lens system. The laser pulses are coupled into a stable, non-confocal optical resonator consisting of two concave mirrors. The reflectivity of the mirrors is typically 0.997 or better, depending on availability and cost. The mirrors have a radius of curvature of $12.5 \mathrm{~cm}$ and are placed at a distance set between $30 \mathrm{~cm}$ and $50 \mathrm{~cm}$. The size of the beam waist in the center of the cavity can be checked employing a set of pinholes with different sizes [37] or a razorblade method [38]. In addition, a CCD-camera is used to record Rayleigh and Mie scattering perpendicular to the cavity axis. More details will be given in Section 2.2.4.

The burner system is placed in the center of the cavity. The position of the burner can be adjusted with micrometer precision along the two axes perpendicular to the cavity axis using 


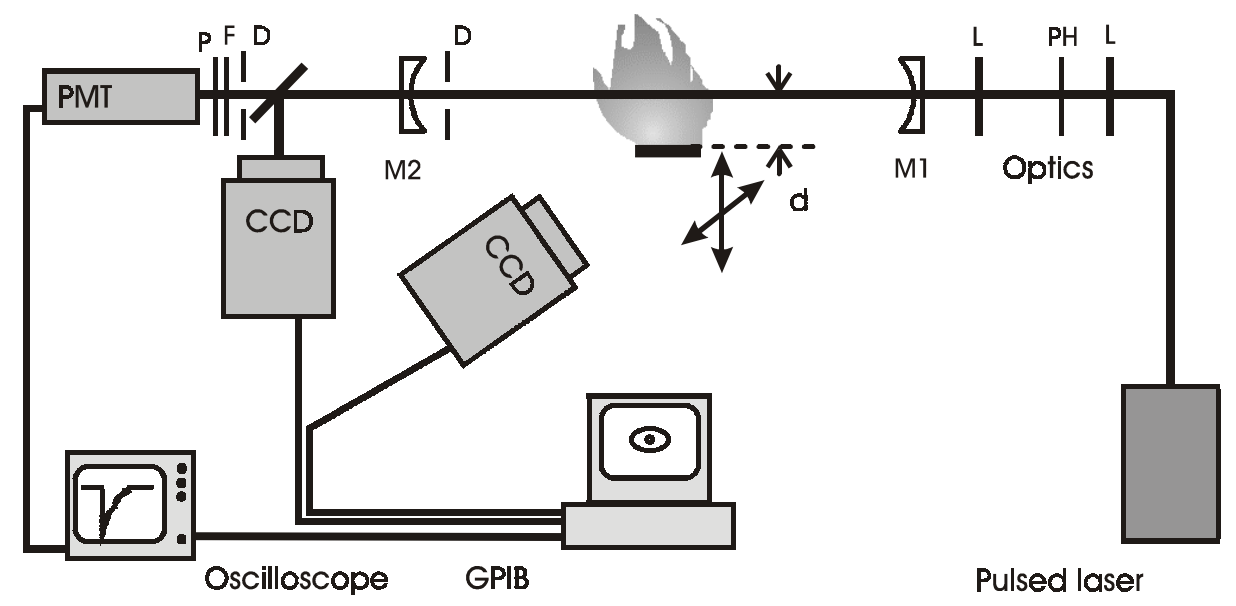

Figure 2.1: General scheme for cavity ring-down experiments. M1, M2 cavity mirrors; L lens; PH pinhole; F filter; D diaphragm; P quartz diffuser plate.

two translation stages. This enables measurements as a function of both the height $d$ above the burner surface and the lateral position, relative to the burner center, which is necessary in order to be able to apply Abel inversion techniques to the experimental data. The CCD camera is used to check the parallel alignment of the burner plate to the laser beam axis. During experiments, both the gated intensified CCD camera and a photomultiplier tube (PMT) detect the light output behind the second cavity mirror employing a beam splitter. The PMT has a nanosecond risetime and a large linear dynamic range. A diaphragm placed behind the outcoupling mirror prevents stray light from impinging on the detector. In front of the PMT an attenuator can be placed to decrease the light intensity, a filter with a suitable transmission window to decrease background signals, and a diffuser, for an evenly distributed illumination of the photosensitive cathode and to prevent wear of the cathode material. During flame experiments, placing a $\varnothing 15$-mm diaphragm inside the resonator near the second cavity mirror can reduce the continuous background signals caused by chemiluminescence of the flame. The cavity alignment can be optimised on-line using the CCD image recorded directly behind the second mirror.

The PMT output is coupled to a digital storage oscilloscope (DSO). The digital oscilloscope offers both a sufficiently high resolution (8-10 bits) and sampling speed (0.1-2.5 Gsamples/s). The transients are digitised and read out to a PC using a general purpose interface (GPIB). Data are analysed with specially designed software containing weighted fitting algorithms to determine ring-down times [39]. 

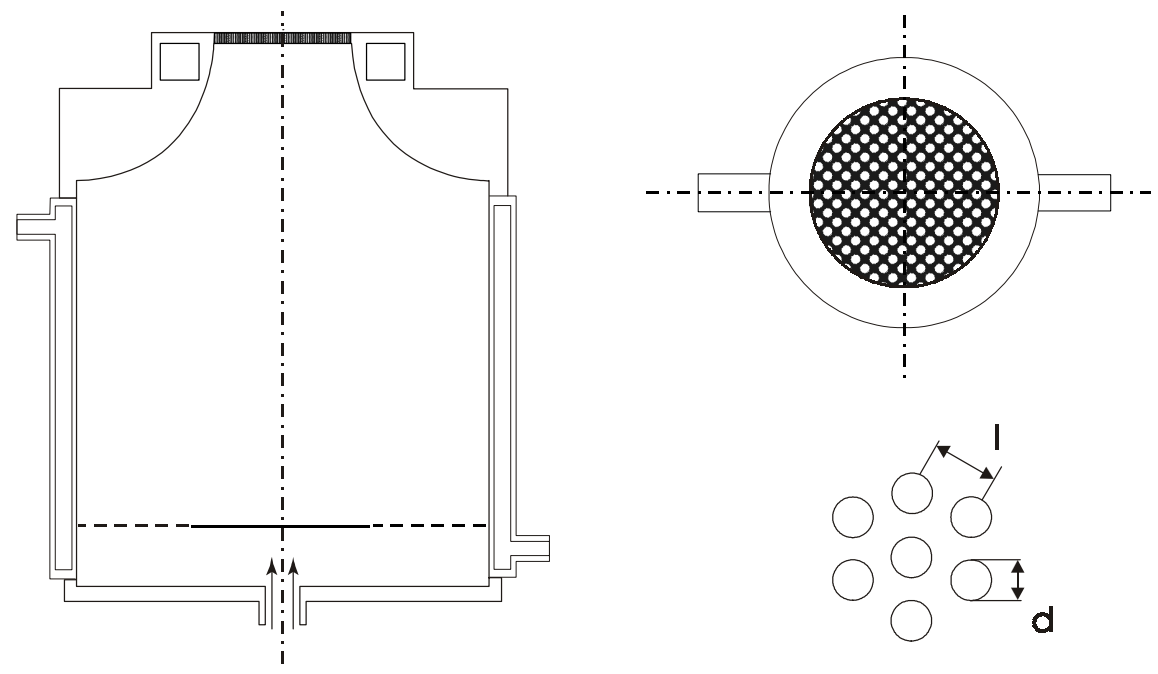

Figure 2.2: A cross-section of the flat flame burner, a top view of the burner plate and the configuration of the holes in the burner plate with diameter $d$ and pitch $l$.

\subsubsection{Flat flame burner}

The majority of the experiments described in this thesis are performed on a flat flame burner, originally developed to offer a method to measure burning velocities [40]. A flat flame burner produces a flat laminar premixed flame, which is relatively simple to describe theoretically. The methane/air flat flame burner used in the current experiments, depicted in Figure 2.2, has been developed at Eindhoven University of Technology. Extensive details on its properties can be found in reference [41]. Here, only a short description of its main characteristics will be given.

This burner is especially designed for the production of flat adiabatic methane/air flames using the so-called heat flux method. With this method, the burner surface is kept at a temperature which is higher than the temperature of the unburned gas mixture. Consequently, the unburned gas mixture is heated when it flows through the burner plate. In addition to this heat flux, after ignition of the flame there is also a heat flux from the flame to the burner. There will be no net heat flux from the burner to the flame when both fluxes are in equilibrium. In this case, the resulting flame is a so-called adiabatic flat flame with a well defined burning velocity $u_{l}=S_{L}$, the adiabatic burning velocity. In case the heat loss of the flame to the burner surface is larger than the heat gain of the unburned gas, a so-called burner stabilized flame will develop, with a different burning velocity. The net heat flux can be determined by measuring the temperature distribution with five thermocouples, which are placed at different radial distances in the burner plate. From the temperature profile of the burner plate, the net flux can be calculated. For this type of burner, it has been shown both numerically and experimentally that for hydrocarbon/air mixtures a flat reaction layer develops above the burner surface [42-45]. 
A scheme of the flat flame burner is given in Figure 2.2. The circular burner plate has a diameter of $30 \mathrm{~mm}$ and consists of a $2-\mathrm{mm}$ thick perforated brass plate with a hexagonal pattern of holes of $0.4-\mathrm{mm}$ diameter and $0.6-\mathrm{mm}$ pitch. The design of the current burner is optimised for methane/air mixtures. The burner housing is stabilized to a temperature of $293 \mathrm{~K}$ using an efficient water-cooling jacket. As a result, the premixed gases are also stabilized to this temperature. A second cooling circuit heats the burner plate to a temperature of about $350 \mathrm{~K}$. The flow velocity and the mixing ratio of the gases are regulated by carefully calibrated mass flow controllers (MFCs; Bronckhorst HiTec) using a home built interface and a PC. The flow profiles for this burner have been evaluated using PIV and LDV techniques [41].

In the experiments, a mixture of $\mathrm{CH}_{4}$ (99.5\% purity, Hoekloos) and dry air is used. The temperature of the burner surface is chosen such that a relatively large stand off distance is obtained. Therefore, a cooling temperature of $350 \mathrm{~K}$ or higher is taken. Obviously, the flame conditions, i.e. burner surface temperature, equivalence ratio and flow velocity, influence the structure of the flame and should be considered carefully.

\subsubsection{Numerical simulations}

The laminar premixed flame that develops on top of the flat flame burner can be considered as a one-dimensional flame. This makes modelling relatively simple. The numerical 1D simulations presented here are carried out with the software package Chem1D. Chem1D has been developed at Eindhoven University of Technology [43]. It is a one-dimensional laminar flame code with a graphical user interface [46] and can be used to calculate species densities and temperature profiles, using different reaction mechanisms including GRI-Mech 2.11 and $3.0[47,48]$.

The GRI-Mech mechanisms are optimized mechanisms designed to model natural gas combustion, including NO formation and reburn chemistry. GRI-Mech 3.0 contains 325 elementary chemical reactions and associated rate coefficient expressions and thermochemical parameters for 53 different species. The mechanism is optimized for methane and natural gas premixed combustion systems with stoichiometries of $\phi=0.1$ to $\phi=5$ and a pressure range of $1.3 \cdot 10^{3} \mathrm{~Pa}$ to $1 \cdot 10^{6} \mathrm{~Pa}$.

As an example, Figure 2.3 and Figure 2.4 present the results of a $1 \mathrm{D}$ calculation using the GRI-Mech 3.0 mechanism. The temperature and numerical density profiles for some of the species are plotted as a function of the height above the burner surface for a burner-stabilized methane/air flame using mixture-averaged transport data [43] at $\phi=1.2$ and $u=12 \mathrm{~cm} / \mathrm{s}$ at atmospheric pressure. 


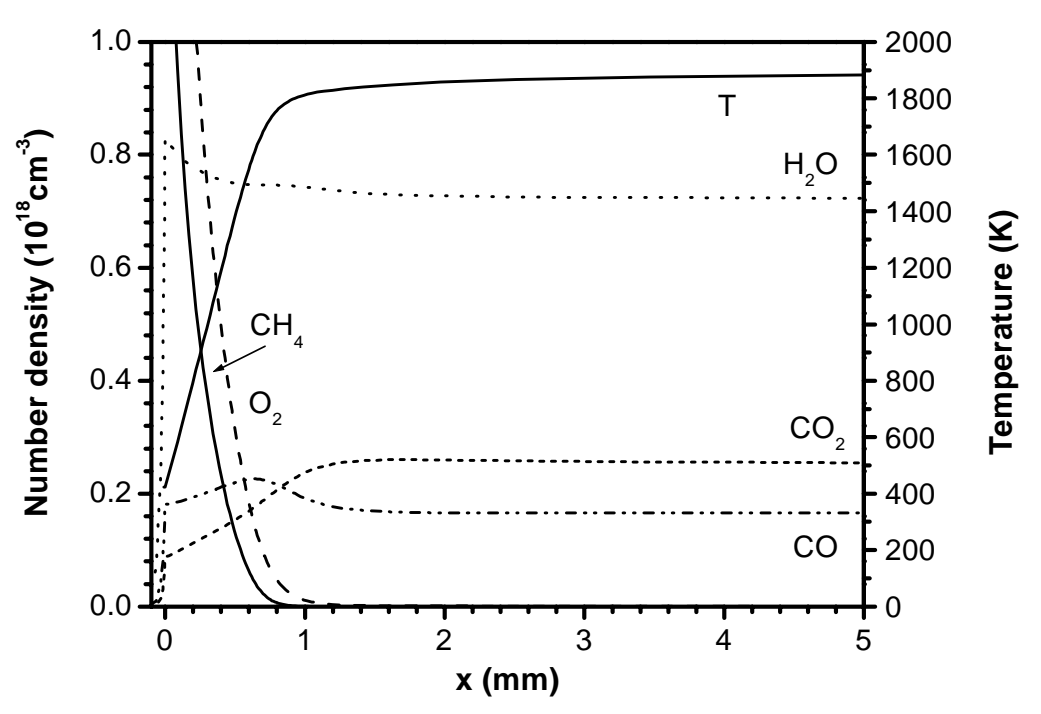

Figure 2.3: Numerical number density distributions of some of the main species and temperature profile in a $1 D$ burner-stabilized methane/air flame, calculated using the GRIMech 3.0 mechanism [47] and Chem1D [43] with $\phi=1.2, u=12 \mathrm{~cm} / \mathrm{s}$ and $T_{\text {burner }}=350 \mathrm{~K}$ at atmospheric pressure.

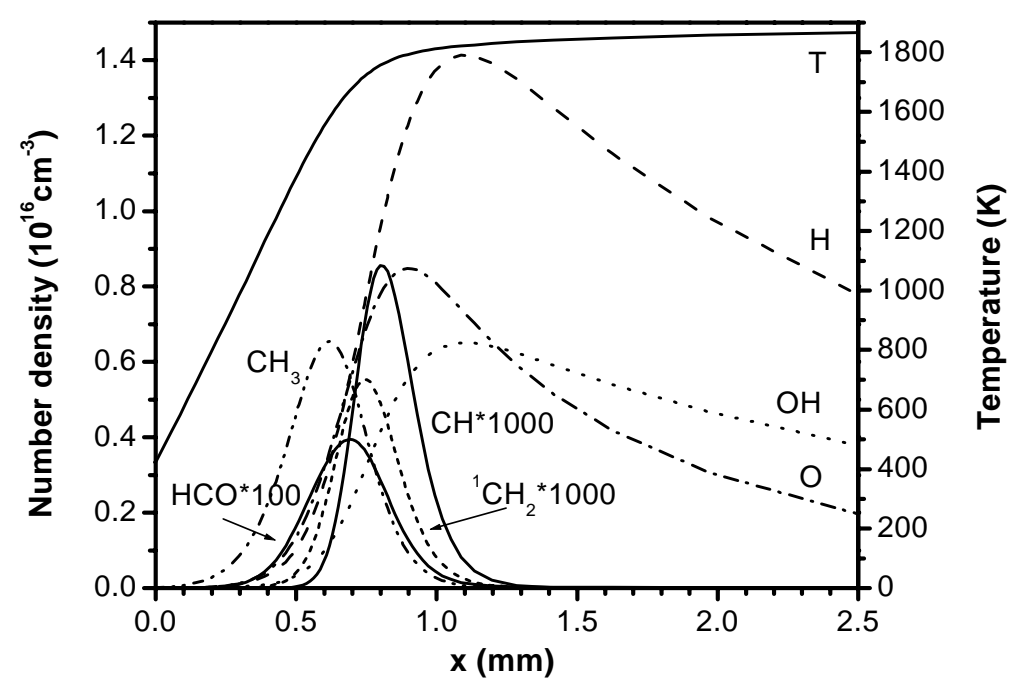

Figure 2.4: Numerical number density distributions of some of the radicals and temperature profile in a $1 D$ burner-stabilized methanelair flame, calculated using the GRI-Mech 3.0 mechanism [47] Chem1D [43] with $\phi=1.2, u=12 \mathrm{~cm} / \mathrm{s}$ and $T_{\text {burner }}=350 \mathrm{~K}$ at atmospheric pressure. 


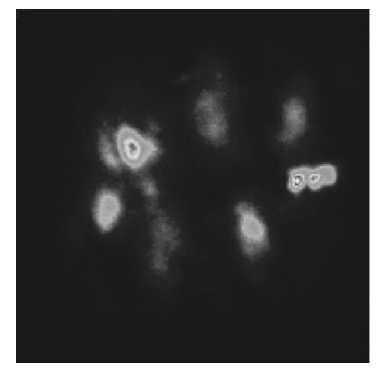

a

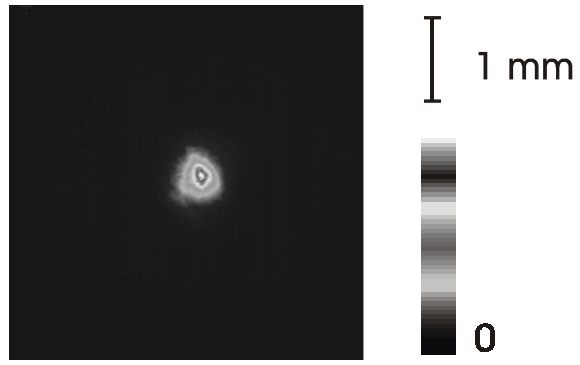

b

Figure 2.5a and b: CCD images of the light intensity recorded behind the second cavity mirror a) before and b) after adjustment of the optical cavity. The images are scaled individually for a good contrast. The total image measures about $18 \mathrm{~mm}^{2}$.

\subsubsection{Cavity alignment and thermal deflection}

In order to achieve good spatial resolution, optimization of the cavity alignment is a prerequisite. An important issue in a resonator setup is the arrangement of the cavity mirrors relative to the laser beam as this will influence the size and width of the laser beam inside the cavity [49-51]. In case of an ideal single mode $\mathrm{TEM}_{00}$ (with respect to the cavity) laser pulse coupled into the resonator along the axis of a symmetric non-confocal resonator, the size of the waist $w_{0}$ in the center of the cavity can be described as [51]:

$$
w_{0}^{2}=\frac{\lambda}{\pi} \sqrt{\frac{d}{2}\left(r-\frac{d}{2}\right)}
$$

with $r$ the radius of curvature of the mirrors, $d$ the distance between the cavity mirrors and $\lambda$ the wavelength of the beam. For a given $\lambda$, this waist is a property of the cavity. However, it is possible to observe non-Gaussian intensity distributions in the cavity, which will always result in a larger beam waist and thus a reduced spatial resolution. The degree to which higher order transversal $\left(\mathrm{TEM}_{\mathrm{nm}}\right)$ modes are present in the cavity depends on the way the light is coupled in. If the presence of higher order transversal modes is not suppressed, the shape of the intensity profile inside the cavity will not be represented by a pure Gaussian shape. In other words: the $\mathrm{TEM}_{00}$ first order approximation is not always valid. In the experiments presented here, the spatial width of the beam coupled into the cavity exceeds the dimensions of the minimum waist and it can be expected that this results in the excitation of multiple cavity modes.

The CCD camera is an excellent tool to optimize the incoupling of light into the cavity [10, 52]. Using this device, an impression of the light distribution and cavity modes can be obtained. Figures 2.5a and $\mathrm{b}$ depict CCD-images of the light intensity recorded behind the second cavity mirror taken during the alignment of the cavity. The first image (a) shows a 


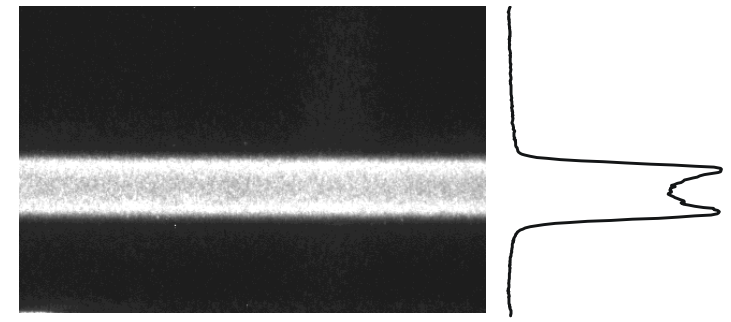

a

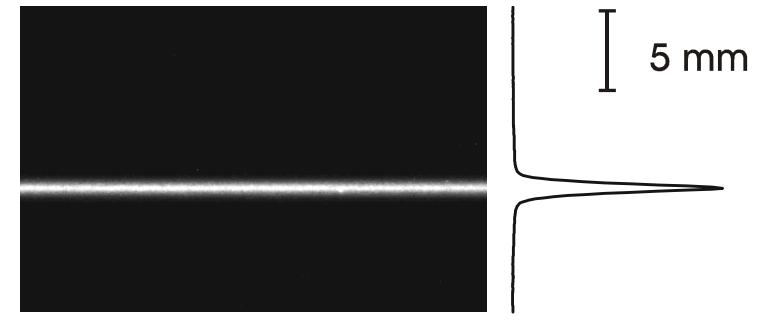

b

Figure 2.6a and b: Rayleigh/Mie scattering images of a $308 \mathrm{~nm}$ laser beam in a 30-cm cavity, a) before adjustment ( $\tau=1050 \pm 13 \mathrm{~ns}), \mathrm{b})$ after adjustment $(\tau=1088 \pm 16 \mathrm{~ns})$. The images are scaled individually for a good contrast.

typical mode pattern with a diameter of approximately $2.2 \mathrm{~mm}$ at the second mirror surface. Several spots can be seen, attributable to higher order modes. The size and shape of the pattern can be easily changed by adjustment of the cavity mirrors to obtain a circular spot with a smaller diameter, as is shown in Figure 2.5b. This smaller spot size at the cavity exit may be expected to result in a narrower intensity distribution inside the cavity as well. This was verified by Rayleigh/Mie scattering experiments. A typical example of a Rayleigh/Mie scattering image of the laser beam taken perpendicular to the cavity axis is given in Figure 2.6a and $b$. These images show the average intensity distribution of the laser beam inside the cavity recorded with a gated CCD camera over 6000 laser shots. The images are scaled individually for a good contrast. The ring-down times relating to the Rayleigh/Mie scattering images before and after adjustment are $\tau=1050 \pm 13 \mathrm{~ns}$ and $\tau=1088 \pm 16 \mathrm{~ns}$, respectively, both signals showing the expected single-exponential behaviour. This shows that major differences in beam waist have only little effect on the ring-down times, and a CCD camera is a prerequisite to obtain a good spatial resolution. After alignment, the beam waist matched a Gaussian profile and measured $0.65 \mathrm{~mm}$ FWHM. The size of the waist can also be determined with pinholes of various sizes and recording the induced cavity losses [38]. The determination of the beam waist with pinholes matched the Rayleigh/Mie scattering images within $60 \mu \mathrm{m}$. However, with this method a $\mathrm{TEM}_{00}$ mode is assumed, which is not necessarily the case, as could be observed experimentally. Therefore, imaging of the Rayleigh/Mie scattering was preferred and pinholes were used to obtain a first estimate of the dimension of the waist.

\section{Beam deflection}

Upon ignition of the flame, serious deflection of the probe beam may occur, depending on the position of the probe beam relative to the burner surface. This can be measured with the CCDcamera as well, as is shown in Figure $2.7 \mathrm{a}$ for an adiabatic flat flame at $\phi=0.8$. In this figure, 


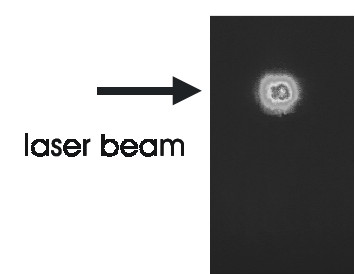

0.80

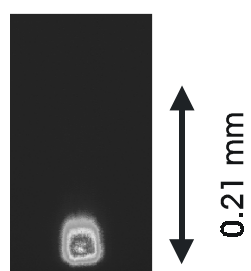

$0.25 \mathrm{~mm}$ height laser above surface

a

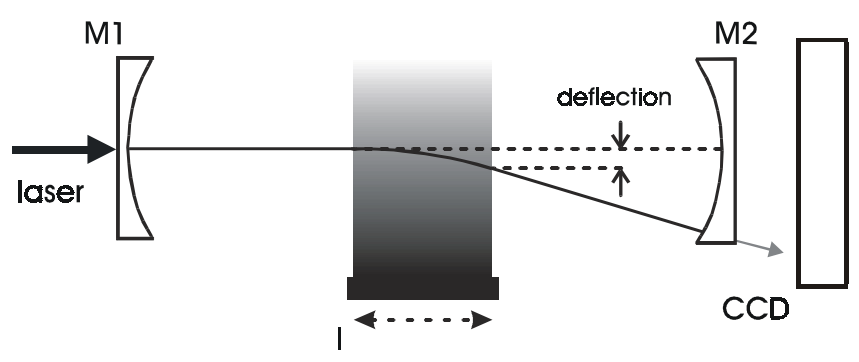

b

Figure 2.7a and b: CCD images of the light intensity recorded behind the second cavity mirror taken at two different heights of the laser beam above the burner surface illustrating beam deflection effects. The deflection of $0.21 \mathrm{~mm}$ has been calculated for the position just after the flame. $\phi=0.8, \quad u=24 \mathrm{~cm} / \mathrm{s}$ at atmospheric pressure. The images are scaled individually for a good contrast. b) Scheme of the trajectory of the laser beam inside the cavity.

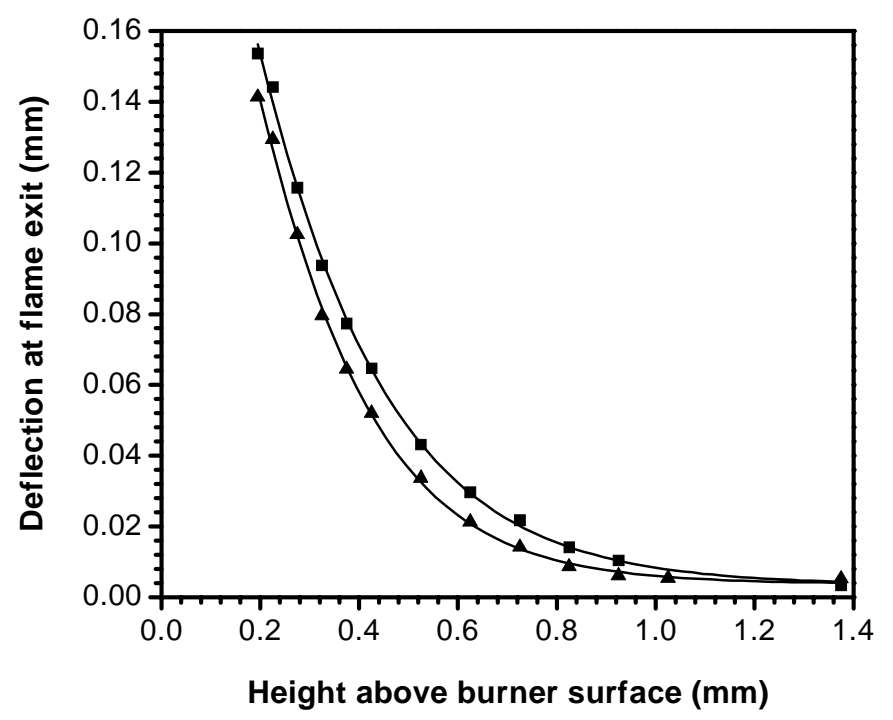

Figure 2.8: Probe beam deflection in a $\mathrm{CH}_{4}$ /air flat flame due to refractive index changes as a function of the distance between the probe beam and the burner surface. $\boldsymbol{E}$ experimental data for $\phi=1.2$, $\Delta$ experimental data for $\phi=1.1$, fitted to an exponentially decaying function, with $\mathrm{u}=12 \mathrm{~cm} / \mathrm{s}$ at atmospheric pressure. 
the deflection of the laser beam after passing the whole flame has been calculated and compared at two different positions of the probe beam above the burner surface. The scheme shown in Figure 2.7b clarifies the path of the laser beam as it travels through the flame. The steep temperature rise from room temperature to about $2000 \mathrm{~K}$ within a few millimeters in the direction of the flame propagation causes variations in density and thus a refractive index gradient [53] which causes the deflection of the probe beam. Figure 2.8 shows the deflection of the laser beam for a methane/air flame with $\phi=1.2$ and $\phi=1.1,12 \mathrm{~cm} / \mathrm{s}$ at atmospheric pressure. To obtain this figure, the position of the laser beam after passing over the flame front has been calculated from the measurement of the height of the probe beam relative to the undisturbed beam measured at $40 \mathrm{~cm}$ behind the burner for different probe distances. From the figure it can be seen that at atmospheric pressures the magnitude of this thermal deflection in a flat flame can be several tenths of a millimeter over the flame. The deflection increases at distances closer to the burner surface up to $0.16 \mathrm{~mm}$ at $\phi=1.2$ for the points closest to the surface. Fortunately, in the center of the region of interest, i.e. in the center of the reaction zone with the occurrence of intermediate radical species, deflections over the flame are less than 75 micrometer. In the experiments the deflections are taken into account by taking the average of the beam path. In order to maintain a properly aligned ring-down cavity, the alignment of the cavity is continuously optimized when the probe height or other experimental settings are changed.

\subsection{Temperature and density: the hydroxyl radical as an example}

Hydroxyl is a radical that is present in relatively large concentrations throughout the combustion process and plays a key role in a substantial number of elementary reactions. The $\mathrm{OH}$ radical is probably the most studied radical in combustion science, not in the least because it can be easily observed by LIF [54]. Techniques like planar-LIF [55] can be used for the imaging of flames by recording fluorescence of $\mathrm{OH}$ radicals. However, the quantification of number densities based on LIF measurements can be tedious due to unknowns like the quenching parameters, which makes a calibration requisite to obtain correct absolute $\mathrm{OH}$ number densities. Obviously, methods based on absorption spectroscopy provide quantitative data in a more direct way.

An example of $\mathrm{OH}$ detection with CRDS applied to the premixed flat flame burner is given in Figure 2.9. In this figure, two spectral lines of the $\mathrm{OH} \mathrm{A}^{2} \Sigma^{+} \leftarrow \mathrm{X}^{2} \Pi$ transition in the range from $308.32 \mathrm{~nm}$ to $308.36 \mathrm{~nm}$ (vacuum wavelengths) are shown, involving vibrational levels $\mathrm{v}^{\prime \prime}=0$ and 1 in an adiabatic methane/air flame with $\phi=0.9$. At these conditions, the $\mathrm{P}_{1}\left(\mathrm{~N}^{\prime \prime}=24\right)$ $\mathrm{v}^{\prime}=2 \leftarrow \mathrm{v}^{\prime \prime}=1$ line can be expected to be a factor of 9000 weaker than the most intense $\mathrm{Q}_{1}\left(\mathrm{~N}^{\prime \prime}=6\right) \mathrm{v}^{\prime}=0 \leftarrow \mathrm{v}^{\prime \prime}=0$ line at $308.86 \mathrm{~nm}$ of the $\mathrm{A} \leftarrow \mathrm{X}$ band system [56]. The notation of the lines follows Dieke and Crosswhite [57]: $\Delta \mathrm{N}_{\mathrm{f}, \mathrm{F}}\left(\mathrm{N}^{\prime \prime}\right)$, with $\mathrm{f}$ and $\mathrm{F}$ denoting the spin-orbit 


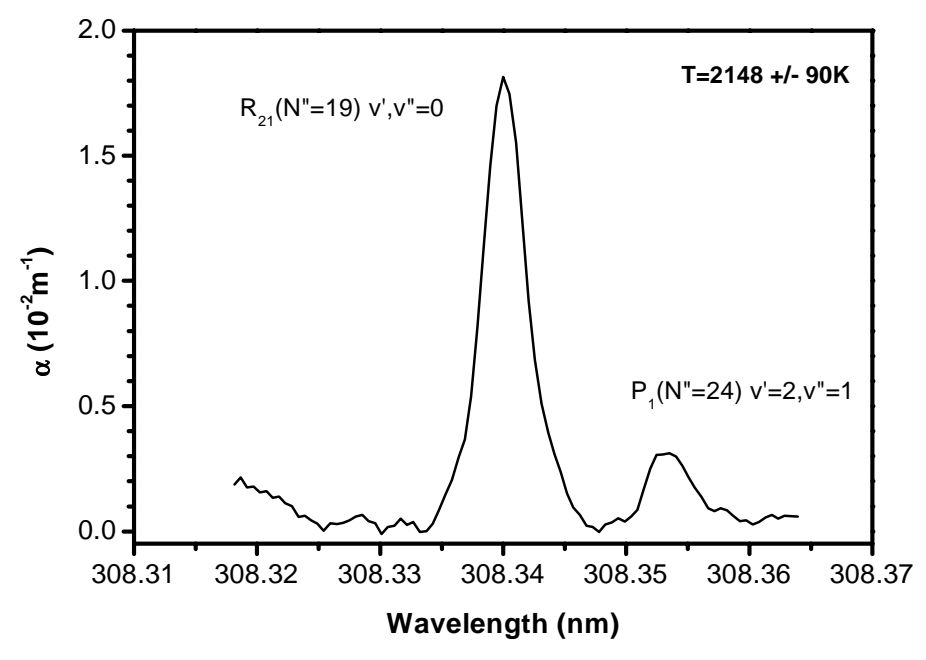

Figure 2.9: The CRDS absorption spectrum of the ro-vibrational $O H P_{1}\left(N^{\prime \prime}=24\right) \quad v^{\prime}=2 \leftarrow v^{\prime \prime}=1$ transition in an adiabatic methane/air flat flame, $\phi=0.9,36 \mathrm{~cm} / \mathrm{s}$ at $d=9.5 \mathrm{~mm}$ above the burner surface.

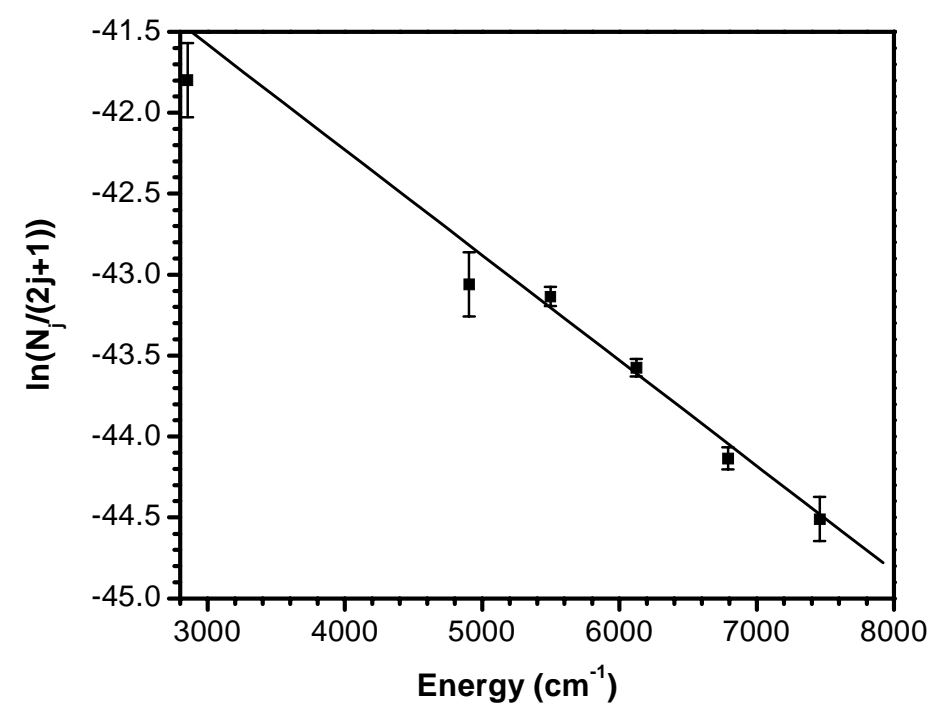

Figure 2.10: Boltzmann-plot constructed from CRDS measurements on $\mathrm{OH}$ in an adiabatic methane/air flat flame, $\phi=0.9,36 \mathrm{~cm} / \mathrm{s}$ at $d=7.2 \mathrm{~mm}$ above the burner surface, including the experimental error bars. The resulting flame temperature is found to be $2200 \mathrm{~K} \pm 150 \mathrm{~K}$. 
ladder of the $\mathrm{A}$ and $\mathrm{X}$ state, respectively, and $\Delta \mathrm{N}=\mathrm{N} "-\mathrm{N}^{\prime}$ being the difference between the ground and excited state total orbital angular momentum $\mathrm{N}^{\prime \prime}$ and $\mathrm{N}^{\prime}$, respectively. The $\mathrm{f}$ is omitted when $\mathrm{f}=\mathrm{F}$, and $\mathrm{O}, \mathrm{P}, \mathrm{Q} \mathrm{R}$ and $\mathrm{S}$ are used to label $\Delta \mathrm{N}=+2,+1,0,-1,-2$ transitions, respectively. The total $\mathrm{OH}$ number density of $6.3 \cdot 10^{15} \mathrm{~cm}^{-3}$ at the position of the probe beam, calculated from CRDS and direct absorption measurements as will be presented in the next paragraph, combined with the low population of the $\mathrm{OH}\left(\mathrm{N}^{\prime \prime}=24, \mathrm{v}^{\prime}=1\right)$ level at $2100 \mathrm{~K}$, gives a density for $\mathrm{OH}\left(\mathrm{N}^{\prime \prime}=24, \mathrm{v}^{\prime}=1\right)$ in the ppb-range, demonstrating the sensitivity of the technique. An approximate temperature can be calculated from the ratio of the $\mathrm{P}_{1}\left(\mathrm{~N}^{\prime \prime}=24\right) \mathrm{v}^{\prime}=2 \leftarrow \mathrm{v}^{\prime \prime}=1$ and the $\mathrm{R}_{21}\left(\mathrm{~N}^{\prime \prime}=19\right) \quad \mathrm{v}^{\prime}=0 \leftarrow \mathrm{v}^{\prime \prime}=0$ lines, using data provided by LIFBASE [56]. The temperature obtained in this way is $T=2148 \pm 90 \mathrm{~K}$, which compares well to $1 \mathrm{D}$ numerical simulations and CARS measurements which give a value of $2100 \pm 50 \mathrm{~K}$ [58].

Of course, the construction of Boltzmann-plots is a more reliable method to obtain rotational temperatures and less susceptible to systematic errors if carried out with care [59]. In a Boltzmann-plot the energy of the lower level is plotted versus $\ln \left(\mathrm{N}_{\mathrm{J}} /(2 \mathrm{~J}+1)\right.$, with $\mathrm{N}_{J}$ the number density of the lower $\mathrm{J}$ level. The temperature can be extracted from the slope of the fitted line which is $1 / \mathrm{kT}$, in which $\mathrm{k}$ is Boltzmann's constant. To calculate the temperature, it is assumed that the species under study is not found in the colder regions outside the flame. The absorption lines should be carefully selected to avoid saturation and multi-exponential effects, i.e. weak transitions are preferred. There is always a boundary layer between the flame and the surroundings at room temperature, which can result in an under-prediction of the flame temperature. In case of short living minority radicals this problem is largely eliminated, but other problems due to the small dimensions of the flame front play a role. The resulting temperature data from line-of-sight measurements must always be interpreted considering the convolution of number density profiles, temperature gradients and the dimensions of the probe beam.

Figure 2.10 shows an example of a Boltzmann-plot, constructed from CRDS measurements on $\mathrm{OH}$ in an adiabatic flat flame, $\phi=0.9,36 \mathrm{~cm} / \mathrm{s}$ at a height of $d=7.2 \mathrm{~mm}$ above the burner surface. The non-overlapping lines that were selected included $\mathrm{R}_{21}\left(\mathrm{~N}^{\prime \prime}=16,17,18\right.$ and 20$)$ and $\mathrm{S}_{21}\left(\mathrm{~N}^{\prime \prime}=12\right.$ and 19) in the region 302.5 to $307.7 \mathrm{~nm}$. The temperature calculated from this graph is $2200 \pm 150 \mathrm{~K}$, in close agreement with the predictions [58]. From the steep temperature decline outside the flame combined with the high rotational levels which are probed, it is expected that the contribution of $\mathrm{OH}$ outside the flame can be ignored.

To study the influence of the laser bandwidth in the determination of absolute number densities, which was pointed out in Section 1.4 to be a specific issue in cavity ring-down spectroscopy, $\mathrm{OH}$ number densities were measured using two different laser bandwidths and results were compared to a direct-absorption measurement. $\mathrm{OH}$ is present in sufficiently high concentrations to make direct absorption detection possible. A Nd:YAG/dye laser combination (Quantel YG781C/TDL50) with a mixture of rhodamine 640 and sulforhodamine 640 with a bandwidth of either $0.16 \mathrm{~cm}^{-1}$ or, combined with a special beam expander, less 
than $0.06 \mathrm{~cm}^{-1}$ (the latter bandwidth was determined by measuring the $\mathrm{Q}_{1}(1)$ transition of $\mathrm{OH}$ in a jet-cooled molecular beam setup) was used to measure $\mathrm{OH}$ in a burner-stabilized methane/air flame with $\phi=0.9$ and $12 \mathrm{~cm} / \mathrm{s}$ at $8 \mathrm{~mm}$ above the burner surface. The Doppler broadening for $\mathrm{OH}$ at $2100 \mathrm{~K}$ and $308 \mathrm{~nm}$ is about $0.26 \mathrm{~cm}^{-1}$. The direct absorption number densities were performed on the $\mathrm{Q}_{1}(8)$ line at $309.33 \mathrm{~nm}$, whereas the cavity ring-down measurements involved the $\mathrm{R}_{21}\left(\mathrm{~N}^{\prime \prime}=16,17,18\right.$ and 19$)$ and $\mathrm{S}_{21}(\mathrm{~N}=12$ and 19) lines. The ringdown times were determined from a weighted fit to the first part of the ring-down curve. No non-exponential behaviour was observed. Absolute $\mathrm{OH}$ number densities were obtained using the rotational temperature derived from a Boltzmann plot constructed from the CRDS measurements. The results are shown in Table 2.1. The numerical results are also included in the table. From a comparison of the experimental data it can be concluded that no influence of the bandwidth could be found with the current experimental procedure and that both direct absorption and cavity ring-down spectroscopy measurements resulted in the same $\mathrm{OH}$ number densities. The data presented here is derived from the peak maxima corrected for background losses, and calculations using peak areas yielded similar results. There is a quantitative disagreement by a factor of 2 between the measured and calculated $\mathrm{OH}$ number densities. However, this has also been reported in literature with similar differences between the experimental and numerical values for this type of flame $[3,60]$ and it can most probably be attributed to the reaction mechanism. A thorough evaluation of this subject is currently in progress.

Table 2.1: Comparison of cavity ring-down, direct absorption and numerical $\mathrm{OH}$ number densities in an adiabatic methane/air flame with $\phi=0.9$ at $8 \mathrm{~mm}$ above the burner surface.

\begin{tabular}{lcc}
\hline Method & $\begin{array}{c}{[\mathrm{OH}]} \\
\left(10^{15} \mathrm{~cm}^{-3}\right)\end{array}$ & $\begin{array}{c}T \\
(\mathrm{~K})\end{array}$ \\
\hline \hline CRDS $\left(0.16 \mathrm{~cm}^{-1}\right)$ & $6.3 \pm 0.2$ & $2030 \pm 120$ \\
CRDS $\left(0.06 \mathrm{~cm}^{-1}\right)$ & $6.4 \pm 0.3$ & \\
DA $\left(0.16 \mathrm{~cm}^{-1}\right)$ & $6.3 \pm 0.8$ & \\
Simulation & 12.0 & 2160 \\
\hline
\end{tabular}




\section{References}

1. Kohse-Höinghaus, K., Jeffries, J.B., eds. Applied combustion diagnostics, Taylor and Francis, New York, 2002.

2. Meijer, G., Boogaarts, M.G.H., Jongma, R.T., Parker, D.H., Wodtke, A.M., Coherent cavity ring down spectroscopy. Chem. Phys. Lett. 217:112-116 (1994).

3. Lozovsky, V.A., Derzy, I., Cheskis, S., Radical concentration profiles in a low-pressure methane-air flame measured by intracavity laser absorption and cavity ring-down spectroscopy. Proc. Combust. Inst. 27:445-452 (1998).

4. Scherer, J.J., Rakestraw, D.J., Cavity ringdown laser absorption spectroscopy detection of formyl (HCO) radical in a low pressure flame. Chem. Phys. Lett. 265:169-176 (1997).

5. Cheskis, S., Derzy, I., Lozovsky, V.A., Kachanov, A., Romanini, D., Cavity ring-down spectroscopy of OH radicals in low pressure flames. Appl. Phys. B 66:377-381 (1998).

6. Lozovsky, V.A., Derzy, I., Cheskis, S., Nonequilibrium concentrations of the vibrationally excited OH radical in a methane flame measured by cavity ring-down spectroscopy. Chem. Phys. Lett. 284:407-411 (1998).

7. Derzy, I., Lokovsky, V.A., Cheskis, S., Absolute CH concentration in flames measured by cavity ringdown spectroscopy. Chem. Phys. Lett. 306:319-324 (1999).

8. Derzy, I, Lozovsky, V.A., Ditzian, N., Rahinov, I., Cheskis, S., Absorption spectroscopy measurements of $\mathrm{NH}$ and $\mathrm{NH}_{2}$ absolute concentrations in methane/air flames doped with $\mathrm{N}_{2} \mathrm{O}$. Proc. Combust. Inst. 28:1741-1748 (2000).

9. Derzy, I., Lokovsky, V.A., Cheskis, S., $\mathrm{CH}, \mathrm{NH}$, and $\mathrm{NH}_{2}$ concentration profiles in Methane/air flames doped with $\mathrm{N}_{2} O$. Israel J. Chem. 39:49-54 (1999).

10. Thoman, J.W., Jr., McIlroy, A., Absolute CH radical concentrations in rich low-pressure methaneoxygen-argon flames via cavity ringdown spectroscopy of the $A^{2} \Delta-X^{2} \Pi$ transition. J. Phys. Chem. A 104:4953-4961 (2000).

11. McIlroy, A., Laser studies of small radicals in rich methane flames: $\mathrm{OH}, \mathrm{HCO}$, and ${ }^{1} \mathrm{CH}_{2}$. Israel $\mathrm{J}$. Chem. 39:55-62 (1999).

12. McIlroy, A., Direct measurement of ${ }^{1} \mathrm{CH}_{2}$ in flames by cavity ringdown laser absorption spectroscopy. Chem. Phys. Lett. 296:151-158 (1998).

13. Luque, J., Jeffries, J.B., Smith, G.P., Crosley, D.R., Predissociation of $C H B^{2} \Sigma^{+} v^{\prime}=0,1$ levels studied by cavity ringdown absorption spectroscopy. Chem. Phys. Lett. 346:209-216 (2001).

14. Luque, J., Jeffries, J.B., Smith, G.P., Crosley, D.R., Erratum to: Predissociation of $C H B^{2} \Sigma^{+} v^{\prime}=0,1$ levels studied by cavity ringdown absorption spectroscopy. Chem. Phys. Lett. 352:133 (2002).

15. Luque, J., Jeffries, J.B., Smith, G.P., Crosley, D.R., Scherer, J.J., Combined cavity ringdown absorption and laser-induced fluorescence imaging measurements of $\mathrm{CN}(\mathrm{B}-\mathrm{X})$ and $\mathrm{CH}(\mathrm{B}-\mathrm{X})$ in low-pressure $\mathrm{CH}_{4}$ $\mathrm{O}_{2}-\mathrm{N}_{2}$ and $\mathrm{CH}_{4}-\mathrm{NO}-\mathrm{O}_{2}-\mathrm{N}_{2}$ flames. Combust. Flame 126:1725-1735 (2001).

16. Mercier, X., Therssen, E., Pauwels, J.F., Desgroux, P., Quantitative features and sensitivity of cavity ring-down measurements of species concentrations in flames. Combust. Flame 125:656-667 (2001).

17. Mercier, X., Pillier, L., Pauwels, J.-F., Desgroux, P., Quantitative measurement of CN radical in a lowpressure methane/air flame by cavity ring-down spectroscopy. C.R. Acad. Sci. IV 2:965-972 (2001).

18. Pillier, L., Moreau, C., Mercier, X., Pauwels, J.F., Desgroux, P., Quantification of stable minor species in confined flames by cavity ring-down spectroscopy: application to NO. Appl. Phys. B 74:427-434 (2002). 
19. Scherer, J.J., Voelkel, D., Rakestraw, D.J., Infrared cavity ringdown laser absorption spectroscopy (IRCRLAS) in low pressure flames. Appl. Phys. B 64:699-705 (1997).

20. Scherer, J.J., Aniolek, K.W., Cernansky, N.P., Rakestraw, D.J., Determination of methyl radical concentrations in a methanelair flame by infrared cavity ringdown laser absorption spectroscopy. $\mathrm{J}$. Chem. Phys. 107:6196-6203 (1997).

21. Luque, J., Jeffries, J.B., Smith, G.P., Crosley, D.R., Quasi-simultaneous detection of $\mathrm{CH}_{2} \mathrm{O}$ and $\mathrm{CH}$ by cavity ring-down absorption and laser-induced fluorescence in a methanelair low-pressure flame. Appl. Phys. B 73:731-738 (2001).

22. Mercier, X., Therssen, E., Pauwels, J.F., Desgroux, P., Cavity ring-down measurements of OH radical in atmospheric premixed and diffusion flames. A comparison with laser-induced fluorescence and direct laser absorption. Chem. Phys. Lett. 299:75-83 (1999).

23. Mercier, X., Jamette, P., Pauwels, J.F., Desgroux, P., Absolute CH concentration measurements by cavity ring-down spectroscopy in an atmospheric diffusion flame. Chem. Phys. Lett. 305:334-342 (1999).

24. Xie, J., Paldus, B.A., Wahl, E.H., Martin, J., Owano, T.G., Kruger, C.H., Harris, J.S., Zare, R.N., Nearinfrared cavity ringdown spectroscopy of water vapor in an atmospheric flame. Chem. Phys. Lett. 284:387-395 (1998).

25. Stolk, R.L., Ter Meulen, J.J., Laser diagnostics of CH in a diamond depositing flame. Diamond Relat. Mater. 8:1251-1255 (1999).

26. Evertsen, R., Stolk, R.L.,Ter Meulen, J.J., Investigations of Cavity Ring Down Spectroscopy applied to the detection of $\mathrm{CH}$ in Atmospheric Flames. Combust. Sci. Technol. 149:19-34 (1999).

27. Evertsen, R., Stolk, R.L.,Ter Meulen, J.J., Investigations of Cavity Ring Down Spectroscopy applied to the detection of $\mathrm{CH}$ in Atmospheric Flames. Combust. Sci. Technol. 157:341-342 (2000).

28. Staicu, A., Stolk, R.L., Ter Meulen, J.J., Absolute concentrations of the $C_{2}$ radical in the $A^{1} \Pi_{u}$ state measured by cavity ring down spectroscopy in an atmospheric oxyacetylene flame. Applied Optics 91:969-974 (2002).

29. Spaanjaars, J.J.L., Ter Meulen, J.J., Meijer, G., Relative predissociation rates of $O H\left(A^{2} \Sigma, v^{\prime}=3\right)$ from combined cavity ring down-laser-induced fluorescence measurements. Chem. Phys. 107:2242-2248 (1997).

30. Dreyer, C.B., Spuler, S.M., Linne, M., Calibration of laser induced fluorescence of the OH radical by cavity ringdown spectroscopy in premixed atmospheric pressure flames. Combust. Sci. Technol. 171:163-190 (2001).

31. Cheskis, S., Intracavity laser absorption spectroscopy detection of HCO radicals in atmospheric pressure hydrocarbon flames. J. Chem. Phys. 102:1851-1854 (1995).

32. Lozovsky, V.A., Cheskis, S., Kachanov, A., Stoeckel, F., Absolute HCO concentration measurements in methane/air flame using intracavity laser spectroscopy. J. Chem. Phys. 106:8384-8391 (1997).

33. Derzy, I., Lokovsky, V.A., Cheskis, S., Absorption cross-sections and absolute concentration of singlet methylene in methane/air flames. Chem. Phys. Lett. 313:121-128 (1999).

34. Cheskis, S., Derzy, I., Lozovsky, V.A., Kachanov, A., Stoeckel, F., Intracavity laser absorption spectroscopy detection of singlet $\mathrm{CH}_{2}$ radicals in hydrocarbon flames. Chem. Phys. Lett. 277:423-429 (1997).

35. Lozovsky, V.A., Cheskis, S., Intracavity laser absorption spectroscopy study of HNO in hydrocarbon flames doped with $\mathrm{N}_{2} \mathrm{O}$. Chem. Phys. Lett. 332:508-514 (2000).

36. Peeters, R., Berden, G., Meijer, G., Near-infrared cavity enhanced absorption spectroscopy of hot water and $\mathrm{OH}$ in an oven and in flames. Appl. Phys. B 73:65-70 (2001). 
37. Vander Wal, R. L., Ticich, T. M., Cavity ringdown and laser-induced incandescence measurements of soot. Appl. Opt. 38:1444-1451 (1999).

38. Zhao, M., Wahl, E.H., Owano, T.G., Largent, C.C., Zare, R.N., Kruger, C.H., Near-surface reduction of cavity ring-down spectroscopy detection sensitivity. Chem. Phys. Lett. 318:555-560 (2000).

39. Jongma, R.T., Boogaarts, M.G.H., Holleman, I., Meijer, G., Trace gas detection with cavity ring down spectroscopy. Rev. Sci. Instrum. 66:2821-2828 (1995).

40. Glassman, I.: Combustion, Academic Press, San Diego, CA, 1996.

41. Van Maaren, A., One-step chemical reaction parameters for premixed laminar flames, Ph.D. thesis, Eindhoven University of Technology, the Netherlands, http://www.tue.nl/bib/, Eindhoven, 1994.

42. Van Maaren, A., Thung, D.S., De Goey, L.P.H., Measurement of flame temperature and adiabatic burning velocity of methane/air mixtures. Combust. Sci. Technol. 96:327-344 (1994).

43. Somers, L.M.T., The simulation of flat flames with detailed and reduced chemical models, Ph.D. thesis, Eindhoven University of Technology, Eindhoven, the Netherlands, http://www.tue.nl/bib/, 1994.

44. De Goey, L.P.H., Van Maaren, A., Quax., R.M., Stabilization of adiabatic premixed laminar flames on a flat flame burner. Combust. Sci. Technol. 92:201-207 (1993).

45. De Goey, L.P.H., Somers, L.M.T., Bosch, W.M.M.L., Mallens, R.M.M., Modeling of the small scale structure of flat burner-stabilized flames. Combust. Sci. Technol. 104:387-400 (1995).

46. Chem1D, http://www.combustion.tue.nl/chem1d.

47. Smith, G.P., Golden, D.M., Frenklach, M., Moriarty, N.W., Eiteneer, B., Goldenberg, M., Bowman, C.T., Hanson, R.K., Soonho Song, Gardiner Jr., W.C., Lissianski, V.V., Qin, Z., GRI-Mech 3.0. http://www.me.berkeley.edu/gri_mech/ (2000).

48. Bowman, C.T., Hanson, R.K., Davidson, D.F., Gardiner, W.C., Lissianski, V., Smith, G.P., Golden, D.M., Frenklach, H., GRI-Mech 2.11. http://www.me.berbeley.edu/gri_mech/(1995).

49. Demtröder, W.: Laser spectroscopy, 2nd. ed., Springer Verlag, Berlin, 1998.

50. Busch, K.W., Busch, M.A., ed. Cavity ring down spectroscopy, American Chemical Society, Washington DC, 1999.

51. Siegman, A.E.: Lasers, University Science Books, Sausalito, 1986.

52. Hodges, J.T., Looney, J.P., Van Zee, R.D., Response of a ring-down cavity to an arbitrary excitation. J. Chem. Phys. 105:10278-10288 (1996).

53. Weinberg, F.J.: Optics of flames, Butterworths, London, 1963.

54. Eckbreth, A.C.: Laser Diagnostics for combustion temperature and species, 2nd. ed., Gordon and Breach Publishers, Amsterdam, 1996.

55. Bombach, R., Kaeppeli, B., Simultaneous visualisation of transient species in flames by planar-laserinduced fluorescence using a single laser system. Appl. Phys. B 68:251-255 (1999).

56. Luque, J., Crosley, D.R., LIFBASE: Database and Spectral Simulation Program (version 1.4), SRI International Report MP 96-001, 1998.

57. Dieke, G.H., Crosswhite, H.M., The ultraviolet bands of OH. J. Quant. Spectrosc. Radiat. Transfer. 2:97-199 (1962).

58. Bosschaart, K.J., Versluis, M., Knikker, R., Van der Meer, Th. H., Schreel, K.R.A.M., De Goey, L.P.H., Van Steenhoven, A.A., The heat flux method for producing burner stabilized adiabatic flames: an evaluation with CARS thermometry. Combust. Sci. Techn. 168:1-19 (2001).

59. Rensberger, K.J., Jeffries, J.B., Copeland, R.A., Kohse-Hoinghaus, K., Wise, M.L., Crosley, D.R., Laser-induced fluorescence determination of temperatures in low pressure flames. Appl. Opt. 28:35563566 (1989). 
60. Schreel, K.R.A.M., Versluis, M., De Goey, L.P.H., The quantitative detection of $\mathrm{OH}$ densities in reactive flows using bi-directional LIF. Combust. Flame, submitted (2002). 


\title{
CHAPTER 3
}

\section{Absolute CH Concentration Measurements in PREMiXed ATMOSPHERIC Flat FLAMES ${ }^{1}$}

\begin{abstract}
Absolute $\mathrm{CH}$ densities in premixed atmospheric flat $\mathrm{CH}_{4}$ /air flames have been determined with cavity ring-down spectroscopy (CRDS). $\mathrm{CH}$ is excited from the $\mathrm{X}^{2} \Pi$ to the $\mathrm{A}^{2} \Delta$ state at $430 \mathrm{~nm}$. Since at atmospheric pressure the $\mathrm{CH}$ radical is present only in a very thin layer at the flame front, specific problems due to the finite size of the laser beam and thermal deflection are encountered. An intensified CCD camera is used as an aid to take these effects into account. $\mathrm{CH}$ density distributions are obtained for two different stoichiometries $(\phi=1.1$ and 1.2) in a burner-stabilized flame. Signal-to-noise ratios indicated that total $\mathrm{CH}$ number densities down to $4 \cdot 10^{11} \mathrm{~cm}^{-3}$, corresponding to $1.5 \mathrm{ppb}\left(\mathrm{S} / \mathrm{N}_{\mathrm{p}-\mathrm{p}}=2\right)$, can be detected at atmospheric pressure. Flame uniformity was verified with an Abel inversion technique. Data were analysed using both an analytical deconvolution and a maximum entropy approach, both leading to similar results. The rotational flame temperature is derived from measured Boltzmann distributions. The results are compared to model calculations using GRI-Mech 2.11 and 3.0. As compared to the experimental results, the predictions from both models show higher maximum $\mathrm{CH}$ concentrations, which are located further away from the burner surface. In both cases, the computed $\mathrm{CH}$ maximum is predicted at a higher temperature. Analyses of the effect of errors in the experimental settings and direct absorption measurements of $\mathrm{OH}$ have been used to verify positional differences. The results indicate that the differences may be attributed to the reaction mechanisms.
\end{abstract}

\footnotetext{
${ }^{1}$ Evertsen, R., Van Oijen, J.A., De Goey, L.P.H., Ter Meulen, J.J.; Absolute CH concentration measurements in a premixed atmospheric flat flame by cavity ring-down spectroscopy, Combust. Flame, in press.
} 


\subsection{Introduction}

The $\mathrm{CH}$ radical is an important intermediate in combustion processes. It is often used as an indicator of the flame front and it plays an important role in prompt-NO formation in flames [1]. $\mathrm{CH}$ in atmospheric flames has been studied mainly using laser-induced fluorescence (LIF) techniques [2-4]. Applications of CRDS to study species in combustion environments, as reported in literature, mainly involve experiments carried out at reduced pressure. Several papers report on the detection of $\mathrm{CH}$ in a low-pressure flame from a McKenna type burner [57]. Under atmospheric conditions, application of the technique is more difficult, as the reaction zone thickness of the flame is in the order of one mm. Mercier et al. [8] reported on $\mathrm{CH}$ measurements in an atmospheric diffusion flame. Stolk and Ter Meulen reported on a correlation between $\mathrm{CH}$ density and diamond growth rate in a diamond-depositing oxyacetylene flame [9].

Since at atmospheric pressure the $\mathrm{CH}$ radical is present only in a very thin layer at the flame front, specific problems due to the finite size of the laser beam and thermal deflection are encountered. In addition, background losses due to scattering or absorption by soot particles may occur [10]. In the study described in this chapter, with these effects taken into account, absolute $\mathrm{CH}$ density distributions will be presented at two different stoichiometries in a premixed flat $\mathrm{CH}_{4}$ /air flame. The experimental $\mathrm{CH}$ density profiles and temperatures are compared to results calculated using GRI-Mech 2.11 and 3.0 [11, 12].

\subsection{Experimental setup}

The general experimental setup is explained in Chapter 2 of this thesis. The $\mathrm{CH}$ radicals are probed via the $A^{2} \Delta v^{\prime}=0 \leftarrow X^{2} \Pi v^{\prime \prime}=0$ transition at $430 \mathrm{~nm}$. The third harmonic of a Nd:YAG laser (Quantel YG781C), operated at a repetition rate of $10 \mathrm{~Hz}$ with a pulse duration of $7 \mathrm{~ns}$, is used to pump a dye laser (Quantel TDL-50, stilbene $420,0.14 \mathrm{~cm}^{-1}$ bandwidth). The distance between the cavity mirrors (Laser Optik, radius of curvature $250 \mathrm{~mm}$ ) is $300 \mathrm{~mm}$. Their reflectivity was 0.997 at $430 \mathrm{~nm}$, corresponding to typical cavity ring-down times of $445 \mathrm{~ns}$ in the present setup. The laser beam is narrowed by a lens-pinhole-lens system before it is coupled into the cavity. The resulting beam waist in the center of the cavity was $0.39 \mathrm{~mm}$ FWHM, which was checked employing a set of pinholes, a razorblade method [13] and using Rayleigh and Mie scattering, collected with a CCD camera mounted perpendicular to the cavity. The burner system [14] is placed in the center of the cavity. The flame is stabilized with a mixture of $\mathrm{CH}_{4}$ (99.5\% purity, Hoekloos) and air with fuel equivalence ratios of $\phi=1.2$ and 1.1 , and a flow velocity of $u=12 \mathrm{~cm} / \mathrm{s}$. These conditions were selected in order to obtain a high concentration of $\mathrm{CH}$ in a plane at a relatively large stand-off distance from the burner surface. A CCD camera is used to check the parallel alignment of the burner plate to the laser 


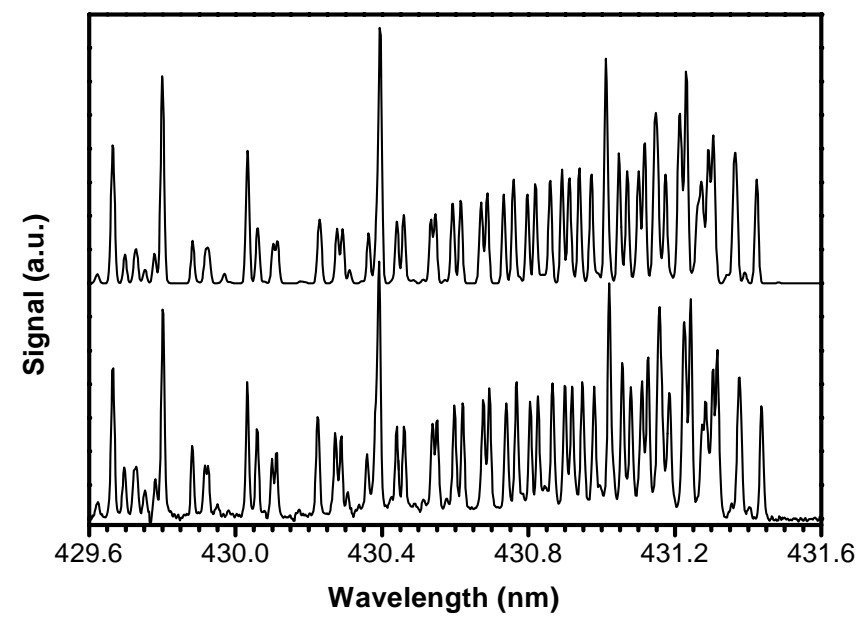

Figure 3.1: Part of the cavity ring-down absorption spectrum of the $A^{2} \Delta\left(v^{\prime}=0\right) \leftarrow X^{2} \Pi$ $\left(v^{\prime \prime}=0\right)$ transition of $\mathrm{CH}$ in a burner-stabilized flat flame, $\phi=1.2, u=12 \mathrm{~cm} / \mathrm{s}$ (bottom) and a simulated CH absorption spectrum at $1500 \mathrm{~K}$ [16] (top).

beam axis. Errors in the alignment were typically smaller than $0.075 \mathrm{~mm}$ over a length of 30 $\mathrm{mm}$. The output is detected with both a gated intensified CCD camera (Princeton Instruments 512-T) and a photomultiplier tube (Thorn-EMI 9863 QA/350) with a 2.5-ns risetime and a wide linear dynamic range, coupled to a $10 \mathrm{bit}, 100$ Msamples/s digital oscilloscope (Yokogawa DL4200). In all results presented below, each data point represents an average over 32 laser pulses. The single exponential behaviour of the curves was checked whenever any parameters were changed. Upon ignition of the flame, the off-resonance ring-down times decreased by $10 \%$ to $20 \%$, depending on the position of the burner surface relative to the probe beam. The cavity alignment was continuously optimised using the CCD image recorded directly behind the second mirror. The $\mathrm{CH}$ distributions were measured at different distances $d$ between burner surface and laser beam. The distance $d$ can be varied by moving the burner in vertical direction with micrometer precision. In the calculations, the temperature is assumed to be constant over the total path above the cylindrically symmetric burner [15]. To reduce the background signal, caused mainly by chemiluminescence of the flame, a diaphragm of $15 \mathrm{~mm}$ is placed inside the cavity and both a diaphragm and a narrow bandpass filter $(\lambda=430 \pm 5 \mathrm{~nm})$ are mounted in front of the photomultiplier tube. 


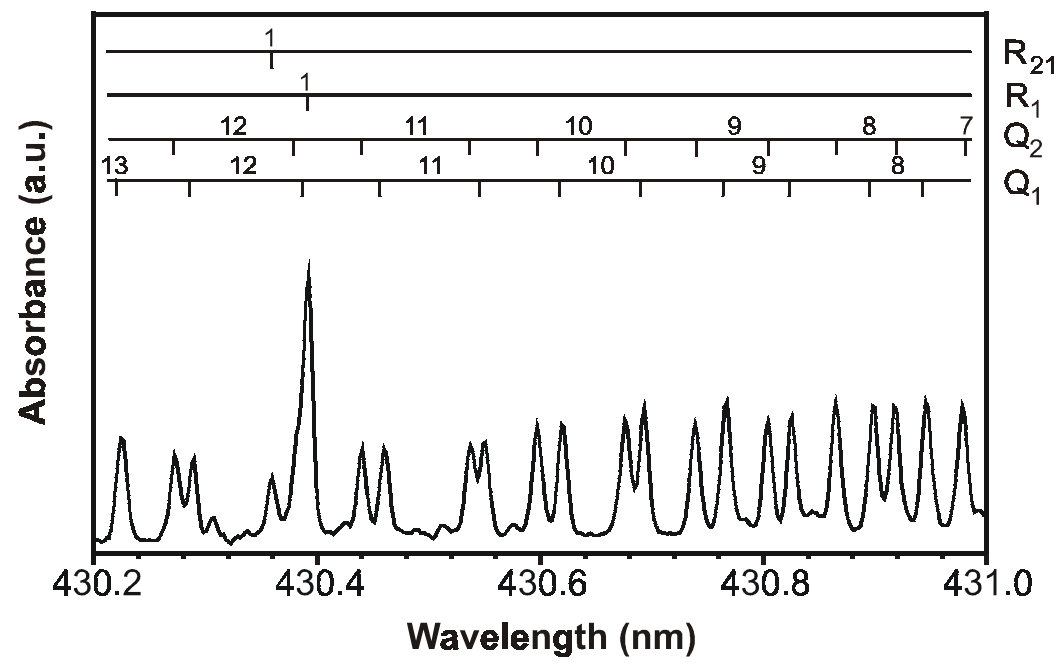

Figure 3.2: Experimental cavity ring-down absorption spectrum of a selected region of the $\mathrm{CH} \mathrm{A}^{2} \Delta\left(v^{\prime}=0\right) \leftarrow X^{2} \Pi\left(v^{\prime \prime}=0\right)$ band with the assignment of the transitions recorded in $a$ burner-stabilized flat flame, $\phi=1.2, u=12 \mathrm{~cm} / \mathrm{s}$.

\subsection{Experimental results}

\subsubsection{Cavity alignment and thermal deflection}

As stated in Chapter 2, upon ignition of the flame, serious deflection of the probe beam can occur. Fortunately, in the region of the $\mathrm{CH}$-radical profile, under the current experimental conditions, deflections are less than 75 micrometer over the total absorption path length in the centre of the region of interest, as measured with the CCD-camera and as was shown in Chapter 2. The deflection increases at distances closer to the burner surface, reaching up to $0.18 \mathrm{~mm}$ at $\phi=1.2$ for the points closest to the burner surface. This has been taken into account in the final experimental results.

\subsection{2 $\mathrm{CH}$ radical distributions in a flat flame}

In Figure 3.1, a part of the CRD absorption spectrum of the $\mathrm{A}^{2} \Delta\left(\mathrm{v}^{\prime}=0\right) \leftarrow \mathrm{X}^{2} \Pi\left(\mathrm{v}^{\prime \prime}=0\right)$ transition of $\mathrm{CH}$ at $430 \mathrm{~nm}$, corrected for background absorption is shown. Comparison to spectral simulations [16] shows a good agreement both for the line positions and their relative intensities. A closer examination of a small region of the experimental absorption spectrum is given in Figure 3.2 with the accompanying assignments [17].

Several spectral lines were selected and their absorption was recorded at different distances $d$ above the burner plate. Figure 3.3 shows the results for the $\mathrm{CH}$ number density distribution obtained for the maximum absorption path through the center of the cylindrically symmetric flat flame at $\phi=1.2, u=12 \mathrm{~cm} / \mathrm{s}$. The figure gives the population of the $\mathrm{F}_{1 \mathrm{f}}\left(\mathrm{N}^{\prime \prime}=11\right)$ state of $\mathrm{CH}$ 


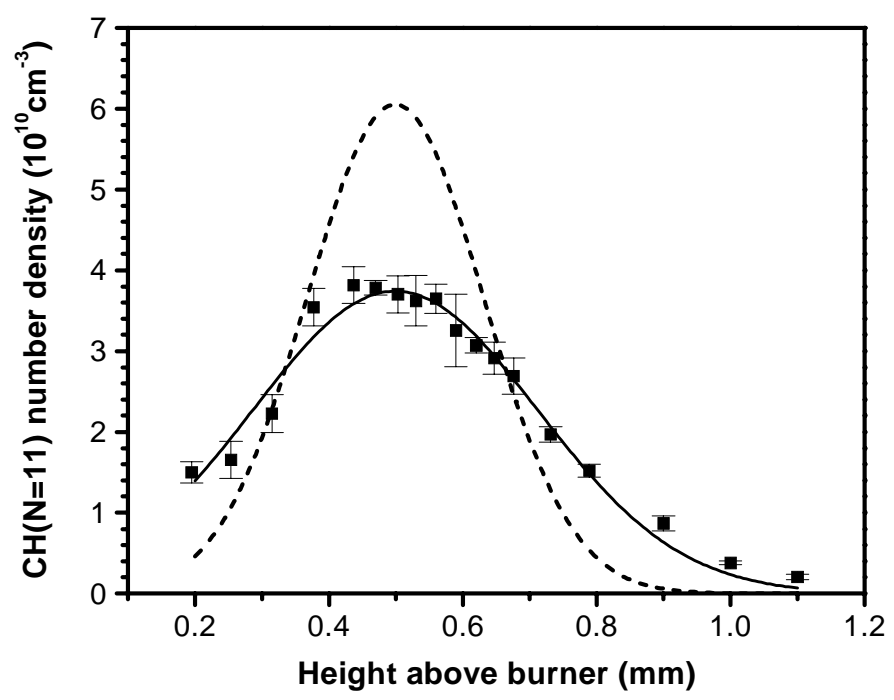

Figure 3.3: Measured and deconvoluted $\mathrm{CH}_{F_{1 f}}\left(N^{\prime \prime}=11\right)$ number density profile as a function of height above the burner surface for a burner-stabilized flame at $\phi=1.2, \quad u=12 \mathrm{~cm} / \mathrm{s}$, calculated from the $Q_{1}$ and $Q_{2}\left(N^{\prime \prime}=11\right)$ lines. - experimental data, --- deconvoluted result.

which was calculated from the measured absorptions on the $\mathrm{Q}_{1}$ and $\mathrm{Q}_{2}(\mathrm{~N}=11)$ lines averaged over three spectral scans. These particular states were found to be relatively insensitive to the temperature in the range between $1400-1800 \mathrm{~K}$ (less than $10 \%$ change in population) [18]. As stated above, the small deflection of the laser beam for each point was measured and the position of the data was corrected accordingly. Number densities are derived from the difference between the on- and off-resonance ring-down times. Cavity losses due to $\mathrm{CH}$ absorption were small $(\Delta \tau<10 \%)$ and the ring-down time was determined by fitting the first 1/e-time window of the signal. Therefore, the bandwidth of the laser could easily be taken into account [19-21]. Signals showed single-exponential behaviour over more than 2.5 times $\tau$. Densities were obtained by including the Doppler width $\left(0.18 \mathrm{~cm}^{-1}\right)$ of the transition and assuming an absorption path length of $L=26.8 \mathrm{~mm}$ (see below). The $\mathrm{CH}$ radicals are found in a thin layer at the flame front between $d=0.2$ and $1.1 \mathrm{~mm}$ above the burner plate. The maximum $\mathrm{CH}$ populations (averaged over the width of the laser beam profile) in the $\mathrm{F}_{1 \mathrm{f}}\left(\mathrm{N}^{\prime \prime}=11\right)$ level are found to be $3.7 \cdot 10^{10} \mathrm{~cm}^{-3}$ at $d=0.50 \mathrm{~mm}$ and $2.4 \cdot 10^{10} \mathrm{~cm}^{-3}$ at $d=0.41 \mathrm{~mm}$ for $\phi=1.2$ and $\phi=1.1$, respectively. The experimental accuracy is typically $8 \%$. 


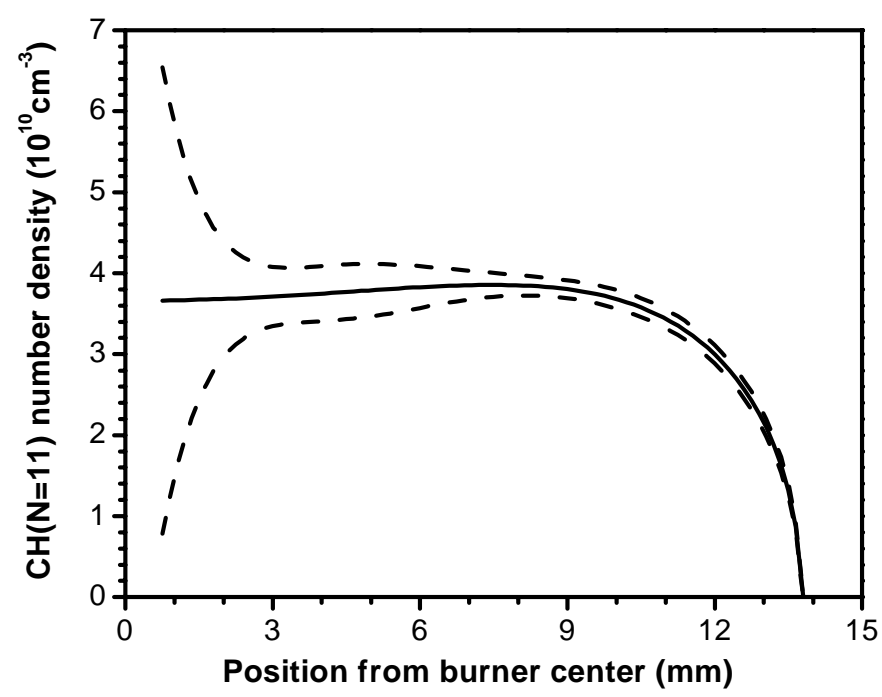

Figure 3.4: The $\mathrm{CH}$ number density profile as a function of radial position in a burnerstabilized flame at $\phi=1.2, u=12 \mathrm{~cm} / \mathrm{s}$ resulting from an Abel transformation of measurements taken at different parallel intersections with the flame. - data, --- error bars.

Due to the cylindrical symmetry of the flame, an Abel transformation can be applied to a data set when the $\mathrm{CH}$-distribution is measured at several different parallel intersections from the flame center. Because of the symmetry of the flame, the absorption path length decreases when going from the flame axis to the edges as $2 \times\left(R^{2}-y^{2}\right)^{1 / 2}$, where $R$ is a cut-off radius defining an area outside which the $\mathrm{CH}$ concentration is zero and $y$ is the minimum distance of the laser beam to the flame axis. Using an Abel-inversion technique [22, 23], density profiles as a function of the radial position can be reconstructed from line-of-sight measurements at different parallel positions through the axisymmetric object. The result of this procedure is shown in Figure 3.4. This figure shows the number density at the height of the maximum $\mathrm{CH}$ density (see Figure 3.3) as a function of the radial position in the flame, yielding a maximum flame diameter of $D=27.5 \mathrm{~mm}$ and an average diameter of $26.4 \mathrm{~mm}$ over which the $\mathrm{CH}$ concentration can be considered to be constant. The figure also shows the typical behaviour of the error bars on the resulting curve due to the nature of the method to solve the inversion problem. Chemiluminescence measurements of excited state $\mathrm{CH}$ with the iCCD camera with a bandpass filter $(430 \pm 5 \mathrm{~nm}$ ) resulted in a flame diameter of $27.1 \mathrm{~mm}$. In the calculations of the number densities a diameter of $26.8 \mathrm{~mm}$ was taken. 


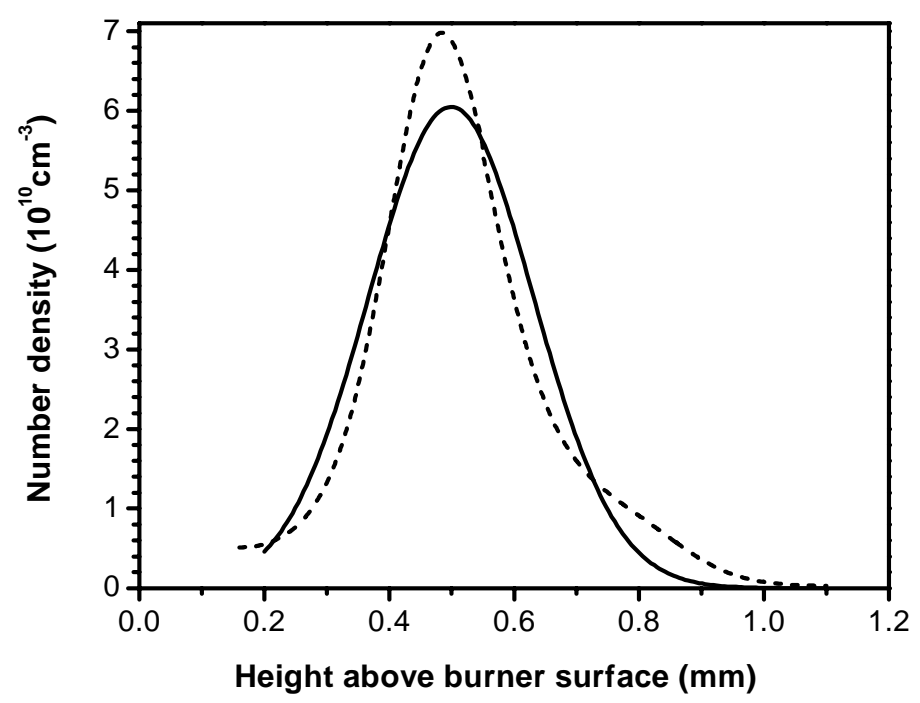

Figure 3.5: Comparison between analytical deconvolution assuming gaussian profiles (-)

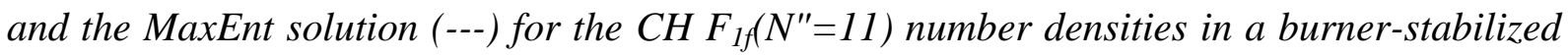
methane/air flame at $\phi=1.2, u=12 \mathrm{~cm} / \mathrm{s}$, calculated from the $Q_{1}$ and $Q_{2}\left(N^{\prime \prime}=11\right)$ lines, at different heights above the burner surface.

\subsubsection{Deconvolution}

In view of the narrow width of the $\mathrm{CH}$ density distribution, a correction has to be made for the spatial laser beam profile. Both the beam profile in the $z$-direction (perpendicular to the burner surface) and the $\mathrm{CH}$ density distributions obtained as a function of $d$ could be fitted well to a Gaussian profile. Deviations from the minimum beam waist in the middle of the cavity due to the Gaussian behaviour of the light inside the cavity were estimated to be smaller than $5 \%$ over the diameter of the burner (Rayleigh range $z_{R}=0.41 \mathrm{~m}$ ). The next step was an analytical deconvolution of the fitted experimental density distribution by the fitted laser beam profile. The resulting $\mathrm{CH}$ density distribution after deconvolution for the richer flame $(\phi=1.2)$ is also shown in Figure 3.5 and additionally in Figure 3.3 to enable a quick comparison with the nondeconvoluted curve. As can be seen from these graphs, the deconvoluted curve has a maximum of $6.0 \cdot 10^{10} \mathrm{~cm}^{-3}$ and a width of $0.31 \mathrm{~mm}$ (FWHM) while its area equals that of the non-deconvoluted curve. For the $\phi=1.1$ flame, this procedure results in a maximum of $5.4 \cdot 10^{10} \mathrm{~cm}^{-3}$ and a width of $0.19 \mathrm{~mm}$ (FWHM), as shown in Figure 3.6.

Obviously, an analytical deconvolution of two Gaussian profiles can only be applied if both profiles can be approximated by a Gaussian profile. Therefore, also a more general mathematical approach was followed to solve the deblurring or deconvolution of the 


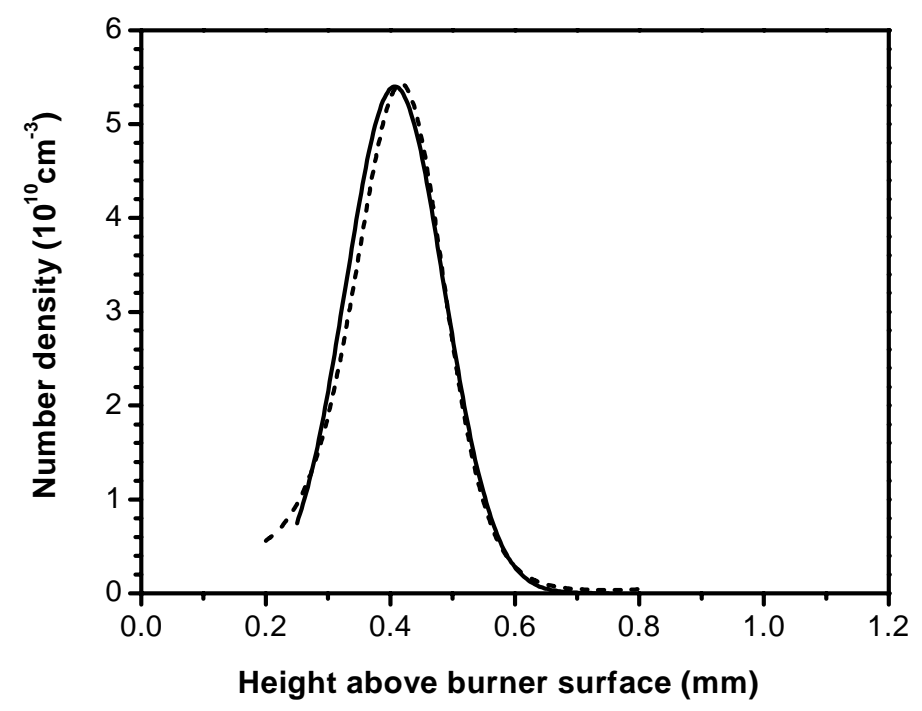

Figure 3.6: Comparison between the analytical deconvolution assuming Gaussian profiles (-) and the MaxEnt solution (--) for the $\mathrm{CH} F_{1 f}\left(N^{\prime \prime}=11\right)$ number densities in a burnerstabilized flame at $\phi=1.1, u=12 \mathrm{~cm} / \mathrm{s}$, calculated from the $Q_{1}$ and $Q_{2}\left(N^{\prime \prime}=11\right)$ lines, at different heights above the burner surface.

experimental data set. The experimental data set $h(x)$ can be represented as a convolution of the original function $f(x)$ and a response function $g(x)$

$$
h(x)=f(x) \otimes g(x)=\int_{-\infty}^{\infty} f(y) g(x-y) \mathrm{d} y
$$

In practice, noise should be added to equation (3.1), and this is a well-known source of problems in applying deconvolution procedures. Deconvolution algorithms solving the convolution problem include among others fast Fourier transform (FFT) spectral methods and the maximum entropy method [24]. In our case, the number of data points was limited making the FFT method less suitable. Therefore, the deconvolution was performed with the maximum entropy (MaxEnt) method [25]. The MaxEnt method or MEM is also called the all-poles model or autoregressive model. Among the different applications of the method is the possibility to estimate the real data from convoluted, blurred or otherwise imperfect data. The deconvolution problem can be described in the general discrete form by 


$$
h_{i}=\sum_{k=1}^{N} f_{k} g_{i k}+\sigma_{i}
$$

where $\sigma_{i}$ represents the noise in each point at position $i, f_{k}$ is the original spectrum, $g_{i k}$ the response or blurring function and $N$ the number of steps or points. This relation is similar to the previous convolution equation (3.1), but now the steps are discrete and a noise-term is included. According to the principle of maximum entropy, the 'best' estimate of $f_{k}$ is the function with the minimum information content, or, equivalently, the maximum entropy, $S$, which is defined as

$$
S=-k \sum_{i=1}^{N} f_{i} \ln f_{i}
$$

in which $k$ is an arbitrary positive constant. The possible estimates of $f_{k}$ fulfilling equation (3.3) result from a test of the calculated data $F_{i}$ and the convoluted experimental data according to

$$
\sum_{i=1}^{N} \frac{\left(h_{i}-H_{i}\right)^{2}}{\sigma_{i}^{2}}=N
$$

with $H_{i}$ the reconstructed spectrum from the calculated data $F_{i}$ and the response function $g_{i}$ and $N$ the number of points. More details on the procedure can be found in [24, 25].

The results of the application of the method to the experimental data are also shown in Figures 3.5 and 3.6. As can be seen from a comparison with the analytically deconvoluted data, the two different approaches result in similar experimental profiles. The MaxEnt results show slightly asymmetrical curves. The areas under the curves are found to equal the areas of the non-deconvoluted data. Differences could have been attributed to the noise term. The maximum intensity in case of the $\phi=1.2$ flame is slightly different for the two deconvolution methods, but a reconstruction of the convoluted data shows that this is within the expected error of the method. In principle, this method can also be applied to invert integrated line-ofsight data, instead of Abel-inversion techniques. In general, if the deconvolution cannot be performed analytically using fits of the experimental data to reduce noise, it should preferentially be performed using a statistical approach like the MaxEnt method or a similar mathematical technique. 


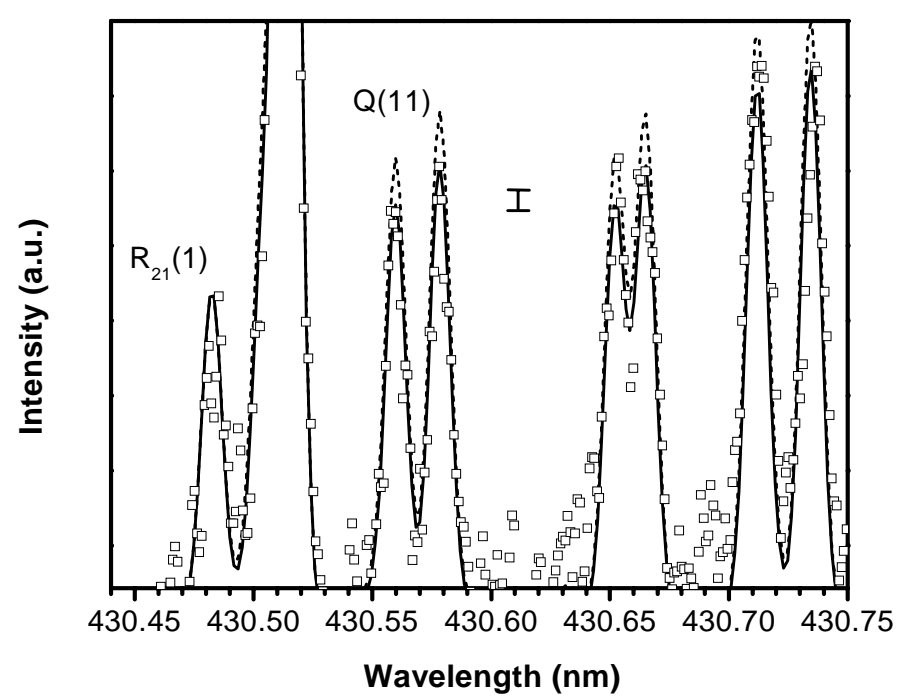

Figure 3.7: Simulated CH A-X absorption spectra at $1500 \mathrm{~K}(-)$ and $1600 \mathrm{~K}(--)$ [16] and experimental CRDS CH spectrum ( $\square$ ) in a burner-stabilized flat $\mathrm{CH}_{4} /$ air flame, $\phi=1.2$, $u=12 \mathrm{~cm} / \mathrm{s}$ at $0.55 \mathrm{~mm}$ above the burner surface.

\subsubsection{Temperature and total number densities}

To extract quantitative results from the recorded cavity ring-down data, the temperature profile should be accurately known. The Boltzmann distribution describes the relative population of the levels as a function of temperature. Temperatures can therefore be extracted from known population distributions of the species under investigation [26]. A visual representation is given in Figure 3.7 for $\mathrm{CH}$ in a $\phi=1.2$, burner-stabilized flame at $d=0.55 \mathrm{~mm}$ above the burner surface. In this figure, the experimental $\mathrm{CH}$ spectrum is compared to spectral simulations at two different temperatures. The construction of Boltzmann-plots at the height of the $\mathrm{CH}$ density maxima at $\phi=1.2$ and $\phi=1.1$ results in temperatures of $1565 \pm 50 \mathrm{~K}$ and $1569 \pm 50 \mathrm{~K}$, respectively. The experimental spectra have been corrected for broad-band absorption and/or losses due to the small change in reflectivity of the mirrors over the scanned interval before the evaluation. Assuming flame temperatures of $1565 \mathrm{~K}$ and $1569 \mathrm{~K}$, total $\mathrm{CH}$ number densities of $4.6 \cdot 10^{12} \mathrm{~cm}^{-3}$ and $3.5 \cdot 10^{12} \mathrm{~cm}^{-3}$ are obtained at the maxima of the deconvoluted experimental profiles for $\phi=1.2$ and $\phi=1.1$, respectively. The experimental errors lead to a relative error in the concentration in the order of $20 \%$. From the signal-tonoise ratio it follows that total $\mathrm{CH}$ densities down to $4 \cdot 10^{11} \mathrm{~cm}^{-3}$, corresponding to $1.5 \mathrm{ppb}$ can be detected $\left(\mathrm{S} / \mathrm{N}_{\mathrm{p}-\mathrm{p}}=2\right)$ when measured on the $\mathrm{Q}_{1}(11)$ transition. Four times lower detection limits could be reached by selecting the stronger transitions in this wavelength range. 


\subsection{Comparison to Simulations}

In Figures 3.8 and 3.9 the deconvoluted experimental profiles are presented in combination with numerically calculated profiles and temperatures for both stoichiometries. The theoretical $\mathrm{CH}\left(\mathrm{N}^{\prime \prime}=11\right)$ number density profiles were calculated from the total $\mathrm{CH}$ number density profile [27] for a 1D burner-stabilized flame, using GRI-Mech 2.11 and 3.0 [11, 12] and mixture-averaged transport data, taking the numerically obtained temperature profile into account. In this way, the experimental profile needs no correction with a (experimental) temperature profile to make a good comparison. The results for the maximum $\mathrm{CH}$ number densities, positions and temperatures are given in Table 3.1. The widths of the experimental and theoretical profiles are comparable for $\phi=1.1$. In case of $\phi=1.2$, the width of the experimental profile is $0.23 \mathrm{~mm}$ (FWHM) against $0.24 \mathrm{~mm}$ for the theoretical value using GRI-Mech 3.0. Both the simulated and measured data show a reduction in $\mathrm{CH}$ concentration when changing $\phi$ from 1.2 to 1.1. However, there is a discrepancy between the absolute experimental and theoretical values for the $\mathrm{CH}$ concentrations, the theoretical value being approximately $30 \%$ higher at the maximum of the profile for $\phi=1.2$ and $\phi=1.1$ for GRI-Mech 2.11 and a factor of two for GRI-Mech 3.0. Figures 3.8 and 3.9 also show a disagreement between the positions of the maxima of the experimental and simulated curves of 0.2 to 0.3 $\mathrm{mm}$. The experimental temperature at the maximum $\mathrm{CH}$ number density is also included in the figures. At the maximum of the theoretical $\mathrm{CH}$ concentration profiles the calculated temperatures are about $200 \mathrm{~K}$ higher than the measured temperature at the height of the experimental $\mathrm{CH}$ maximum. If the calculated $\mathrm{CH}$ peak is shifted to the lower (experimentally determined) temperature in the calculated temperature profile, this would lead to a shift of approximately $0.20 \mathrm{~mm}$ towards the burner. When the experimentally determined temperatures are used to calculate the theoretical $\mathrm{CH}\left(\mathrm{N}^{\prime \prime}=11\right)$ number densities from the

Table 3.1: Experimental and calculated maximum $\mathrm{CH}$ number densities, positions and temperatures.

\begin{tabular}{|c|c|c|c|c|}
\hline Parameter & $\begin{array}{c}{[\mathrm{CH}]_{\max }} \\
\left(10^{12} \mathrm{~cm}^{-3}\right)\end{array}$ & $\begin{array}{c}{\left[\mathrm{CH}_{\mathrm{N} "=11}\right]_{\max }} \\
\left(10^{11} \mathrm{~cm}^{-3}\right)\end{array}$ & $\begin{array}{l}\text { Position }_{\mathrm{CH}, \max } \\
(\mathrm{mm})\end{array}$ & $\begin{array}{c}T_{C H, \max } \\
\quad(\mathrm{K})\end{array}$ \\
\hline$\phi=1.2$ Exp. & 4.6 & 7.0 & 0.48 & 1565 \\
\hline GRI 2.11 & 6.0 & 8.4 & 0.75 & 1730 \\
\hline GRI 3.0 & 8.6 & 12.1 & 0.81 & 1763 \\
\hline$\phi=1.1$ Exp. & 3.5 & 5.4 & 0.42 & 1569 \\
\hline GRI 2.11 & 5.1 & 7.0 & 0.62 & 1651 \\
\hline GRI 3.0 & 7.3 & 10.0 & 0.65 & 1680 \\
\hline
\end{tabular}




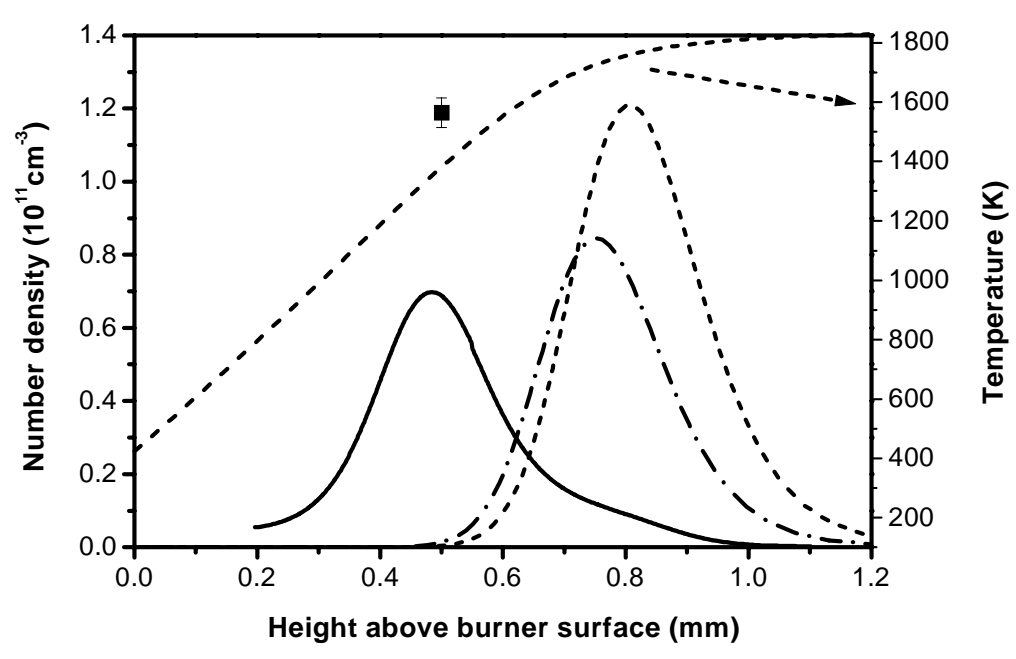

Figure 3.8: Deconvoluted experimental and numerical $C H F_{1 f}\left(N^{\prime \prime}=11\right)$ number densities for a burner-stabilized flame at $\phi=1.2, u=12 \mathrm{~cm} / \mathrm{s}$, calculated from the $Q_{1}$ and $Q_{2}\left(N^{\prime \prime}=11\right)$ lines, at different heights above the burner surface. - measured data,

- experimental temperature, -.- numerical curve GRI-Mech 2.11, --- numerical curve and temperature profile GRI-Mech 3.0 .

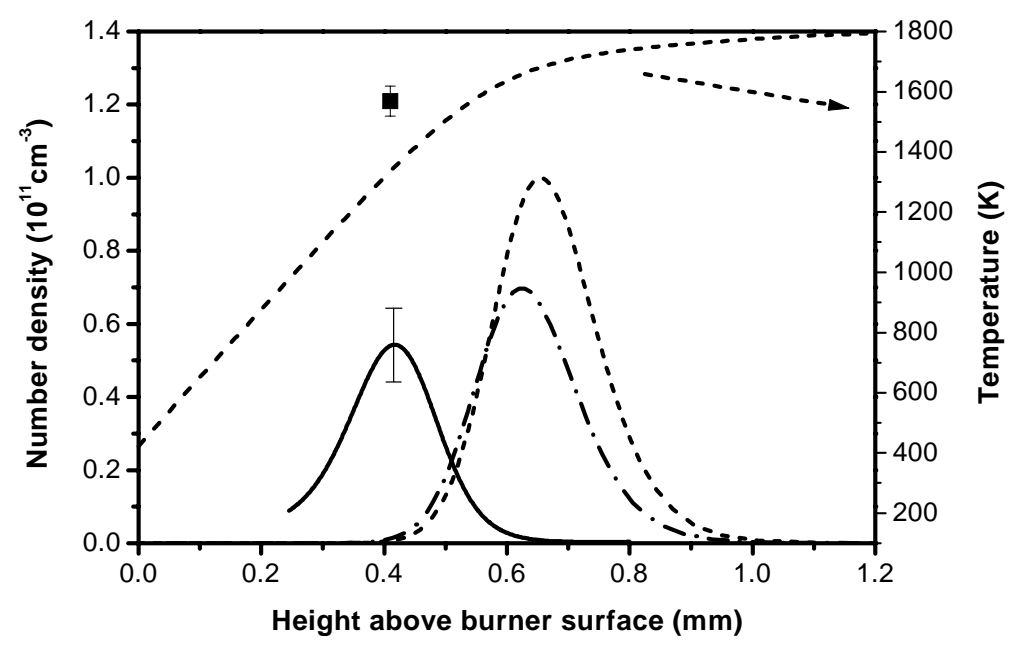

Figure 3.9: Deconvoluted experimental and numerical $C H F_{1 f}\left(N^{\prime \prime}=11\right)$ number densities for a burner-stabilized flame at $\phi=1.1, u=12 \mathrm{~cm} / \mathrm{s}$, calculated from the $Q_{1}$ and $Q_{2}\left(N^{\prime \prime}=11\right)$ lines, at different heights above the burner surface. - measured data, - experimental temperature, -.- numerical curve GRI-Mech 2.11, --- numerical curve and temperature profile GRI-Mech 3.0. 
calculated total $\mathrm{CH}$ number density profiles, this would lead to a $5 \%$ decrease of the calculated $\mathrm{CH}$ densities.

To verify the measured position of the $\mathrm{CH}$-profile with a different method, it was checked experimentally for $\phi=1.2$ by $\mathrm{CH}$ chemiluminescence measurements with an iCCD camera with a $430 \pm 5 \mathrm{~nm}$ bandpass filter. The result showed a maximum at $0.48 \pm 0.08 \mathrm{~mm}$, comparable to and supporting the CRDS data.

In the following, we will investigate whether the observed differences can be caused by a shift of the flame structure as a whole (i.e. all species profiles together, including $\mathrm{CH}$ and temperature). At the burner, the temperature is well fixed due to efficient cooling. The resulting burner-stabilized flame has a spatial structure and temperature which are almost independent of the boundary condition at the burner: a less efficient cooling gives the same flame, which is stabilized a little closer to the burner with little effect on the $\mathrm{CH}$ and temperature profile [28]. Investigations of flat flames at adiabatic conditions with CARS [15] showed a good agreement between predicted and measured flame temperature profiles.

Firstly, radiation was included in the numerical model and the effect of experimental errors in the settings was studied with a set of numerical calculations. The inclusion of radiation in the model showed no influence on the flame structure and temperature up to $10 \mathrm{~mm}$ above the burner surface. Therefore, it was justified to ignore this in the first place. To study the effect of experimental errors in the settings of the unburned gas velocity, equivalence ratio, gas and burner temperature, the input parameters have been varied within the experimental errors in a set of numerical calculations. The results on the computed $\mathrm{CH}$ density, position and temperature are shown in Table 3.2. The effects are nearly linear in this small regime and a change of sign would result in similar differences with opposite sign. From the table, it can be concluded that the disagreement in position can not be attributed to the uncertainty in these parameters because these would only lead to very small deviations.

In a 1D numerical approach, more-dimensional effects are not accounted for. To study

Table 3.2: Influence of experimental errors in the settings on the calculated $\mathrm{CH}$ number density, position and temperature.

\begin{tabular}{lllll}
\hline Parameter & Change & $\begin{array}{l}\Delta \text { Position }_{\mathrm{CH}, \max } \\
(\mathrm{mm})\end{array}$ & $\begin{array}{l}\Delta[\mathrm{CH}]_{\max } \\
(\%)\end{array}$ & $\begin{array}{l}\Delta T_{\mathrm{CH}, \max } \\
(\mathrm{K})\end{array}$ \\
\hline $\mathrm{u}$ & $+4 \%$ & -0.015 & +6 & +5 \\
$\phi$ & $+2 \%$ & +0.021 & +5 & +14 \\
$\mathrm{~T}_{\text {gas }}$ & $+2 \mathrm{~K}$ & +0.002 & -1 & -0.7 \\
$\mathrm{~T}_{\text {burner }}$ & $+10 \mathrm{~K}$ & -0.004 & -0.1 & $<0.1$ \\
\hline
\end{tabular}




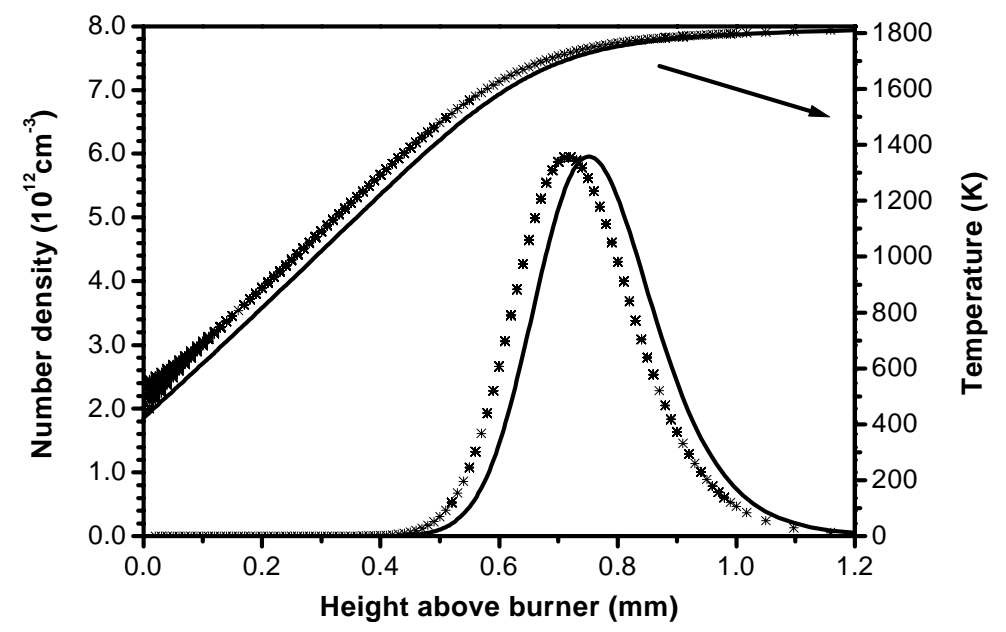

Figure 3.10: Numerically computed total $\mathrm{CH}$ number densities and temperatures for a burner-stabilized flame at $\phi=1.2, u=12 \mathrm{~cm} / \mathrm{s}$, calculated with GRI-Mech 2.11 using a 1D and a 2D approach. - 1D flamelet generated manifold method, *2D flamelet generated manifold method.

possible effects on the flame structure, 2D numerical simulations [27] were performed using GRI-Mech 2.11 and the flamelet generated manifold (FGM) method to reduce the computation time [29]. One of the results is shown in Figure 3.10. The figure shows a comparison of the $2 \mathrm{D}$ results with the $1 \mathrm{D}$ profiles for the $\mathrm{CH}$ density and the flame temperature for $\phi=1.2, u=12 \mathrm{~cm} / \mathrm{s}$ calculated with the FGM method using GRI-Mech 2.11. The 1D FGM results cannot be distinguished from those obtained from the detailed 1D calculations, supporting the validity to use the FGM approach to compute the flame structure. From the comparison with the $2 \mathrm{D}$ result, it follows that more-dimensional effects only have a minor influence on the position of the complete flame structure (a shift of $0.034 \mathrm{~mm}$ towards the burner surface).

To further investigate in an independent way whether a shift of the flame structure is the reason for the observed differences, the $\mathrm{OH}$ density profiles, which are also predicted by numerical simulation, were measured by direct absorption on the $\mathrm{OH} A-\mathrm{X} \mathrm{Q}_{1}(8)$ line. This line was selected because it has a large absorption cross-section and a relatively constant population at temperatures between $1600 \mathrm{~K}$ and $2100 \mathrm{~K}$. The experimental $\mathrm{OH}(\mathrm{N}=8)$ density profiles are given in Figure 3.11 and show $\mathrm{OH}$ profiles typically expected for this type of flame [27]. The experimental maxima are found at $0.92 \pm 0.09 \mathrm{~mm}$ and $1.11 \pm 0.09 \mathrm{~mm}$ for $\phi=1.1$ and $\phi=1.2$, respectively. Also presented in the figure are the simulated $\mathrm{OH}(\mathrm{N}=8)$ density profiles, calculated from the total $\mathrm{OH}$ number density and temperature profiles 


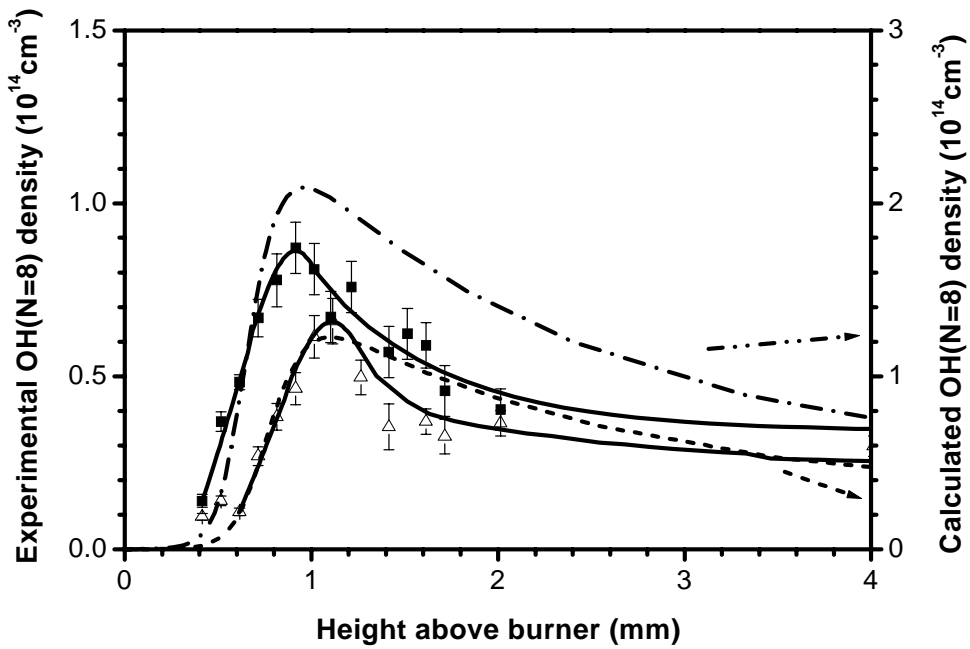

Figure 3.11: Measured and calculated $\mathrm{OH}\left(Q_{1}(8)\right)$ density profiles using $1 D$ GRI-Mech 3.0 at $\phi=1.2$ and $\phi=1.1,12 \mathrm{~cm} / \mathrm{s}$. - experimental data $\phi=1.2, \Delta$ experimental data $\phi=1.1$, --- numerical curve $\phi=1.2,-.-$ numerical curve $\phi=1.1$. Solid lines are drawn as a guide to the experimental values.

numerically simulated with GRI-Mech 3.0. Although quantitatively not in agreement [30], these profiles show the maximum of the $\mathrm{OH}$ density at $0.95 \mathrm{~mm}$ and $1.09 \mathrm{~mm}$ for $\phi=1.1$ and $\phi=1.2$, respectively. From this, it can be concluded that the position of the $\mathrm{OH}$ maximum for both stoichiometries is in agreement with the numerical value within the experimental accuracy. A shift of the calculated temperature profile and flame structure towards the burner within the available error margins results in an agreement of the experimental and calculated temperatures within their error ranges. Concluding, when shifting the whole flame structure within the error bar with $0.08 \mathrm{~mm}$ and $0.09 \mathrm{~mm}$ for $\phi=1.2$ and $\phi=1.1$, respectively, the experimental and calculated $\mathrm{OH}$ maximum and temperature agree. However, the experimental $\mathrm{CH}$ density profile is still much closer to the burner surface than expected. The disagreement between the positions of the $\mathrm{CH}$ maxima of the experimental and simulated curves remains 0.11 to $0.26 \mathrm{~mm}$. From this, in combination with the findings discussed above, the most probable cause for the shift in the $\mathrm{CH}$ position in the flame structure in relation to the temperature is the reaction mechanism, which predicts that the computed $\mathrm{CH}$ peak appears at a higher temperature, and thus further away from the burner. The quantitative disagreement between the measured and calculated $\mathrm{OH}$ number densities has also been observed in a different experiment [30] and has also been reported in literature for this type of flame [31]. The disagreement can most probably be attributed to the reaction mechanism. The thorough evaluation of the cause for this is currently in progress. 


\subsection{Conclusions}

Cavity ring-down spectroscopy was applied to an atmospheric premixed $\mathrm{CH}_{4} /$ air flat flame to obtain $\mathrm{CH}$ densities as a function of distance to the burner surface. During experiments, the use of an intensified CCD camera was a necessity to recognise beam deflection and alignment problems. The $\mathrm{CH} \mathrm{A}^{2} \Delta\left(\mathrm{v}^{\prime}=0\right) \leftarrow \mathrm{X}^{2} \Pi\left(\mathrm{v}^{\prime \prime}=0\right)$ transition at $430 \mathrm{~nm}$ has been probed. Both qualitative and quantitative data on the burner-stabilized laminar flat flame have been obtained at two different flame stoichiometries: $\phi=1.2$ and $\phi=1.1$ at $u=12 \mathrm{~cm} / \mathrm{s}$. Experimental data have been corrected for the Doppler width, laser bandwidth, spatial width of the laser beam and deflection due to thermal lensing effects. Although CRDS is a line-of-sight technique, due to the cylindrical symmetry of the system, the dimensions of the flame front could be determined by different lateral measurements through the flame and applying an Abel inversion technique. The experimental number density profiles have been deconvoluted with the spatial beam profile using an analytical deconvolution and a numerical approach with the MaxEnt method. The results of both methods differ only slightly.

Sensitivities down to $1.5 \mathrm{ppb}$ have been reached (improvement by a factor of four seems possible), restricted mainly by flame stability. The maximum total $\mathrm{CH}$ concentrations have been found to be $(4.6 \pm 0.6) \cdot 10^{12} \mathrm{~cm}^{-3}$ for $\phi=1.2$ and $(3.5 \pm 0.4) \cdot 10^{12} \mathrm{~cm}^{-3}$ for $\phi=1.1$ at $u=12$ $\mathrm{cm} / \mathrm{s}$. Temperature information was obtained by a comparison of the experimental data with spectral simulations and from the construction of Boltzmann-plots. The experimental density profiles have been compared with calculated $\mathrm{CH}$ distributions using two different reaction mechanisms. This showed a discrepancy in the position and height of the $\mathrm{CH}$ profiles. The numerically obtained absolute $\mathrm{CH}$ densities are higher than the experimental results by $30 \%$ and $100 \%$, comparing less favourable for GRI-Mech 3.0 than for 2.11. The reaction mechanism appears to predict the $\mathrm{CH}$ peak position at a higher temperature, that is, further away from the burner surface. Variations in the parameters, the inclusion of radiation into the model and a 2D numerical simulation can not explain the difference in the position of the $\mathrm{CH}$ profile or the lower experimental temperature. From direct absorption measurements on $\mathrm{OH}$ it follows that a small shift of the whole flame structure towards the burner surface accounts for the experimentally obtained temperatures. However, the experimental $\mathrm{CH}$ density profile is still shifted further towards the burner surface. Therefore, it is expected that the reaction mechanisms predict the $\mathrm{CH}$ radical at too high a temperature and position in atmospheric flames. 


\section{References}

1. Miller, J.A., Bowman, C.T., Mechanism and modelling of nitrogen chemistry in combustion. Prog. Energy Combust. Sci. 15:287-338 (1989).

2. Luque, J., Crosley, D.R., Absolute CH concentrations in low-pressure flames measured with laserinduced fluorescence. Appl. Phys. B 63:91-98 (1996).

3. Chen, Y.-C., Mansour, M.S., Simultaneous Rayleigh scattering and laser induced CH fluorescence for reaction zone imaging in high-speed premixed hydrocarbon flames. Appl. Phys. B 64:599-605 (1997).

4. Berg, P.A., Hill, D.A., Noble, A.R., Smith, G.P., Jeffries, J.B., Crosley, D.R., Absolute CH concentration measurements in low-pressure methane flames: comparisons with model results. Combust. Flame 121:223-235 (2000).

5. Derzy, I., Lokovsky, V.A., Cheskis, S., Absolute CH concentration in flames measured by cavity ringdown spectroscopy. Chem. Phys. Lett. 306:319-324 (1999).

6. Thoman, J.W., Jr., McIlroy, A., Absolute CH radical concentrations in rich low-pressure methaneoxygen-argon flames via cavity ringdown spectroscopy of the $A^{2} \Delta-X^{2} \Pi$ transition. J. Phys. Chem. A 104:4953-4961 (2000).

7. Luque, J., Jeffries, J.B., Smith, G.P., Crosley, D.R., Scherer, J.J., Combined cavity ringdown absorption and laser-induced fluorescence imaging measurements of $C N(B-X)$ and $C H(B-X)$ in low-pressure $\mathrm{CH}_{4}-\mathrm{O}_{2}-\mathrm{N}_{2}$ and $\mathrm{CH}_{4}-\mathrm{NO}-\mathrm{O}_{2}-\mathrm{N}_{2}$ flames. Combust. Flame 126:1725-1735 (2001).

8. Mercier, X., Jamette, P., Pauwels, J.F., Desgroux, P., Absolute CH concentration measurements by cavity ring-down spectroscopy in an atmospheric diffusion flame. Chem. Phys. Lett. 305:334-342 (1999).

9. Stolk, R.L., Ter Meulen, J.J., Laser diagnostics of CH in a diamond depositing flame. Diamond Relat. Mater. 8:1251-1255 (1999).

10. Vander Wal, R. L., Ticich, T. M., Cavity ringdown and laser-induced incandescence measurements of soot. Appl. Opt. 38:1444-1451 (1999).

11. Bowman, C.T., Hanson, R.K., Davidson, D.F., Gardiner, W.C., Lissianski, V., Smith, G.P., Golden, D.M., Frenklach, H., GRI-Mech 2.11. http://www.me.berbeley.edu/gri_mech/(1995).

12. Smith, G.P., Golden, D.M., Frenklach, M., Moriarty, N.W., Eiteneer, B., Goldenberg, M., Bowman, C.T., Hanson, R.K., Soonho Song, Gardiner Jr., W.C., Lissianski, V.V., Qin, Z., GRI-Mech 3.0. http://www.me.berkeley.edu/gri_mech/ (2000).

13. Zhao, M., Wahl, E.H., Owano, T.G., Largent, C.C., Zare, R.N., Kruger, C.H., Near-surface reduction of cavity ring-down spectroscopy detection sensitivity. Chem. Phys. Lett. 318:555-560 (2000).

14. Van Maaren, A., Thung, D.S., De Goey, L.P.H., Measurement of flame temperature and adiabatic burning velocity of methane/air mixtures. Combust. Sci. Technol. 96:327-344 (1994).

15. Bosschaart, K.J., Versluis, M., Knikker, R., Van der Meer, Th. H., Schreel, K.R.A.M., De Goey, L.P.H., Van Steenhoven, A.A., The heat flux method for producing burner stabilized adiabatic flames: an evaluation with CARS thermometry. Combust. Sci. Techn. 168:1-19 (2001).

16. Luque, J., Crosley, D.R., LIFBASE: Database and Spectral Simulation Program (version 1.4), SRI International Report MP 96-001, 1998.

17. Zachwieja, M., New investigations of the $A^{2} \Delta-X^{2} \Pi$ band system in the $C H$ radical and a new reduction of the vibration-rotation spectrum of $\mathrm{CH}$ from the ATMOS spectra. J. Molec. Spect. 170:285-309 (1995).

18. Evertsen, R., Stolk, R.L.,Ter Meulen, J.J., Investigations of Cavity Ring Down Spectroscopy applied to the detection of $\mathrm{CH}$ in Atmospheric Flames. Combust. Sci. Technol. 149:19-34 (1999). 
19. Jongma, R.T., Boogaarts, M.G.H., Holleman, I., Meijer, G., Trace gas detection with cavity ring down spectroscopy. Rev. Sci. Instrum. 66:2821-2828 (1995).

20. Zalicki, P., Zare, R.N., Cavity ring-down spectroscopy for quantitative absorption measurements. J. Chem. Phys. 102:2708-2717 (1995).

21. Hodges, J.T., Looney, J.P., Van Zee, R.D., Laser bandwidth effects in quantitative cavity ring-down spectroscopy. Appl. Opt. 35:4112-4116 (1996).

22. Zalicki, P., Ma, Y., Zare, R.N., Wahl, E.H., Owano, T.G., Kruger, C.H., Measurement of the methyl radical concentration profile in a hot-filament reactor. Appl. Phys. Lett. 67:144-146 (1995).

23. Dasch, C.J., One-dimensional tomography: a comparison of Abel, onion-peeling, and filtered backprojection methods. Appl. Opt. 31:1146-1152 (1992).

24. Press, W.H., Flannery, B.P., Teukolsky, S.A., Vetterling, W.T.: Numerical recipes, the art of scientific computing, Cambridge University Press, New York, 1986.

25. Buck, B., Macaulay, V.A., eds. Maximum entropy in action, Oxford university press, Oxford, 1991.

26. Rensberger, K.J., Jeffries, J.B., Copeland, R.A., Kohse-Hoinghaus, K., Wise, M.L., Crosley, D.R., Laser-induced fluorescence determination of temperatures in low pressure flames. Appl. Opt. 28:35563566 (1989).

27. Somers, L.M.T., The simulation of flat flames with detailed and reduced chemical models, Ph.D. thesis, Eindhoven University of Technology, Eindhoven, the Netherlands, http://www.tue.nl/bib/, 1994.

28. De Goey, L.P.H., Van Maaren, A., Quax., R.M., Stabilization of adiabatic premixed laminar flames on a flat flame burner. Combust. Sci. Technol. 92:201-207 (1993).

29. Van Oijen, J. A., De Goey, L.P.H., Modeling of premixed laminar flames using flamelet-generated manifolds. Combust. Sci. Technol. 161:113-138 (2000).

30. Schreel, K.R.A.M., Versluis, M., De Goey, L.P.H., The quantitative detection of OH densities in reactive flows using bi-directional LIF. Combust. Flame, submitted (2002).

31. Lozovsky, V.A., Derzy, I., Cheskis, S., Radical concentration profiles in a low-pressure methane-air flame measured by intracavity laser absorption and cavity ring-down spectroscopy. Proc. Combust. Inst. 27:445-452 (1998). 


\title{
CHAPTER 4
}

\section{ABSOLUTE HCO AND ${ }^{1} \mathrm{CH}_{2}$ CONCENTRATION Measurements in a Premixed Atmospheric Flat \\ FLAME ${ }^{1}$}

\begin{abstract}
Singlet methylene $\left({ }^{1} \mathrm{CH}_{2}\right)$ and the formyl radical (HCO) have been studied in a premixed atmospheric flat $\mathrm{CH}_{4} /$ air flame by cavity ring-down spectroscopy. The spectral absorption lines lie in the same spectral region for both species. The ${ }^{1} \mathrm{CH}_{2}$ radicals are probed via the $\tilde{\mathrm{b}}^{1} \mathrm{~B}_{1}(0,13,0) \leftarrow \tilde{\mathrm{a}}^{1} \mathrm{~A}_{1}(0,0,0)$ band at $622 \mathrm{~nm}$, the $\mathrm{HCO}$ radicals via the $\tilde{\mathrm{A}}^{2} \mathrm{~A}^{\prime}(0,9,0)$ $\leftarrow \tilde{\mathrm{X}}^{2} \mathrm{~A} "(0,0,0)$ band at $615 \mathrm{~nm}$. Absolute ${ }^{1} \mathrm{CH}_{2}$ and $\mathrm{HCO}$ densities as a function of height above the burner surface have been obtained and compared to numerical simulations using both the GRI-Mech 2.11 and 3.0 mechanisms, showing a relatively good agreement.
\end{abstract}

\footnotetext{
${ }^{1}$ Adapted from: Evertsen, R., Van Oijen, J.A., De Goey, L.P.H., Ter Meulen, J.J.; Absolute ${ }^{1} \mathrm{CH}_{2}$ and $\mathrm{HCO}$ concentration measurements in a premixed atmospheric flat flame by cavity ring-down spectroscopy, Combust. Flame, in preparation.
} 


\subsection{Introduction}

This chapter is focussed on the flame chemistry of singlet methylene $\left({ }^{1} \mathrm{CH}_{2}\right)$ and formyl (HCO) radicals, which are both highly reactive species. Among others, $\mathrm{CH}_{2}$ participates in the formation and reduction of nitrogen oxides and in the formation of higher hydrocarbons which may ultimately lead to the formation of soot [1]. Therefore, the prediction of the density profiles of this species is also of environmental interest.

It was recognised early on that two different low-lying electronic states of methylene exist [2]. The radical has a 'metastable' $\tilde{\mathrm{a}}^{1} \mathrm{~A}_{1}$ singlet state, which lies about $3160 \mathrm{~cm}^{-1}$ above the triplet ground state, $\tilde{X}^{3} B_{1}$ [3]. Transitions between both states can be collisionally induced, and due to the small energy difference the singlet state is thermally occupied at temperatures relevant for flame chemistry. For example, at a temperature of $1300 \mathrm{~K}$ approximately $1 \%$ of the $\mathrm{CH}_{2}$ radicals present will be in the $\tilde{a}^{1} \mathrm{~A}_{1}$ singlet state under equilibrium conditions. Both states show a different reactivity. In general, singlet state reaction rates are much faster than their triplet analogues (often by more than a factor 100) [4]. Together with the fast transfer between singlet and triplet state methylene, this means that a significant part of methylene production and consumption in combustion reactions takes place through singlet $\mathrm{CH}_{2}$. Because of their different reactivity, singlet and triplet methylene are treated as different species in reaction mechanisms [4].

Singlet methylene electronic absorption spectra start from the red region in the visible spectrum. Triplet methylene shows absorption in the UV range. An extensive number of studies on the spectrum of singlet methylene in the range from 11,000 to $22,000 \mathrm{~cm}^{-1}$ exist [2, $3,5,6]$. However, because of a strong perturbation by the $\tilde{b}^{1} B_{1}$ state, a large number of rotational lines in this region is still unassigned.

In combustion research the spectroscopic detection of ${ }^{1} \mathrm{CH}_{2}$ has been the subject of a small number of studies. LIF detection of ${ }^{1} \mathrm{CH}_{2}$ via $\tilde{\mathrm{b}}^{1} \mathrm{~B}_{1} \leftarrow \tilde{\mathrm{a}}^{1} \mathrm{~A}_{1}$ has been accomplished in a 660 $\mathrm{Pa}$ flat flame at SRI [7]. However, this was not a simple experiment due to the low number densities and the strong quenching of the excited state even at these low pressures. With the experimental setup described, only one photon was detected for every 3 to 5 laser shots. Derzy et al. recorded a ${ }^{1} \mathrm{CH}_{2}$ spectrum at atmospheric pressure in a Perkin-Elmer burner [8] and studied ${ }^{1} \mathrm{CH}_{2}$ by intracavity laser absorption spectroscopy (ICLAS) in a methane-oxygennitrogen McKenna type flat flame at $3.9 \mathrm{kPa}$ [8-11]. They probed both the ${ }^{1} \mathrm{CH}_{2} \tilde{\mathrm{b}}^{1} \mathrm{~B}_{1}(0,13,0)$ $\leftarrow \tilde{\mathrm{a}}^{1} \mathrm{~A}_{1}(0,0,0)$ band at $622 \mathrm{~nm}$ and the $(0,14,0) \leftarrow(0,0,0)$ band at $593 \mathrm{~nm}$ [9]. In this way, they could derive absorption cross-sections for several of the $\tilde{b}^{1} \mathrm{~B}_{1}(0,13,0) \leftarrow \tilde{\mathrm{a}}^{1} \mathrm{~A}_{1}(0,0,0)$ rotational transitions by comparison with absorption cross-sections of the $(0,14,0) \leftarrow(0,0,0)$ band that are known from literature [12]. McIlroy [13, 14] used CRDS to record the $\mathrm{b}^{1} \mathrm{~B}_{1}(0,13,0) \leftarrow \mathrm{a}^{1} \mathrm{~A}_{1}(0,0,0)$ band at $622 \mathrm{~nm}$ in a $4.13 \mathrm{kPa}$ McKenna type flat flame burner with a $\mathrm{CH}_{4} / \mathrm{O}_{2} / \mathrm{Ar}$ mixture at different stoichiometries and presented a qualitative comparison of the experimental results to simulations with the GRI 2.11 and Prada-Miller mechanisms. 
Thus far, no measurements of absolute ${ }^{1} \mathrm{CH}_{2}$ densities in atmospheric flames have been reported.

HCO plays a key role in the oxidation of hydrocarbons in combustion processes. The formyl radical is part of the primary oxidation pathway for methane and is primarily formed via decomposition and abstraction reactions of formaldehyde, $\mathrm{CH}_{2} \mathrm{O}$. It was also empirically found that there is a temporal and spatial correlation between the HCO number density, the heat release rate and overall flame burning rate [15]. This was suggested to be the result of its rapid consumption, the relation with the carbon flow and its dependence on $\mathrm{CH}_{2} \mathrm{O}$, the formation of which from $\mathrm{CH}_{3}$ shows the largest effect on the heat release rate. However, due to the low number density, detection of HCO by PLIF was found difficult. A combination of $\mathrm{CH}_{2} \mathrm{O}$ and $\mathrm{OH}$ number densities also relating to the heat release rate was found to be simpler to evaluate experimentally [16].

The absorption spectrum of $\mathrm{HCO}$ in the region from 460 to $750 \mathrm{~nm}$ was first observed at high resolution by Herzberg and Ramsay [17]. The bands in this region can be assigned to transitions between the $\tilde{\mathrm{A}}^{2} \mathrm{~A} "$ and $\tilde{\mathrm{X}}^{2} \mathrm{~A}^{\prime}$ states. These states result from the splitting of the ${ }^{2} \Pi$ state due to a strong Renner-Teller interaction.

In combustion, the first LIF-based study by Jeffries et al. focussed on the $\widetilde{\mathrm{B}}(0,0,2)$ $\tilde{\mathrm{X}}(0,0,0)$ band around $244 \mathrm{~nm}$, also known as a hydrocarbon flame band, in a $763 \mathrm{~Pa}$ methane/oxygen flame, but failed to produce quantitative results [18]. In a similar LIF experiment on the $\tilde{\mathrm{B}}(0,0,0)-\tilde{\mathrm{X}}(0,0,0)$ band around $258 \mathrm{~nm}$ in a $3.3 \mathrm{kPaCH} / \mathrm{O}_{2} / \mathrm{N}_{2}$ flame, they compared their quantitative results to simulations using GRI Mech 2.11 [19]. The $\tilde{\mathrm{A}}$ state of HCO is strongly predissociated and a poor candidate for LIF experiments due to the low fluorescence yield. An intracavity laser absorption spectroscopic study of the HCO $\tilde{\mathrm{A}}^{2} \mathrm{~A}^{\prime}(0,9,0)-\tilde{\mathrm{X}}^{2} \mathrm{~A} "(0,0,0)$ band at $614 \mathrm{~nm}$ in the flame of an atmospheric pressure premixed methane/air Perkin-Elmer burner [20] was followed by a more extensive study in a methane/air McKenna burner flame at $3.9 \mathrm{kPa}$ [10]. Scherer and Rakestraw [21] used CRDS detection for the first time on the same band system to measure absolute concentrations in a $4.6 \mathrm{kPa} \mathrm{m} \mathrm{CH} / \mathrm{O}_{2} / \mathrm{N}_{2}$ McKenna burner. McIlroy later presented number density profiles of a $\mathrm{CH}_{4} / \mathrm{O}_{2} / \mathrm{Ar}$ McKenna burner flame at $4.1 \mathrm{kPa}$ for four different stoichiometries [13]. Similar to the ${ }^{1} \mathrm{CH}_{2}$ radical, no studies have yet been reported on $\mathrm{HCO}$ at atmospheric pressure.

In this chapter, we report on the detection of both ${ }^{1} \mathrm{CH}_{2}$ and $\mathrm{HCO}$ in an atmospheric premixed flat flame using cavity ring-down spectroscopy (CRDS). The spectral absorption lines lie in the same spectral region for both species. Therefore, it is in principle possible to record both radicals simultaneously. The aim of this study was to obtain direct quantitative information on radical densities as a function of height above the burner surface in order to validate numerical models involving flame chemistry. Because of the limited amount of data available with respect to the absorption cross-sections for these radicals, the experiment is focussed on recording spectral lines with known absorption cross-sections. The absolute number densities 
obtained will be compared to numerical results using both the GRI-Mech 2.11 and 3.0 mechanisms [22, 23].

\subsection{Experimental setup}

The general experimental setup is explained in Chapter 2 of this thesis. The ${ }^{1} \mathrm{CH}_{2}$ radicals are probed via the $\tilde{\mathrm{b}}^{1} \mathrm{~B}_{1}(0,13,0) \leftarrow \tilde{\mathrm{a}}^{1} \mathrm{~A}_{1}(0,0,0)$ band at $622 \mathrm{~nm}$. The HCO radicals are probed via the $\tilde{\mathrm{A}}^{2} \mathrm{~A}^{\prime}(0,9,0) \leftarrow \tilde{\mathrm{X}}^{2} \mathrm{~A}^{\prime \prime}(0,0,0)$ transition at $615 \mathrm{~nm}$. The second harmonic of a Nd:YAG laser (Quantel YG781C), operated at a repetition rate of $10 \mathrm{~Hz}$ with a pulse duration of $7 \mathrm{~ns}$, is used to pump a dye laser (Quantel TDL-50) using a mixture of rhodamine 640 and DCM $\left(0.07 \mathrm{~cm}^{-1}\right.$ bandwidth). The wavelength of the laser is calibrated using the frequency-doubled output of the dye laser and recording the CRDS absorption spectrum of the $\mathrm{OH}$ radical. The distance between the cavity mirrors (Laser Optik, radius of curvature $250 \mathrm{~mm}$ ) with a reflectivity $\geq$ 0.998 is $310 \mathrm{~mm}$. The laser beam is spatially filtered by a lens-pinhole-lens system before it is coupled into the cavity. The resulting beam waist in the centre of the cavity was $0.31 \mathrm{~mm}$ FWHM (Rayleigh length $\mathrm{z}_{\mathrm{R}}=0.18 \mathrm{~m}$ ) as measured by both the use of pinholes and imaging of the Rayleigh/Mie scattering.

The burner is placed in the center of the cavity. Two burner systems were employed, a welding torch and a flat flame burner. The welding torch has an orifice of $\varnothing 1.3 \mathrm{~mm}$. The oxyacetylene flame has a flow of $59 \mathrm{~m} / \mathrm{s}$ and an equivalence ratio of $\phi=1.07$ with a mixture of oxygen (99.995\% purity, Hoekloos) and acetylene (98\% purity, Hoekloos). The flat flame is stabilised with a mixture of $\mathrm{CH}_{4}(99.5 \%$ purity, Hoekloos) and air with fuel equivalence ratios of $\phi=1.2$ and 1.1 , and a flow velocity of $u=12 \mathrm{~cm} / \mathrm{s}$. The motivations for the experimental flat flame conditions are given in Chapter 3 . The output is detected with both a gated intensified CCD camera (Princeton Instruments 512-T) and a fast photomultiplier tube that is coupled to a 10-bit, 100-Msamples/s digital oscilloscope (Yokogawa DL4200). In all results presented below, each data point represents an average over 32 laser pulses. The single exponential behaviour of the curves was checked whenever any parameters were changed. The cavity alignment was optimised on-line using the CCD image recorded directly behind the second mirror. The $\mathrm{HCO}$ and $\mathrm{CH}_{2}$ densities were measured at different distances $d$ between burner surface and laser beam. The distance $d$ could be varied by moving the burner in vertical direction with micrometer precision. The temperature is assumed to be constant over the total path above the cylindrically symmetric flat flame burner [24]. In order to reduce the background signal, caused mainly by chemiluminescence, a diaphragm of $15 \mathrm{~mm}$ is placed inside the cavity and both a diaphragm, a low wavelength cut-off filter $(\lambda=590 \mathrm{~nm})$ and a diffuser are mounted in front of the photomultiplier tube. 


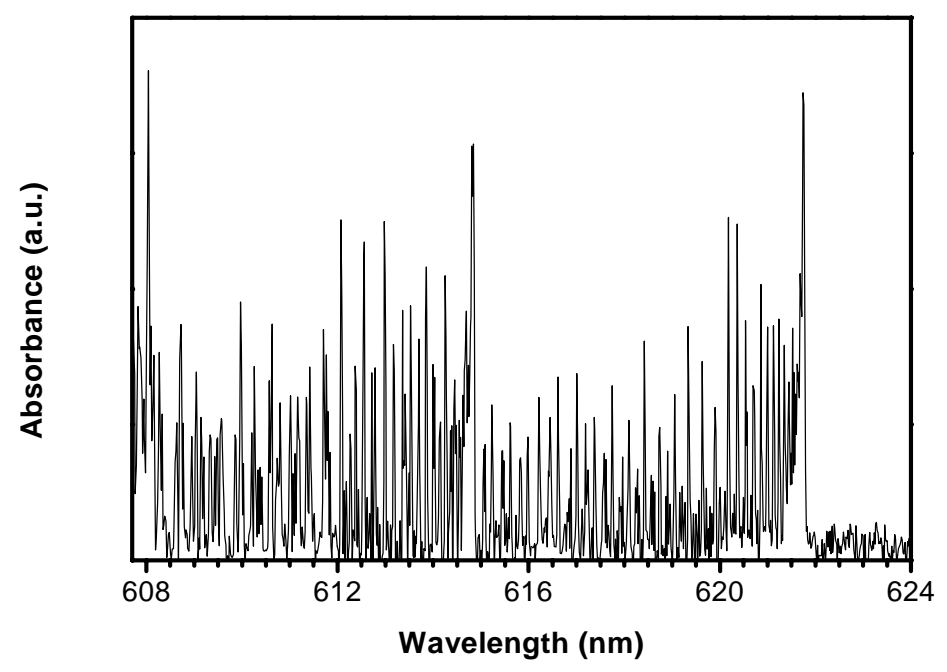

Figure 4.1: Part of the cavity ring-down absorption spectrum in the wavelength region $608 \mathrm{~nm}$ to $624 \mathrm{~nm}$ recorded through the flame front of an atmospheric oxyacetylene welding torch at $7 \mathrm{~mm}$ downstream of the burner exit with $\phi=1.07$ and $u=59 \mathrm{~m} / \mathrm{s}$. All spectral structure is attributable to the $d^{3} \Pi_{g}\left(v^{\prime}=0\right) \leftarrow a^{3} \Pi_{u}\left(v^{\prime \prime}=2\right)$ Swan band system of $C_{2}$.

\subsection{Results}

\subsubsection{Spectral interference}

Expecting $\mathrm{HCO}$ and $\mathrm{CH}_{2}$ to be more abundant in carbon rich flames, initial investigations focussed on the oxyacetylene flame of a welding torch at atmospheric pressure. Figure 4.1 shows the resulting CRDS absorption spectrum in the region from 608 to $624 \mathrm{~nm}$ in a rich oxyacetylene flame. From the figure, it can be seen that in this spectral region the expected occurrence of absorption lines due to formyl radicals is completely obscured by the strong presence of $C_{2}$. All the lines shown in the figure are the result of the $d^{3} \Pi_{g}\left(v^{\prime}=0\right) \leftarrow a^{3} \Pi_{u}$ ( $v^{\prime \prime}=2$ ) Swan bands of $\mathrm{C}_{2}$, occurring in the same spectral region as the $\mathrm{HCO}$ bands of interest. Careful and closer inspection did not reveal the presence of absorption features due to formyl. Presumably due to the low signal-to-noise ratio, $\mathrm{CH}_{2}$ could also not be detected. Therefore, subsequent experiments were performed on the stable methane/air flat flame, which showed no absorption by $\mathrm{C}_{2}$ in this spectral region.

During the initial setting up of the experiments, Fabry-Pérot like fringes appeared in the loss spectrum, as shown in Figure 4.2, supposedly due to interference between the mirror surfaces $[25,26]$. The problem could be largely solved by placing the mirrors off-centre under the appropriate angle [27-29]. 


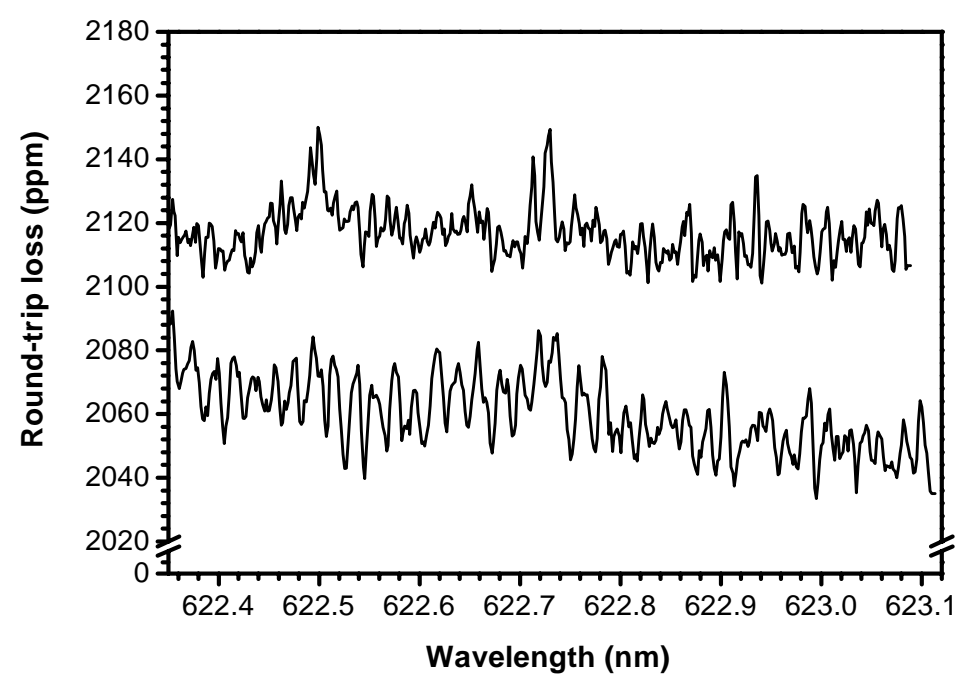

Figure 4.2: Cavity ring-down absorption spectrum in the wavelength region $622.4 \mathrm{~nm}$ to $623.1 \mathrm{~nm}$ in an atmospheric $\mathrm{CH}_{4} /$ air flat flame at $\phi=1.2, u=12 \mathrm{~cm} / \mathrm{s}$ showing interfering spectral features (bottom). Under slightly different alignment conditions (top) part of the $\tilde{b}^{l} B_{I}(0,13,0) \leftarrow \tilde{a}^{I} A_{I}(0,0,0)$ transition of ${ }^{1} \mathrm{CH}_{2}$ can be observed. The top curve has an offset of +40 ppm for clarity.

\subsection{2 ${ }^{1} \mathrm{CH}_{2}$}

Figure 4.3 shows a part of the CRDS spectrum recorded in an atmospheric $\mathrm{CH}_{4} /$ air flat flame at $\phi=1.2, u=12 \mathrm{~cm} / \mathrm{s}$ at $0.8 \mathrm{~mm}$ above the burner surface. In the figure, part of the $\tilde{\mathrm{b}}^{1} \mathrm{~B}_{1}(0,13,0) \leftarrow \tilde{\mathrm{a}}^{1} \mathrm{~A}_{1}(0,0,0)$ band of ${ }^{1} \mathrm{CH}_{2}$ can be seen together with the assignment of a few Q-lines known for this band. The spectrum compares well to reference spectra. Unfortunately, the noise level of the baseline obscures a number of the Q-lines. In the current experiment, the $(0,13,0) 7_{17}\left(\mathrm{~J}_{\mathrm{KaKc}}\right) \leftarrow(0,0,0) 7_{07}$ or ${ }^{\mathrm{r}} \mathrm{Q}_{0,7}$ line at $622.34 \mathrm{~nm}$ is recorded as a function of height above the burner surface. The selection of this line is not only based on its intensity, but also because it is known to be more isolated, as compared to the more intense, blended lines in this wavelength region (e.g. the ${ }^{\mathrm{r}} \mathrm{Q}_{0,3}$ and ${ }^{\mathrm{r}} \mathrm{Q}_{0,5}$ line) and, equally important, because it has a known cross-section.

As stated in Chapter 2, upon ignition of the flame, serious deflection of the probe beam can occur. Fortunately, in the region of the $\mathrm{CH}_{2}$-radical profile, under the current experimental conditions, deflections are less than $75 \mu \mathrm{m}$ over the total absorption path length in the centre of the region of interest, as measured with the CCD-camera and as was shown in Chapter 2. The deflection increases at distances closer to the burner surface up to $0.18 \mathrm{~mm}$ at $\phi=1.2$ for 


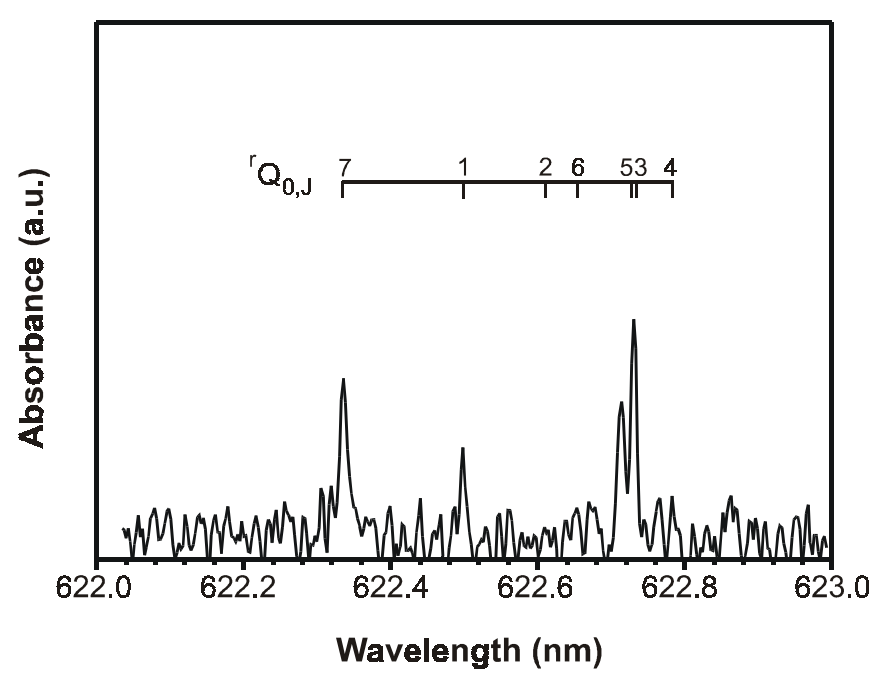

Figure 4.3: Part of the cavity ring-down absorption spectrum in the wavelength region $622 \mathrm{~nm}$ to $623 \mathrm{~nm}$ of the $\tilde{b}^{1} B_{I}(0,13,0) \leftarrow \tilde{a}^{1} A_{I}(0,0,0)$ transition of ${ }^{1} \mathrm{CH}_{2}$ in an atmospheric $\mathrm{CH}_{4}$ /air flat flame at $\phi=1.2, u=12 \mathrm{~cm} / \mathrm{s}$ and $d=0.8 \mathrm{~mm}$ above the burner surface.

the points closest to the burner surface, which is taken into account in the evaluation of the experimental results.

Up to now, little data has been available on the absorption cross-sections of singlet methylene. Its high reactivity and fast collisional quenching to the ground electronic triplet state make it difficult to prepare a known concentration of ${ }^{1} \mathrm{CH}_{2}$ with a known ro-vibrational distribution to evaluate absolute absorption cross-sections. The absorption cross-section for a transition $\mathrm{i} \rightarrow \mathrm{k}$ is calculated from the Einstein B coefficient using [30]

$$
\left(B_{i k}\right)_{v}=\frac{1}{h v_{0}} \int_{0}^{\infty} \sigma_{i k}\left(v-v_{0}\right) \mathrm{d} v
$$

with $B_{i k}$ given in $\mathrm{m}^{2} \mathrm{~J}^{-1} \mathrm{~s}^{-1}, v_{0}$ the center of the line in wavenumbers and $\sigma_{i k}$ the absorption cross-section. For the $(0,13,0) 7_{17} \leftarrow(0,0,0) 7_{07}$ ro-vibrational line, $B_{i k}$ is given as $8.6 \cdot 10^{-8} \mathrm{~m}^{2} \mathrm{~J}^{-1} \mathrm{~s}^{-1}$ with a statistical error $\leq 20 \%$, by ICLAS measurements [9]. This value is the result of a comparison of the experimental data with the absolute emission coefficients for three different rotational lines reported by Garcia-Moreno and Moore [12].

To be able to extract quantitative data from the experimental values, the vibrational and rotational occupation of the energy levels has to be taken into account. The vibrational 


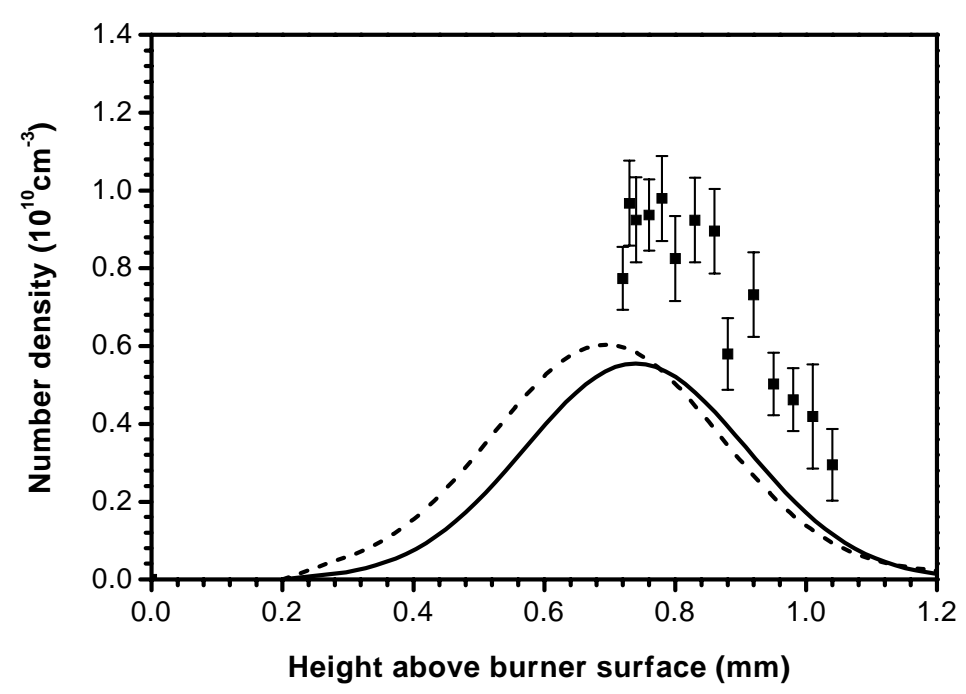

Figure 4.4: Experimental and numerical ${ }^{1} \mathrm{CH}_{2}(0,0,0) \mathrm{J}=7_{07}$ number densities for a burnerstabilised flame at $\phi=1.2, u=12 \mathrm{~cm} / \mathrm{s}$, as a function of height above the burner surface. - measured data, --- numerical curve GRI-Mech 2.11, - numerical curve GRI-Mech 3.0.

partition function can be calculated using the vibration energies given by Comeau et al. [31] with $v_{1}=2787 \mathrm{~cm}^{-1}, v_{2}=1351 \mathrm{~cm}^{-1}$ and $v_{3}=2839 \mathrm{~cm}^{-1}$ and a harmonic oscillator approximation. Assuming a decoupling of the vibrational and rotational wavefunctions, the energy levels can be calculated easily. The transition is a linear-bent transition with an antisymmetric stretch vibration. The ${ }^{1} \mathrm{CH}_{2}$ in the ground state is slightly bent and is an asymmetric prolate rotor with asymmetry parameter $\kappa=-0.36$. However, for calculating the partition function, it can be approximated using the symmetric top formula and including $\mathrm{K}$ doubling for $\mathrm{K} \neq 0$ and $2 \mathrm{~J}+1$ degeneracy. In addition, one has to take the nuclear spin statistics due to the ${ }^{1} \mathrm{H}$ fermions into account, which results in the intensity distribution $\mathrm{K}_{\mathrm{a}}$ even : $\mathrm{K}_{\mathrm{a}}$ odd $=1: 3[32,33]$. The rotational partition function can then be calculated using $\mathrm{A}^{\prime \prime}=20.157 \mathrm{~cm}^{-1}, \mathrm{~B}=11.194 \mathrm{~cm}^{-1}$ and $\mathrm{C}^{\prime \prime}=7.062 \mathrm{~cm}^{-1}[3]$.

To obtain absolute number densities the area below the spectral line was determined. In this way spectral broadening by the temperature and the bandwidth of the laser are also taken into account [34]. The resulting ${ }^{1} \mathrm{CH}_{2}(0,0,0) \mathrm{J}=7_{07}$ number density as a function of height above the burner surface in the $\mathrm{CH}_{4} /$ air flat flame at $u=12 \mathrm{~cm} / \mathrm{s}$ and $\phi=1.2$ and $\phi=1.1$ is shown in Figures 4.4 and 4.5, respectively. The experimental error in the data is the standard deviation resulting from averaging the values of three measurements. The systematic error in the 


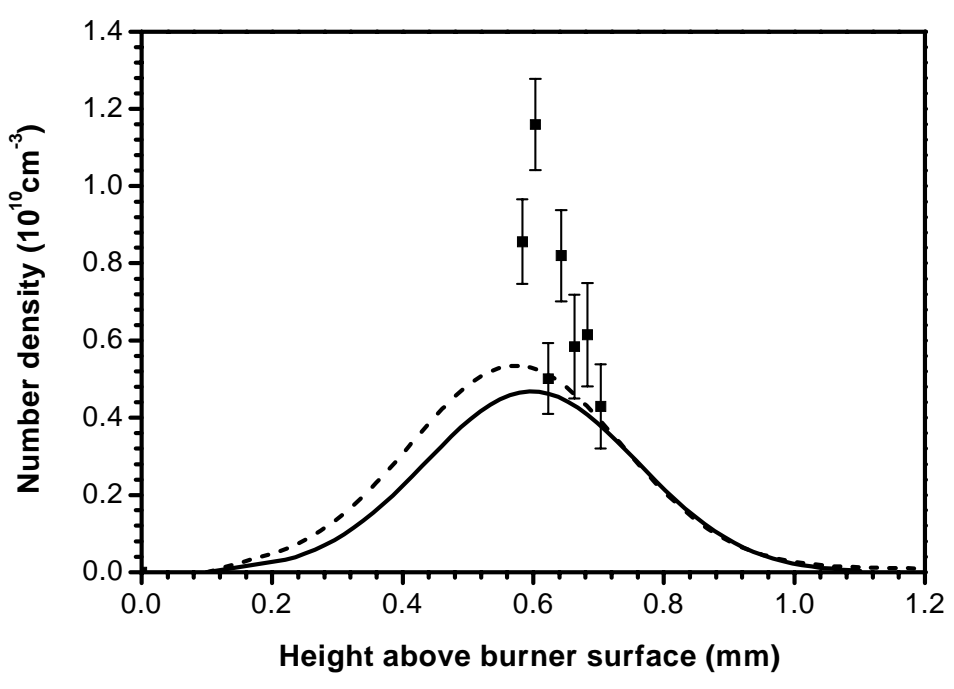

Figure 4.5: Experimental and numerical ${ }^{1} \mathrm{CH}_{2}(0,0,0) \mathrm{J}=7_{07}$ number densities for a burnerstabilised flame at $\phi=1.1, u=12 \mathrm{~cm} / \mathrm{s}$, as a function of height above the burner surface. measured data, --- numerical curve GRI-Mech 2.11, - numerical curve GRI-Mech 3.0.

absorption cross-section is $\leq 30 \%$, based on the error in the ICLAS data and the uncertainty in the emission coefficients $[9,12]$, and is not included in the figures. The measurements showed more experimental noise going from $\phi=1.2$ to $\phi=1$.1. In addition, the flame front is positioned closer to the burner surface. Unfortunately, it was not possible to measure a distinct maximum from the two data series. 


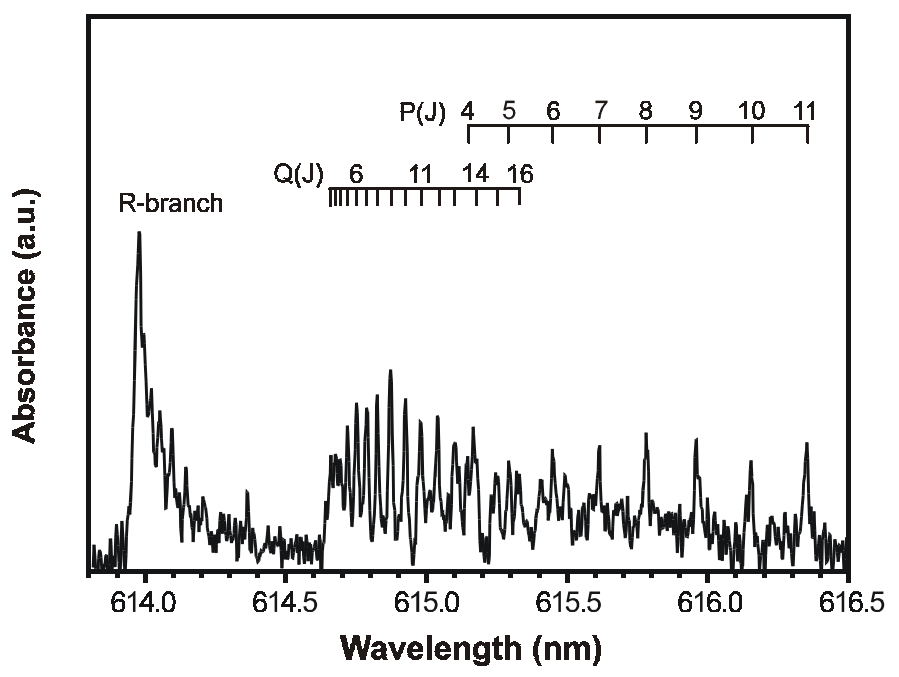

Figure 4.6: Part of the cavity ring-down absorption spectrum of the $\tilde{A}^{2} A^{\prime}(0,9,0)$ $\tilde{X}^{2} A^{\prime \prime}(0,0,0)$ transition of $\mathrm{HCO}$ in a $\mathrm{CH}_{4} /$ air flat flame at $\phi=1.2, u=12 \mathrm{~cm} / \mathrm{s}$ and $d=0.83 \mathrm{~mm}$ above the burner surface in the wavelength region $613.8 \mathrm{~nm}$ to $616.5 \mathrm{~nm}$.

\subsubsection{HCO}

Figure 4.6 shows a part of the CRDS absorption spectrum of $\mathrm{HCO}$ in the wavelength region $614.7 \mathrm{~nm}$ to $616.2 \mathrm{~nm}$ in an atmospheric $\mathrm{CH}_{4} /$ air flat flame at $\phi=1.2, u=12 \mathrm{~cm} / \mathrm{s}$ and $d=0.83 \mathrm{~mm}$ above the burner surface. The figure shows the $\mathrm{R}, \mathrm{Q}$ and $\mathrm{P}$ branches of the $(0,9,0)-(0,0,0) \tilde{\mathrm{A}} \leftarrow \tilde{\mathrm{X}}$ transition. The peaks could be assigned easily from a comparison to other spectral data sources $[17,25]$.

The $\tilde{\mathrm{A}}^{2} \mathrm{~A}^{\prime}(0,9,0) \leftarrow \tilde{\mathrm{X}}^{2} \mathrm{~A} "(0,0,0)$ band system results from a transition from a bent state $\left(\angle \mathrm{HCO}=119.5^{\circ}\right)$ to a linear excited state. The sharp lines are the result of a $\mathrm{K}_{\mathrm{a}}^{\prime}=0 \leftarrow \mathrm{K}_{\mathrm{a}}^{\prime \prime}=1$ transition. Other $\mathrm{K}_{\mathrm{a}}^{\prime}$-states are strongly predissociated and difficult to detect, if detectable at all. The strong predissociation causes a broadening of the lines, with linewidths exceeding the expected Doppler width even at flame temperatures. Although HCO is an asymmetric rotor, with an asymmetry parameter $\kappa$ of -0.992 it behaves as a nearly symmetric prolate top. The energy level structure of this radical can be approximated with the expressions for a prolate symmetric top and $\mathrm{K}$ is a good quantum number, taking into account the $\mathrm{K}$ asymmetry doubling. With the spectroscopic constants $\mathrm{A}^{\prime \prime}=24.294 \mathrm{~cm}^{-1}, \mathrm{~B}=1.494 \mathrm{~cm}^{-1}, \mathrm{C}^{\prime \prime}=1.399 \mathrm{~cm}^{-1}$, $v_{1}=2488 \mathrm{~cm}^{-1}, v_{2}=1080.7 \mathrm{~cm}^{-1}, v_{3}=1861 \mathrm{~cm}^{-1}$ [35], the vibrational and rotational level energies can be calculated. From this, the relative occupation of the levels and their temperature dependence can be calculated to quantify the experimental data. The absorption cross-section for the $\left(0,9^{0}, 0-0,0^{1}, 0\right) \mathrm{P}(9)$ line at $615.95 \mathrm{~nm}$ was calculated from literature 


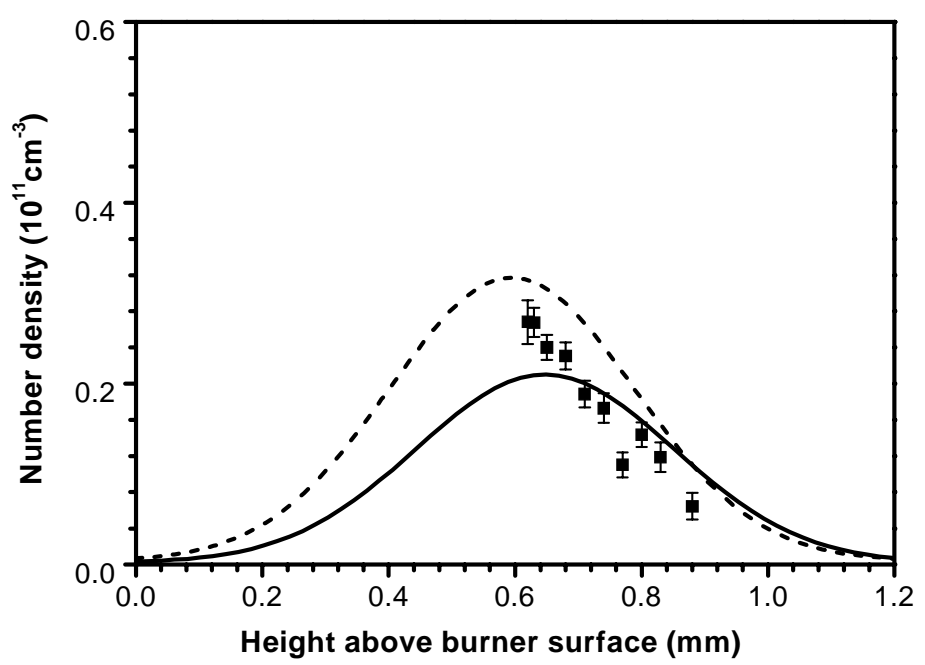

Figure 4.7: Experimental and numerical HCO $\tilde{\mathrm{X}}^{2} \mathrm{~A}^{\prime \prime}\left(0,0^{1}, 0\right) J=9$ number densities for a burner-stabilised flame at $\phi=1.2, u=12 \mathrm{~cm} / \mathrm{s}$, as a function of height above the burner surface. - measured data, --- numerical curve GRI-Mech 2.11, - numerical curve GRI-Mech 3.0.

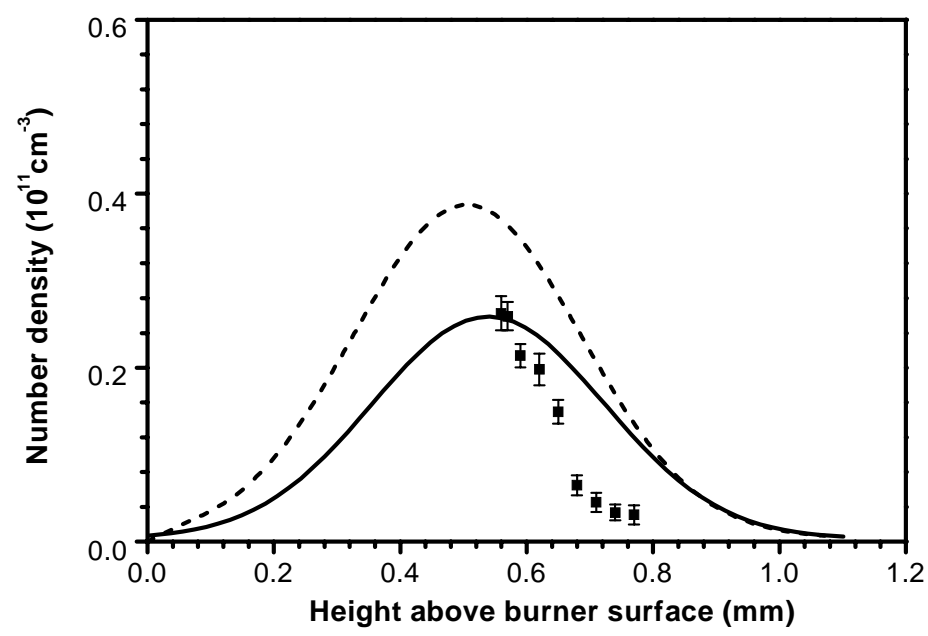

Figure 4.8: Experimental and numerical HCO $\tilde{X}^{2} A^{\prime \prime}\left(0,0^{1}, 0\right) J=9$ number densities for a burner-stabilised flame at $\phi=1.1, u=12 \mathrm{~cm} / \mathrm{s}$, as a function of height above the burner surface. - measured data, --- numerical curve GRI-Mech 2.11, - numerical curve GRI-Mech 3.0. 
values by Lozovsky et al. [11] to be $1 \cdot 1 \cdot 10^{-18} \mathrm{~cm}^{-2}$ at room temperature with an uncertainty of $60 \%$.

The resulting HCO $\tilde{\mathrm{X}}^{2} \mathrm{~A}^{\prime \prime}\left(0,0^{1}, 0\right) \mathrm{J}=9$ number densities for a burner-stabilised flame at $u=12 \mathrm{~cm} / \mathrm{s}, \phi=1.2$ and $\phi=1.1$ above the burner surface are shown in Figures 4.7 and 4.8, respectively, as a function of height above the burner surface. The experimental error in the data is the standard deviation in the average over three spectral scans. The systematic error in the absorption cross-section is given as $60 \%$ [11] and is not included in the figures. The HCO measurements showed less experimental noise than the ${ }^{1} \mathrm{CH}_{2}$ spectra. Unfortunately, also for $\mathrm{HCO}$ it was not possible to record number densities closer to the burner surface to obtain the expected maxima of the profiles.

\subsubsection{Discussion}

The sensitivity limits can be estimated from the experimental spectra and the corresponding absolute number densities. With a $\mathrm{S} / \mathrm{N}_{\mathrm{p}-\mathrm{p}}=1$, this results for ${ }^{1} \mathrm{CH}_{2}(0,0,0) \mathrm{J}=7_{07}$ in a detection limit of $2.4 \cdot 10^{9} \mathrm{~cm}^{-3}$ or $16 \mathrm{ppm}$ total ${ }^{1} \mathrm{CH}_{2}$ assuming a temperature of $1600 \mathrm{~K}$ taken from numerical results. Due to the different formation and consumption mechanisms for triplet and singlet methylene, no definite conclusions can be drawn for triplet ground state densities from the results of the singlet state. However, assuming a thermal equilibrium at $T=1600 \mathrm{~K}$ this would mean a singlet/triplet state ratio of $2 \%$ and a total $\mathrm{CH}_{2}$ concentration of about $820 \mathrm{ppm}$. For HCO the absolute concentration sensitivity is $4.7 \cdot 10^{9} \mathrm{~cm}^{-3} \mathrm{HCO}$ radicals in the $\tilde{\mathrm{X}}^{2} \mathrm{~A} "\left(0,0^{1}, 0\right) \mathrm{J}=9$ state, at $T=1600 \mathrm{~K}$ corresponding to $72 \mathrm{ppm}$ total HCO. The sensitivities reported here for ${ }^{1} \mathrm{CH}_{2}$ and $\mathrm{HCO}$ are a factor of ten lower than those reported for the ICLAS method. However, the current values can still be improved, for example by using mirrors with a higher reflectivity.

In order to compare the numerical simulations directly with the experimental data, the ${ }^{1} \mathrm{CH}_{2}$ and $\mathrm{HCO}$ number density profiles of the appropriate rotational state were derived from the numerically simulated profiles of the total number densities and the temperature [36]. These were calculated for a 1D burner-stabilised flame using GRI-Mech 2.11 and 3.0 [22, 23] and mixture-averaged transport data. As outlined in Chapter 3, the experimental data consist of a convolution of the radical density profile and the spatial laser beam profile. Because the maximum of the experimental profiles could not be obtained, a correct direct comparison can only be made when the numerical simulations are convoluted with the spatial laser beam profile. Fortunately, the laser beam profile and the numerical data could both be fitted well to a Gaussian profile. The data was analytically convoluted and the resulting ${ }^{1} \mathrm{CH}_{2}(0,0,0) \mathrm{J}=7_{07}$ and HCO $\tilde{\mathrm{X}}^{2} \mathrm{~A} "\left(0,0^{1}, 0\right) \mathrm{J}=9$ number densities are also presented in Figures 4.4 and 4.5 , and Figures 4.7 and 4.8, respectively. The figures also show the small differences between the twp versions of the reaction mechanism for both the ${ }^{1} \mathrm{CH}_{2}$ and the $\mathrm{HCO}$ profiles. 
The change in the position of the experimentally determined curves is in qualitative agreement with that of the calculated profiles when going from $\phi=1.2$ to $\phi=1.1$. The experimental number densities of ${ }^{1} \mathrm{CH}_{2}$ appear higher than the numerical values. However, the absolute experimental densities found for both species compare well to the numerically obtained values within the experimental and systematic error ranges. From an estimation of the maximum, the experimental $\mathrm{HCO}$ profiles appear to be positioned a little closer $(0.05 \mathrm{~mm})$ to the burner surface than in the numerical simulations, but this is within the experimental error. A definite conclusion can only be drawn when more information on the position and absolute value of the peak maximum is available.

To study the effect of experimental errors in the settings of the unburned gas velocity, the equivalence ratio, and the gas and burner temperatures, the input parameters have been varied within the experimental errors in a set of numerical calculations. The results on the computed maxima of the $\mathrm{HCO}$ and ${ }^{1} \mathrm{CH}_{2}$ densities, the positions and the temperature at these positions are shown in Table 4.1. The effects are nearly linear in this small regime and a change of sign would result in similar differences with opposite sign. From the table, it can be concluded that experimental errors in the settings lead to very small deviations.

An evaluation of the ${ }^{1} \mathrm{CH}_{2}$ and $\mathrm{HCO}$ radicals in a low-pressure experimental setup will provide more complete number density profiles, as is also shown in literature $[9,10,13,21]$ and as will be presented in Chapter 6 .

Table 4.1: Influence of experimental errors in the settings on the calculated ${ }^{1} \mathrm{CH}_{2}$ and $\mathrm{HCO}$ maximum number densities, their position $\delta$ and the temperatures at this position, based on GRI Mech 2.11.

\begin{tabular}{ll|ccc|ccc}
\hline Parameter & Change & $\begin{array}{c}\Delta \delta^{1} \mathrm{CH}_{2} \\
(\mathrm{~mm})\end{array}$ & $\begin{array}{c}\Delta\left[{ }^{1} \mathrm{CH}_{2}\right] \\
(\%)\end{array}$ & $\begin{array}{c}\Delta T^{1} \mathrm{CH}_{2} \\
(\mathrm{~K})\end{array}$ & $\begin{array}{c}\Delta \delta_{\mathrm{HCO}} \\
(\mathrm{mm})\end{array}$ & $\begin{array}{c}\Delta[\mathrm{HCO}] \\
(\%)\end{array}$ & $\begin{array}{c}\Delta T_{\mathrm{HCO}} \\
(\mathrm{K})\end{array}$ \\
\hline \hline$u$ & $+4 \%$ & -0.014 & +5.5 & +4 & -0.013 & +5.1 & +4 \\
$\phi$ & $+2 \%$ & +0.019 & +2.3 & +14 & +0.015 & -3.7 & +11 \\
$T_{\text {gas }}$ & $+2 \mathrm{~K}$ & +0.002 & -0.9 & -0.7 & +0.002 & -0.8 & -0.6 \\
$T_{\text {burner }}$ & $+10 \mathrm{~K}$ & -0.004 & -0.1 & $<0.1$ & -0.004 & -0.1 & $<0.1$ \\
\hline
\end{tabular}




\subsection{Conclusions}

Cavity ring-down spectroscopy was applied to an atmospheric premixed $\mathrm{CH}_{4} /$ air flat flame. The experiments show that the application of CRDS to the detection of ${ }^{1} \mathrm{CH}_{2}$ and $\mathrm{HCO}$ at atmospheric pressures is feasible. The ${ }^{1} \mathrm{CH}_{2}$ radicals were probed via the $\tilde{\mathrm{b}}^{1} \mathrm{~B}_{1}(0,13,0)$ $\leftarrow \tilde{\mathrm{a}}^{1} \mathrm{~A}_{1}(0,0,0)$ band and the $\mathrm{HCO}$ radicals via the $\tilde{\mathrm{A}}^{2} \mathrm{~A}^{\prime}(0,9,0) \leftarrow \tilde{\mathrm{X}}^{2} \mathrm{~A}^{\prime \prime}(0,0,0)$ transition as a function of height above the burner surface in a burner-stabilised flat flame. Absolute number densities could be obtained for both species. The positions of the maxima of the profiles could not be determined, as these were located too close to the burner surface. From a comparison with numerical simulations, these results appear to qualitatively and quantitatively support the calculations. The absolute experimental values are in agreement with numerically simulated results. The positions of the ${ }^{1} \mathrm{CH}_{2}$ and $\mathrm{HCO}$ number density profiles follow the predicted trend and move closer to the burner surface when going from $\phi=1.2$ to $\phi=1.1$. In addition, the experimental data support the conclusion of Chapter 3 that the position of the whole flame structure is not shifted in relation to the numerical values. Sensitivity limits were $16 \mathrm{ppm}$ for total ${ }^{1} \mathrm{CH}_{2}$ and $72 \mathrm{ppm}$ for total $\mathrm{HCO}$, assuming a temperature of $T=1600 \mathrm{~K}\left(\mathrm{~S} / \mathrm{N}_{\mathrm{p}-\mathrm{p}}=1\right)$. 


\section{References}

1. Warnatz, J., Maas, U., Dibble, R.W.: Combustion, Springer Verlag, Berlin, 1996.

2. Herzberg, G., Johns, J.W.C., The spectrum and structure of singlet $\mathrm{CH}_{2}$. Proc. Roy. Soc. A 295:107128 (1966).

3. Petek, H., Nesbitt, D.J., Moore, C.B., Birss, F.W., Ramsay, D.A., Visible absorption and magneticrotation spectroscopy of ${ }^{1} \mathrm{CH}_{2}$ : the analysis of the ${ }^{1} A_{1}$ state and the ${ }^{1} A_{1}-{ }^{3} B_{1}$ coupling. J. Chem. Phys. 86:1189-1205 (1987).

4. Glassman, I.: Combustion, Academic Press, San Diego, CA, 1996.

5. Green Jr., W.H., Chen, I-C., Bitto, H., Guyer, D.R., Moore, C.B., New vibrational bands of $\mathrm{CH}_{2}\left(b^{1} B_{1}\right)$. J. Molec. Spec. 138:614-629 (1989).

6. Petek, H., Nesbitt, D.J., Darwin, D.C., Moore, C.B., Visible absorption and magnetic-rotation spectroscopy of ${ }^{1} \mathrm{CH}_{2}$ : the analysis of the $b^{1} B_{1}$ state. J. Chem. Phys. 86:1172-1188 (1987).

7. Sappey, A.D., Crosley, D.R., Copeland, R.A., Laser-induced fluorescence detection of singlet $\mathrm{CH}_{2}$ in low-pressure methane/oxygen flames. Appl. Phys. B 50:463-472 (1990).

8. Cheskis, S., Derzy, I., Lozovsky, V.A., Kachanov, A., Stoeckel, F., Intracavity laser absorption spectroscopy detection of singlet $\mathrm{CH}_{2}$ radicals in hydrocarbon flames. Chem. Phys. Lett. 277:423-429 (1997).

9. Derzy, I., Lokovsky, V.A., Cheskis, S., Absorption cross-sections and absolute concentration of singlet methylene in methane/air flames. Chem. Phys. Lett. 313:121-128 (1999).

10. Lozovsky, V.A., Cheskis, S., Kachanov, A., Stoeckel, F., Absolute HCO concentration measurements in methane/air flame using intracavity laser spectroscopy. J. Chem. Phys. 106:8384-8391 (1997).

11. Lozovsky, V.A., Derzy, I., Cheskis, S., Radical concentration profiles in a low-pressure methane-air flame measured by intracavity laser absorption and cavity ring-down spectroscopy. Proc. Combust. Inst. 27:445-452 (1998).

12. Garcia-Moreno, I., Moore, C.B., Spectroscopy of methylene: Einstein coefficients for $C_{2}\left(b^{1} B_{1}-a^{1} A_{1}\right)$. J. Chem. Phys. 99:6429-6435 (1993).

13. McIlroy, A., Laser studies of small radicals in rich methane flames: $\mathrm{OH}, \mathrm{HCO}$, and ${ }^{1} \mathrm{CH}_{2}$. Israel $\mathrm{J}$. Chem. 39:55-62 (1999).

14. McIlroy, A., Direct measurement of ${ }^{1} \mathrm{CH}_{2}$ in flames by cavity ringdown laser absorption spectroscopy. Chem. Phys. Lett. 296:151-158 (1998).

15. Najm, H.N., Paul, P.H., Mueller, C.J., Wyckoff, P.S., On the adequacy of certain experimental observables as measurements of flame burning rate. Combust. Flame 113:312-332 (1998).

16. Paul, P.H., Najm, H.N., Planar laser-induced fluorescence imaging of flame heat release rate. Proc. Combust. Inst. 27:43-50 (1998).

17. Herzberg, G., Ramsay, D.A., The 7500 to $4500 \AA$ A absorption system of the free HCO radical. Proc. R. Soc. Lon. ser-A 233:34-54 (1955).

18. Jeffries, J.B., Crosley, D.R., Wysong, I.J., Smith, G.P., Proc. Combust. Inst. 23:1847-1854 (1990).

19. Diau, E.W.-G, Smith, G.P., Jeffries, J.B., Crosley, D.R., HCO concentration in flames via quantitative laser-induced fluorescence. Proc. Combust. Inst. 27:453-460 (1998).

20. Cheskis, S., Intracavity laser absorption spectroscopy detection of HCO radicals in atmospheric pressure hydrocarbon flames. J. Chem. Phys. 102:1851-1854 (1995).

21. Scherer, J.J., Rakestraw, D.J., Cavity ringdown laser absorption spectroscopy detection of formyl (HCO) radical in a low pressure flame. Chem. Phys. Lett. 265:169-176 (1997). 
22. Bowman, C.T., Hanson, R.K., Davidson, D.F., Gardiner, W.C., Lissianski, V., Smith, G.P., Golden, D.M., Frenklach, H., GRI-Mech 2.11. http://www.me.berbeley.edu/gri_mech/(1995).

23. Smith, G.P., Golden, D.M., Frenklach, M., Moriarty, N.W., Eiteneer, B., Goldenberg, M., Bowman, C.T., Hanson, R.K., Soonho Song, Gardiner Jr., W.C., Lissianski, V.V., Qin, Z., GRI-Mech 3.0. http://www.me.berkeley.edu/gri_mech/ (2000).

24. Bosschaart, K.J., Versluis, M., Knikker, R., Van der Meer, Th. H., Schreel, K.R.A.M., De Goey, L.P.H., Van Steenhoven, A.A., The heat flux method for producing burner stabilized adiabatic flames: an evaluation with CARS thermometry. Combust. Sci. Techn. 168:1-19 (2001).

25. Romanini, D., Lehmann, K.K., Ring-down cavity absorption spectroscopy of the very weak HCN overtone bands with six, seven, and eight stretching quanta. J. Chem. Phys. 99:6287-6301 (1993).

26. Tian, C., Goldstein, S., Fry, E.S., On the etalon effect generated by a Pockels cell with high-quality antireflection coatings. Appl. Opt. 39:1600-1601 (2000).

27. Siegman, A.E.: Lasers, University Science Books, Sausalito, 1986.

28. Remo, J.L., Diffraction losses for symmetrically tilted plane reflectors in open resonators. Appl. Opt. 19:774-777 (1980).

29. Hauck, R., Kortz, H.P., Weber, H., Misalignment sensitivity of optical resonators. Appl. Opt. 19:598601 (1980).

30. Steinfeld, J.I.: Molecules and radiation, Harper and Row, New York, 1974.

31. Comeau, D.C., Shavitt, I., Jensen, P., Bunker, P.R., An ab initio determination of the potential-energy surfaces and rotation-vibration energy levels of methylene in the lowest triplet and singlet states and the singlet-triplet splitting. J. Chem. Phys. 90:6491-6500 (1989).

32. Herzberg, G.: The spectra and structues of simple free radicals, Dover Publications, New York, 1971.

33. Hollas, J.M.: High resolution spectroscopy, Butterworths, London, 1982.

34. Zalicki, P., Zare, R.N., Cavity ring-down spectroscopy for quantitative absorption measurements. J. Chem. Phys. 102:2708-2717 (1995).

35. Serrano-Anders, L., Forsberg, N., Malmqvist, P.-A., Vibronic structure in triatomic molecules: the hydrocarbon flame bands of the formyl radical (HCO). A theoretical study. J. Chem. Phys. 108:72027216 (1998).

36. Somers, L.M.T., The simulation of flat flames with detailed and reduced chemical models, Ph.D. thesis, Eindhoven University of Technology, Eindhoven, the Netherlands, http://www.tue.nl/bib/, 1994. 


\title{
CAVITY RING-DOWN SPECTROSCOPY OF NO AND NO $\mathrm{NOR}_{2}$ POLLUTION ANALYSIS ${ }^{1}$
}

\begin{abstract}
The spectroscopic detection of $\mathrm{NO}$ and $\mathrm{NO}_{2}$ has been investigated in the visible and UV spectral ranges by cavity ring-down spectroscopy (CRDS) for pollution analysis purposes. Firstly, flow samples of $\mathrm{NO}_{2}$ in dry air at atmospheric pressure in the concentration range between $0.1 \mathrm{ppm}$ and $15 \mathrm{ppm}$ have been studied. The absorption cross-section of $\mathrm{NO}_{2}$ between $437 \mathrm{~nm}$ and $450 \mathrm{~nm}$ has been determined and compared to literature. The detection limit of the CRDS system was estimated to be $50 \mathrm{ppb}$. As an example, CRDS has been applied to the burned gas region of an oxyacetylene flame showing the dependence on entrained air for the formation of $\mathrm{NO}_{2}$. In the remainder of the chapter, the application of the technique has been demonstrated for the in situ, quantitative determination of $\mathrm{NO}$ and $\mathrm{NO}_{2}$ in the exhaust gas of a diesel engine. NO absorption has been monitored at the transition from the $\mathrm{X}^{2} \Pi$ ground state to the $\mathrm{A}^{2} \Sigma^{+}$ state at $226 \mathrm{~nm}$. For $\mathrm{NO}_{2}$, the absorption bands in the spectral region from $438 \mathrm{~nm}$ to $450 \mathrm{~nm}$ were used. At the selected engine conditions, concentrations of $212 \pm 22 \mathrm{ppm} \mathrm{NO}$ and $29 \pm 4$ ppm $\mathrm{NO}_{2}$ have been measured, in reasonable agreement with separate chemical exhaust gas analysis. Sensitivities down to $500 \mathrm{ppb}$ for $\mathrm{NO}$ and $30 \mathrm{ppb}$ for $\mathrm{NO}_{2}$ should easily be feasible, under the current experimental conditions.
\end{abstract}

\footnotetext{
${ }^{1}$ Adapted from: Evertsen, R., Staicu, A., Dam, N., Van Vliet, A., Ter Meulen, J.J.; Pulsed cavity ring-down spectroscopy of $\mathrm{NO}$ and $\mathrm{NO}_{2}$ in the exhaust of a running diesel engine, Appl. Phys. B 74: 465-468, 2002.
} 


\subsection{Introduction}

$\mathrm{NO}_{2}$ is a well-known pollutant of the atmosphere, being responsible for acid rain and playing an important role in the destruction of ozone [1]. Its absorption spectrum ranges from the near-UV to the near-IR. Many spectroscopic studies on the spectrum of $\mathrm{NO}_{2}$ focus on the blue visible range, where the molecule can be detected easily in the atmosphere, virtually without interference from other compounds. For that reason, this spectral range is used in on-line atmospheric pollution control systems based on spectroscopic methods such as differential absorption [2] and light detection and ranging (LIDAR) [3].

From a spectroscopic point of view $\mathrm{NO}_{2}$ is an interesting molecule because of the interactions between many close-lying ro-vibrational levels resulting in a heavily congested spectrum. The $\mathrm{NO}_{2}$ spectrum in the blue visible range is the result of transitions between the electronic ground state to the first and second electronically excited states, $\tilde{\mathrm{A}}^{2} \mathrm{~B}_{2} \leftarrow \tilde{\mathrm{X}}^{2} \mathrm{~A}_{1}$ and $\widetilde{\mathrm{B}}^{2} \mathrm{~B}_{1} \leftarrow \tilde{\mathrm{X}}^{2} \mathrm{~A}_{1}$, respectively. The ro-vibrational bands of these transitions overlap, resulting in a complex absorption spectrum [4]. The radiative lifetime of the excited state is in the range of microseconds [5], and due to efficient inelastic collision processes fluorescence from excited electronic states is easily quenched at atmospheric pressures [6]. Due to fast vibrational energy transfer, $\mathrm{NO}_{2}$ shows only a broad fluorescence spectrum without structure, even at subatmospheric pressures. Collisional quenching limits the practical application of LIF of $\mathrm{NO}_{2}$ to low pressures. As a consequence, the quantitative determination of $\mathrm{NO}_{2}$ densities by LIF in complex environments, like combustion processes at atmospheric pressure, does not seem feasible [7]. Nevertheless, $\mathrm{NO}_{2}$ has been reported as a tracer for LIF based flame propagation visualization at concentrations of $700 \mathrm{ppm}$ in a constant-volume combustion experiment [8].

Although several sensitive indirect detection techniques for $\mathrm{NO}_{2}$ exist ([9] for references), a direct analysis with a sensitive absorption technique is preferred to circumvent the problems mentioned above. Cavity ring-down spectroscopy (CRDS) is such a technique, and in this chapter it will be assessed for its potential for $\mathrm{NO}_{2}$-detection in practical devices in complex environments. CRDS measurements of $\mathrm{NO}_{2}$ at a concentration of $16 \mathrm{ppb}$ in ambient air have been demonstrated in the $425-\mathrm{nm}$ to $460-\mathrm{nm}$ wavelength range at a resolution of $0.018 \mathrm{~nm}$ [10]. In the same reference, CRDS spectra of $\mathrm{NO}_{2}$ are given, produced in a purified air mixture passing through a reactor flow cell with an electrical discharge, resulting in concentrations estimated to be in the low ppb range. Romanini et al. have shown the application of $\mathrm{cw}$ diode lasers in CRDS by recording high-resolution spectra around $785 \mathrm{~nm}$ and $796 \mathrm{~nm}$ of $\mathrm{NO}_{2}$ cooled in a supersonic jet [11-13]. More recently, a paper was published on the catalytic degradation and diffusion processes of $\mathrm{NO}_{2}$ monitored at $612.9 \mathrm{~nm}$ by CRDS $[14,15]$.

For accurate monitoring of $\mathrm{NO}_{2}$ in different environments, the influence of temperature on the absorption cross-section was investigated by several groups [16-19]. An overview of $\mathrm{NO}_{2}$ studies up to 1997 has been given by Kirmse et al. [18]. It was concluded that the spectral 
absorption features of $\mathrm{NO}_{2}$ exhibit a decreasing structure with increasing temperature, while the bell-shaped envelope of the overall spectrum slightly broadens.

An overview of the complex chemical formation and destruction pathways of $\mathrm{NO}$ and $\mathrm{NO}_{2}$, collectively called $\mathrm{NO}_{\mathrm{x}}$, in atmospheric and combustion processes, is beyond the scope of this chapter. In short, in combustion processes, four different routes have been identified to be primarily responsible for the formation of $\mathrm{NO}$ and $\mathrm{NO}_{2}$ : thermal $\mathrm{NO}$ (Zeldovich $\mathrm{NO}$ ), prompt NO (Fenimore NO), NO generated via nitrous oxide, and the conversion of fuel nitrogen into NO [20]. When fuel nitrogen is absent and depending on temperature, pressure and flame stoichiometry, thermal and prompt NO formation are normally the most important, but not yet fully quantitatively understood pathways. In combustion science a lot of effort is put into the correct prediction of $\mathrm{NO}_{\mathrm{x}}$ formation. Also considerable effort has been directed to the reduction of $\mathrm{NO}_{\mathrm{x}}$ with primary and secondary methods [20, 21]. Nitric oxide can be detected relatively easily by fluorescence based techniques, e.g. through excitation out of the $\mathrm{X}^{2} \Pi$ electronic ground state to the $\mathrm{D}^{2} \Sigma^{+}$state at $193 \mathrm{~nm}$ or to the $\mathrm{A}^{2} \Sigma^{+}$state around $226 \mathrm{~nm}$. In contrast to $\mathrm{NO}_{2}$, the LIF signal of $\mathrm{NO}$ is not so heavily quenched by collisions. Using LIF, NO can be identified even at very high pressures and under harsh conditions like in the combustion chamber of a diesel engine [22, 23]. Still it is interesting to study the feasibility of CRDS detection of NO. Particularly the prospect to detect NO at half the wavelength used to measure $\mathrm{NO}_{2}$ may supply a method to measure both species simultaneously with the same laser. CRDS combined with LIF for NO detection has been applied to a low-pressure methane/air flame seeded with NO to obtain NO number densities in the non-seeded flame [24].

In this study, CRD detection of $\mathrm{NO}_{2}$ was conducted in the $438 \mathrm{~nm}$ to $450 \mathrm{~nm}$ region and detection of $\mathrm{NO}$ in the $\mathrm{A}^{2} \Sigma^{+}\left(\mathrm{v}^{\prime}=0\right) \leftarrow \mathrm{X}^{2} \Pi$ ( $\left.\mathrm{v}^{\prime \prime}=0\right)$ band at nearly half this wavelength $(226 \mathrm{~nm})$. The feasibility of CRDS for easy trace gas analysis and a better understanding of $\mathrm{NO}_{\mathrm{x}}$ formation in combustion processes is demonstrated by its application to an oxyacetylene flame and to the exhaust gases of a diesel engine.

\subsection{Experimental}

The basic CRDS setup was similar to the setup described in Chapter 2. In the experiments described in this chapter, a tunable dye laser (Lambda Physik Scanmate 2E, dye coumarine 47, bandwidth $0.18 \mathrm{~cm}^{-1}$ ), pumped by the third harmonic of a Nd:YAG laser (Continuum Powerlite 9010) was used to generate radiation in the blue spectral range. For the measurements, three different sets of mirrors were used with $R=250 \mathrm{~mm}$ and reflectivities $R_{\text {eff }}$ of $99.77 \%$ (Laser Optik) and $99.98 \%$ (REO) at $440 \mathrm{~nm}$, respectively, and with $R_{\text {eff }}=99.3 \%$ at $226 \mathrm{~nm}$ (Laser Optik) for detection of NO. The mirrors with lower reflectivity were used for samples with higher $\mathrm{NO}_{2}$ concentrations to avoid saturation effects. 


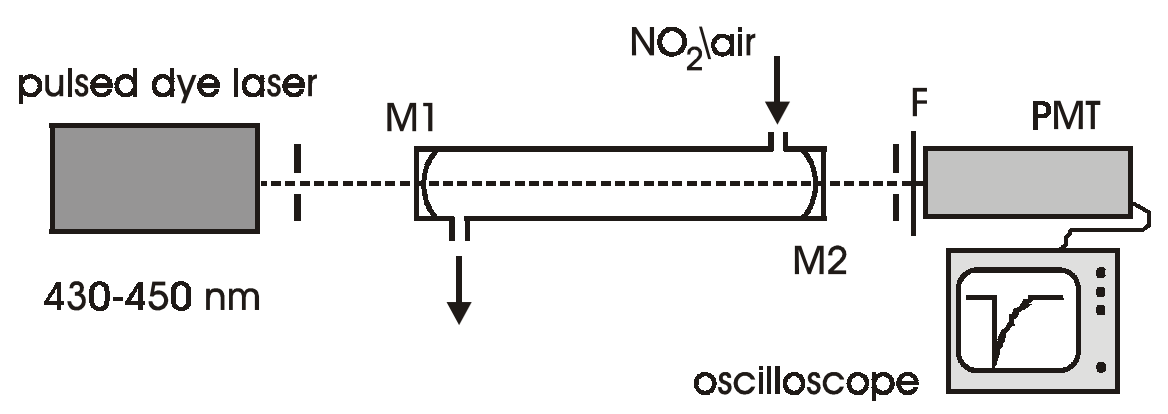

Figure 5.1: Scheme of the experimental CRDS setup for the measurement of $\mathrm{NO}_{2} . \mathrm{M1}, \mathrm{M} 2$ cavity mirrors; $F$ filter.

\subsubsection{Cell}

The $\mathrm{NO}_{2}$ gas was mixed and diluted with pressurized dry air in glass bottles shielded from daylight. The pressure was measured with a capacitance gauge (Balzers ACR 262) for $\mathrm{NO}_{2}$ (accuracy of $\pm 10 \mathrm{~Pa}$ ) and with an analog manometer for air (accuracy of $3.3 \cdot 10^{2} \mathrm{~Pa}$ ). During the recording of the spectra, the gas mixtures were flowed at atmospheric pressure through a glass cell, the adjustable end windows of which also formed the mirrors of the cavity $(l=d=400 \mathrm{~mm})$, as shown schematically in Figure 5.1. The glass cell could be heated uniformly by using a heating wire. Spectra taken at elevated temperatures were acquired from static gas mixtures. The CRDS $\mathrm{NO}_{2}$ spectrum from these mixtures was recorded in the region from $430 \mathrm{~nm}$ to $450 \mathrm{~nm}$.

$\mathrm{NO}_{2}$ forms an equilibrium with its dimer $\mathrm{N}_{2} \mathrm{O}_{4}$, as described by the reaction

$$
2 \mathrm{NO}_{2} \Leftrightarrow \mathrm{N}_{2} \mathrm{O}_{4}
$$

$\mathrm{N}_{2} \mathrm{O}_{4}$ only shows significant absorption cross-sections at wavelengths below $400 \mathrm{~nm}$ [16] and formation of $\mathrm{N}_{2} \mathrm{O}_{4}$ is therefore insignificant for absorption losses in the wavelength range under investigation for $\mathrm{NO}_{2}$. The equilibrium constant $K_{p}$ for reaction (5.1) is $1.39 \cdot 10^{4} \mathrm{~Pa}$ at $298 \mathrm{~K}$ [17] and is given by the expression:

$$
K_{p}=\frac{\left(P_{\mathrm{NO}_{2}}\right)^{2}}{P_{\mathrm{N}_{2} \mathrm{O}_{4}}}
$$

Assuming a final sample of $1 \mathrm{ppm} \mathrm{NO}_{2}$ in air at room temperature, this corresponds to a concentration of 7 ppt $\mathrm{N}_{2} \mathrm{O}_{4}$, which is negligible. At higher temperature, the equilibrium will shift even more towards $\mathrm{NO}_{2}$. 


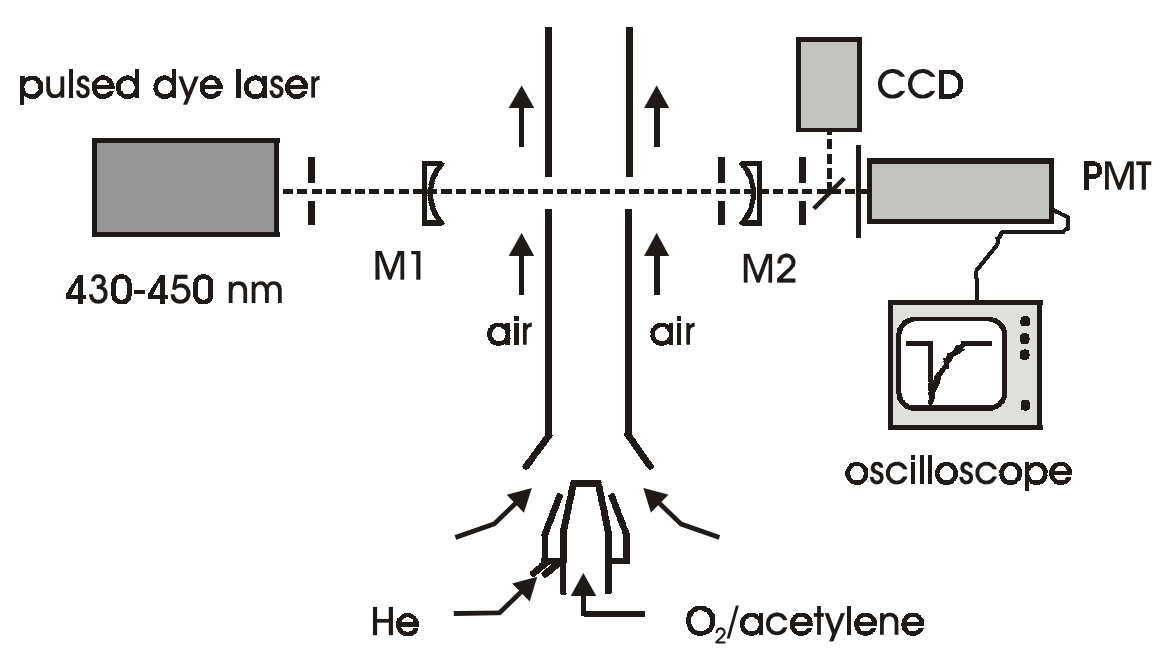

Figure 5.2: Scheme for the CRDS $\mathrm{NO}_{2}$ detection in the flue gases of a welding torch. M1, M2 cavity mirrors.

\subsubsection{Welding torch}

A mixture of acetylene (PraxAir) and oxygen (Air Liquide) was used as fuel for a welding torch with an orifice diameter of $1.0 \mathrm{~mm}$. The burner tip was placed in a cooled housing which also enabled the supply of a coflow. The combustion gases were led through an exhaust tube, $l=95 \mathrm{~cm}, 100 \mathrm{~mm}$ i.d., placed at $15 \mathrm{~cm}$ above the burner exit to avoid diffusion of the combustion gases to the surrounding air. Two 10-mm diameter holes, opposite to each other, were drilled in the tube at about $80 \mathrm{~cm}$ above the burner. The setup is shown schematically in Figure 5.2. A CRD cavity of $400 \mathrm{~mm}$ was built around the pipe to probe the combustion products. Two diaphragms were placed inside and outside the cavity to reduce straylight impinging on the detector. A CCD camera was used to monitor the alignment of the cavity. Two small continuous flows of air parallel to the tube prevented the presence of flue gases in the absorption path length outside the tube. The flue gas temperature was monitored by a thermocouple inside the tube at the location of the cavity.

\subsubsection{Diesel engine}

The modifications to the basic CRD setup are shown schematically in Figure 5.3. The mirrors, at a distance of $l=450 \mathrm{~mm}$, were connected to glass rods and continuously flushed with a small flow of nitrogen. The same tunable dye laser was used to generate radiation in the blue (for $\mathrm{NO}_{2}$ ) and, after frequency doubling, in the UV spectral range (for $\mathrm{NO}$ ). The beam is narrowed by a pinhole $(1.0 \mathrm{~mm})$ before it is coupled into the cavity. The light transmitted through the cavity was detected by a fast photomultiplier tube (Thorn-EMI 9814QB) placed behind the end mirror mounted with a diaphragm $(\varnothing=10 \mathrm{~mm})$ and a bandpass filter $(460 \pm$ 


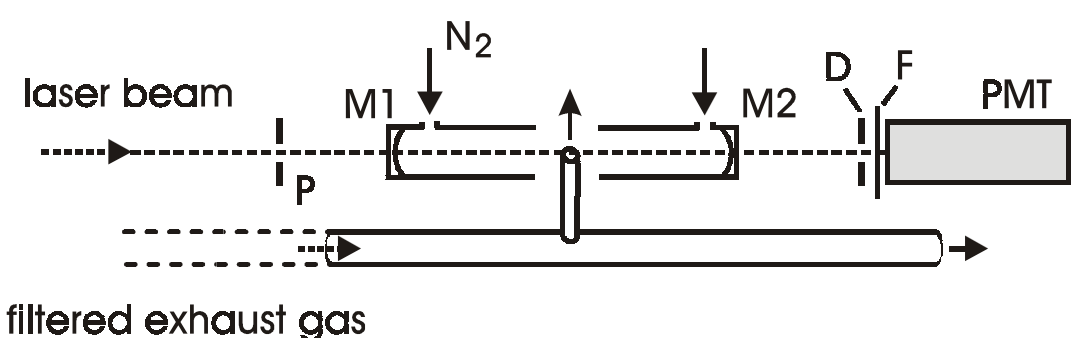

filtered exhaust gas

Figure 5.3: Scheme of the experimental setup for the application of CRDS to the exhaust of a diesel engine. M1, M2 cavity mirrors; $P$ pinhole; $F$ filter; $D$ diaphragm.

$80 \mathrm{~nm}$ ) to reduce background signals. In case of NO detection at $226 \mathrm{~nm}$, the PMT was placed at 90 degrees to the cavity and light was detected via a $225 \pm 10 \mathrm{~nm}$ mirror at 45 degrees to decrease background interference. The signals were recorded on an 8-bits, 300-MHz, 2.5Gsamples/s digital oscilloscope (LeCroy 9361) and averaged over 30 traces.

The exhaust gases of a test engine, a DAF six-cylinder, 11.6 litres, direct injection WS diesel engine running on commercial diesel fuel with an early injection of $15^{\circ}$ (instead of $12^{\circ}$ ) before top dead centre (bTDC) were studied. During operation of the engine, the exhaust gases of three cylinders were led through a fiberglass soot particle filter (Unikat E, filtering $>95 \%$ of $\geq 0.4 \mu \mathrm{m}$ particles). In order to prevent saturation effects, part of the flow in the exhaust pipe (100 mm i.d.) was diverted through a small sampling tube (12.0 mm i.d.) positioned inside the exhaust pipe, probing the middle of the gas stream (path length $95 \mathrm{~mm}$ to tube exit), as shown in Figure 5.3. The distance between the laser beam and the exit of the sampling tube was varied between $2.0 \mathrm{~mm}$ and $6.2 \mathrm{~mm}$, but this did not affect the results. Assuming a turbulent output flow, the difference in width at $0 \mathrm{~mm}$ and $6.2 \mathrm{~mm}$ were calculated to be less than the experimental error. Therefore, the absorption path length was assumed to be constant and equal to the exit diameter of the tube. The temperature and density distributions were assumed constant over the complete absorption path length above the tube exit.

\subsection{Results and Discussion}

\subsubsection{Cell}

The absorption spectrum of $14 \mathrm{ppm} \mathrm{NO}_{2}$ in dry air at atmospheric pressure measured by CRDS in a glass cell is given in Figure 5.4 for the spectral range between $438 \mathrm{~nm}$ and $450 \mathrm{~nm}$ at a resolution of $0.05 \mathrm{~nm}$. It clearly shows three conspicuous absorption features, but also the fine structure superimposed on them is reproducible. In Figure 5.5 the absorption coefficient is given as measured for four different sample concentrations of $\mathrm{NO}_{2}$, varying between 


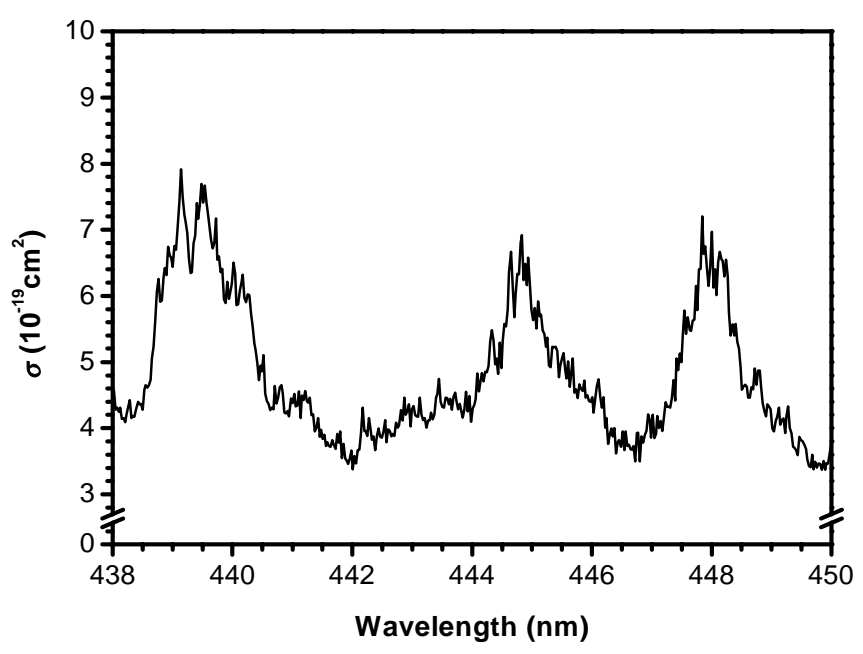

Figure 5.4: The absorption cross-section of $\mathrm{NO}_{2}$ for the wavelength range of $438 \mathrm{~nm}$ to $450 \mathrm{~nm}$ measured by CRDS on a 14 ppm $\mathrm{NO}_{2}$ mixture in air with a total pressure of $1 \cdot 10^{5} \mathrm{~Pa}$ and a resolution of $0.05 \mathrm{~nm}$.

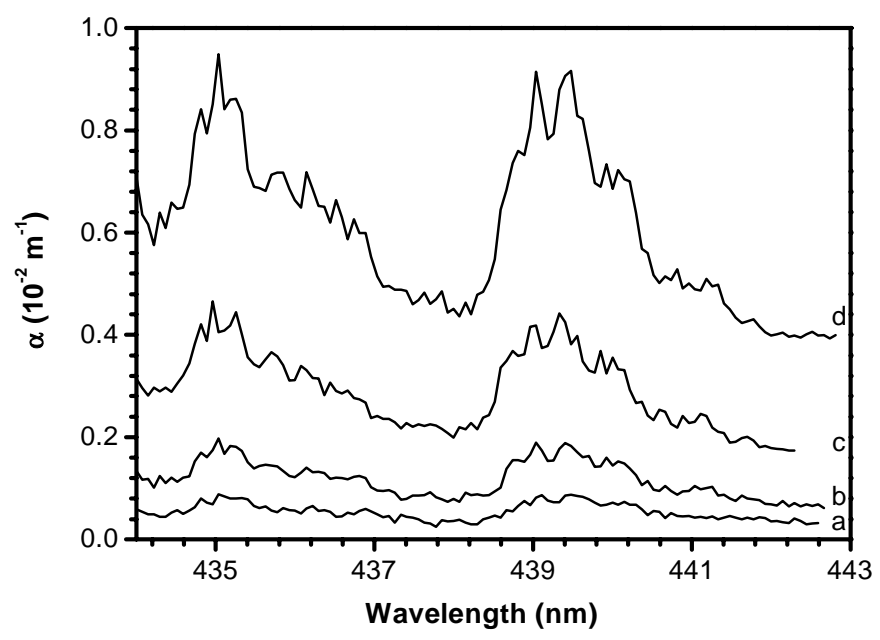

Figure 5.5: The absorption coefficient versus wavelength for different sample concentrations of $\mathrm{NO}_{2}$ in dry air at 1.0.10 $\mathrm{Pa}$ in the spectral range from $434 \mathrm{~nm}$ to $442 \mathrm{~nm}$. The spectral resolution is $0.15 \mathrm{~nm}$. a) $0.5 \mathrm{ppm}, \mathrm{b}) 1.1 \mathrm{ppm}$, c) $2.3 \mathrm{ppm}$, d) $4.5 \mathrm{ppm}$. 

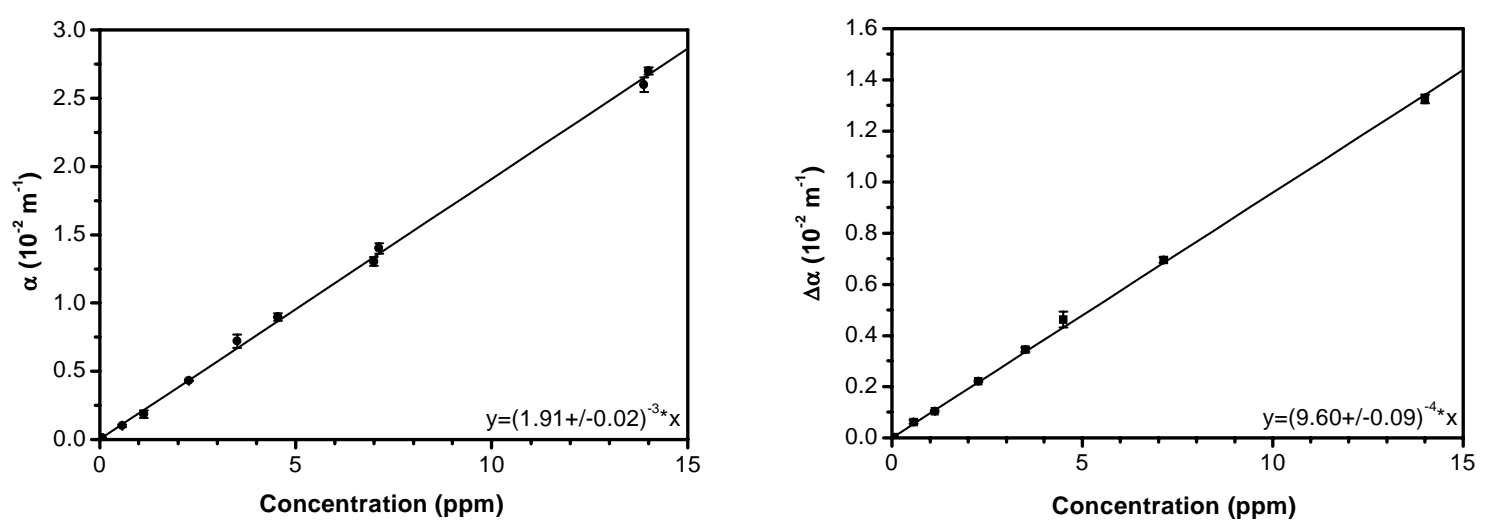

Figure 5.6: a) Absorption coefficient $\alpha$ of $\mathrm{NO}_{2}$ as a function of concentration for the peak at $439.5 \mathrm{~nm}, b)$ Difference $\Delta \alpha$ between the maximum at $439.5 \mathrm{~nm}$ and the minimum at $438 \mathrm{~nm}$.

$0.1 \mathrm{ppm}$ and $4.5 \mathrm{ppm}$, in atmospheric air in the range from $434 \mathrm{~nm}$ to $442 \mathrm{~nm}$ at a resolution of $0.15 \mathrm{~nm}$. Spectra have been corrected with a background spectrum, which was recorded on static air at atmospheric pressure. Clearly, the background depends on mirror reflectivity, cavity alignment and scattering by air and particles inside the cavity.

In Figure 5.6a the total absorption coefficient (that is, including all contributions to the decrease of the CRD time) at $439.5 \mathrm{~nm}$ is given as a function of the $\mathrm{NO}_{2}$ concentration. The experimental data are fitted to a straight line. Figure 5.6b shows the difference $\Delta \alpha$ between the total absorption coefficient at the maximum at $439.5 \mathrm{~nm}$ and at the relative minimum at $438.0 \mathrm{~nm}$ as a function of the $\mathrm{NO}_{2}$ concentration, fitted to a straight line. By using $\Delta \alpha$ rather than $\alpha$, only absorption due to $\mathrm{NO}_{2}$ will be accounted for. These results show that it is possible to determine absolute $\mathrm{NO}_{2}$ densities in complex mixtures containing interfering components showing broad-band absorption in this spectral range. With the known values for the $\mathrm{NO}_{2}$ concentration, the absorption cross-sections can be calculated at various wavelengths from the results in Figure 5.6b. This results in $\sigma(439.5 \mathrm{~nm})=(7.95 \pm 0.65) \cdot 10^{-19} \mathrm{~cm}^{2}$ and $\sigma$ $(438.0 \mathrm{~nm})=(3.96 \pm 0.36) \cdot 10^{-19} \mathrm{~cm}^{2}$. The experimental errors include both the precision of the fit and the experimental standard deviation, including fluctuations due to drift in the manually controlled pressure system $(1.00 \pm 0.01) \cdot 10^{5} \mathrm{~Pa}$ that affects both flow density and cavity alignment. In Table 5.1 a comparison with relevant literature values is made, showing a reasonable agreement. The values for $\sigma$ in the table are derived at $T=298 \mathrm{~K}$. To study the effect of an elevation of the temperature on the absorption coefficient the glass cell was preheated to $377 \mathrm{~K}$ and $433 \mathrm{~K}$ and filled with $7.6 \mathrm{ppm} \mathrm{NO}$ in air. The ratios of the absorption coefficients at these temperatures and the coefficient at room temperature showed no change of the cross-section within this temperature range. From literature, it is known that the 


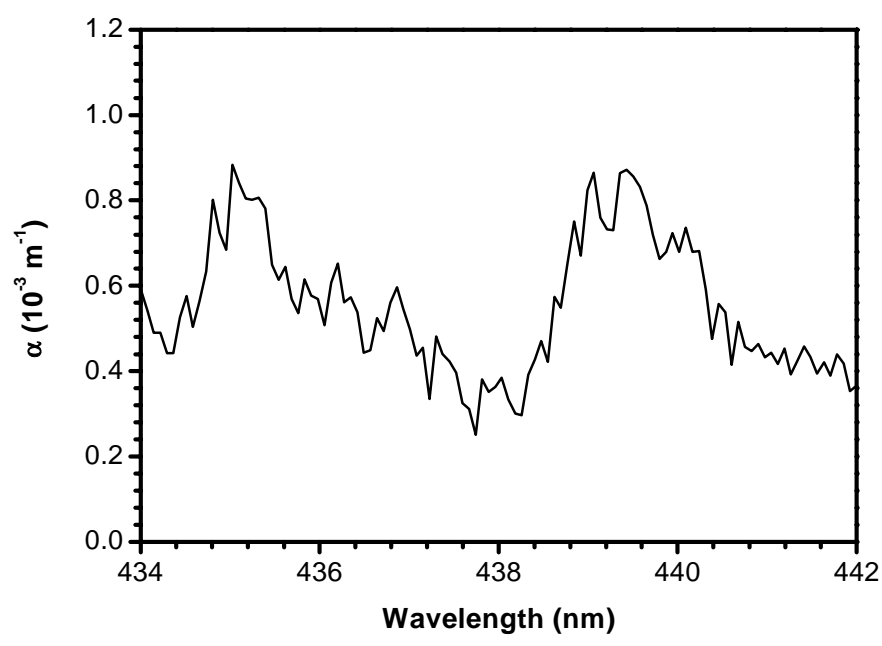

Figure 5.7: The absorption coefficient as a function of wavelength for a sample of $500 \mathrm{ppb}$ $\mathrm{NO}_{2}$ in air at $1.0 \cdot 10^{5} \mathrm{~Pa}$.

influence of temperature on the $\mathrm{NO}_{2}$ absorption spectrum is small at the current resolution $[18,19]$.

The sensitivity of the system was determined by insertion of the mirrors with the highest reflectivity (99.985\%). In Figure 5.7, the CRD spectrum taken of a $500 \mathrm{ppb}$ sample of $\mathrm{NO}_{2}$ in air at atmospheric pressure is given. From a comparison with the reference spectrum, most of the features from the spectrum can be attributed to spectral structure. From this figure, the detection limit is estimated to be $50 \mathrm{ppb}\left(\mathrm{S} / \mathrm{N}_{\mathrm{p}-\mathrm{p}}=1\right)$.

Table 5.1: The experimental absorption cross-section at 439.5 and $438.0 \mathrm{~nm}$ and comparison to literature values.

\begin{tabular}{cccc}
\hline $\begin{array}{c}\sigma_{439.5 \mathrm{~nm}} \\
\left(10^{-19} \mathrm{~cm}^{2}\right)\end{array}$ & $\begin{array}{c}\sigma_{438.0 \mathrm{~nm}} \\
\left(10^{-19} \mathrm{~cm}^{2}\right)\end{array}$ & $\begin{array}{c}\text { Resolution } \\
(\mathrm{nm})\end{array}$ & Ref. \\
\hline $7.00(28)$ & $3.40(14)$ & 0.04 & {$[4]$} \\
$7.00(56)$ & $3.80(30)$ & 0.05 & {$[18]$} \\
$7.95(67)$ & $3.96(34)$ & 0.05 & This work \\
\hline
\end{tabular}




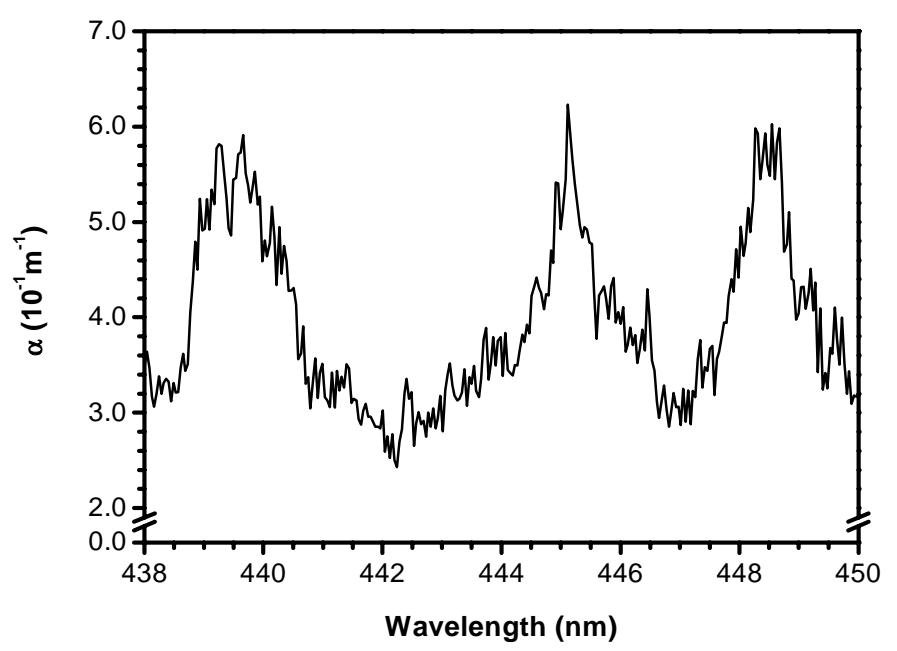

Figure 5.8: $\mathrm{CRD}$ spectrum of $\mathrm{NO}_{2}$ taken from the combustion products of a stoichiometric oxyacetylene flame at $83 \mathrm{~cm}$ above the burner tip, $u=254 \mathrm{~cm} / \mathrm{s}$ at $T=391 \mathrm{~K}$ at atmospheric pressure.

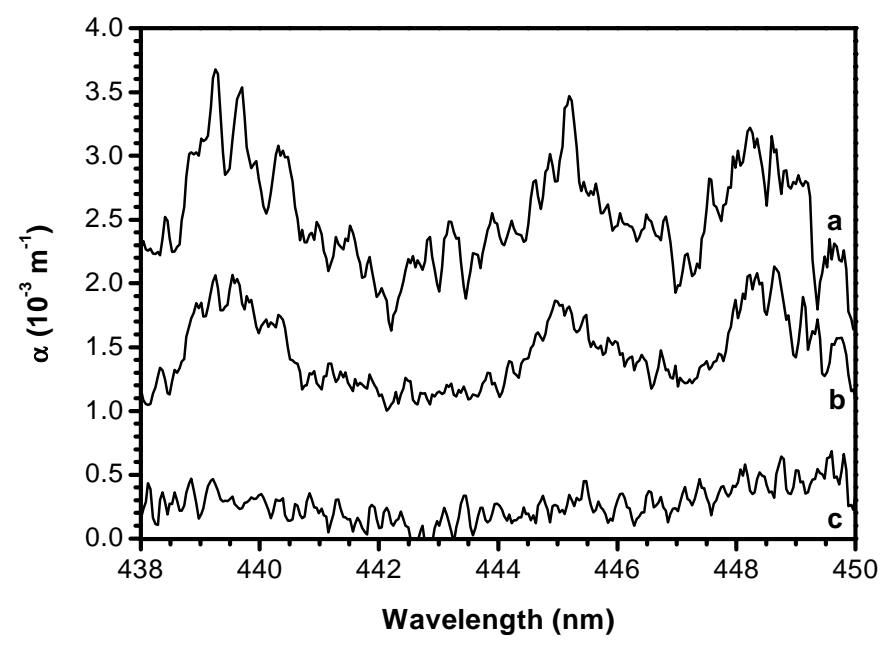

Figure 5.9: Influence of coflow and addition of nitrogen to the formation of $\mathrm{NO}_{2}$ in a stoichiometric oxyacetylene welding torch at $83 \mathrm{~cm}$ above the burner tip at atmospheric pressure. a) No coflow, b) $1.3 \% \mathrm{~N}_{2}$ added to the gasmixture with a He coflow, c) Coflow of pure He. $u=170 \mathrm{~cm} / \mathrm{s}$ at $T=391 \mathrm{~K}$. 


\subsubsection{Welding torch}

To demonstrate the feasibility of CRDS to detect $\mathrm{NO}_{\mathrm{x}}$ in flames, it was applied to measure $\mathrm{NO}_{2}$ in the combustion gases of an oxyacetylene flame. A freely burning oxyacetylene torch was used with a premixed gas mixture containing oxygen and acetylene but no nitrogen. Therefore, the formation of $\mathrm{NO}$ and $\mathrm{NO}_{2}$ results purely from mixing of surrounding air with the combustion products. Due to the high temperature of acetylene flames [25, 26], secondary reactions can lead to the formation of large concentrations of $\mathrm{NO}$ and, indirectly, $\mathrm{NO}_{2}$, the former mostly via the Zeldovich mechanism.

Direct application of CRD to probe the flame or its surroundings at small distances from the flame front suffers from turbulence resulting in very low $\mathrm{S} / \mathrm{N}$ ratios. In such cases, the combined effect of flow geometry, temperature gradients and diffusion effects, renders quantification of the experimental data hardly feasible. Therefore, the experimental setup shown in Figure 5.2 was used. Figure 5.8 shows the CRD spectrum of $\mathrm{NO}_{2}$ for a stoichiometric oxyacetylene flame, from which an average density of $14 \mathrm{ppm}$ was derived. The local absolute densities can only be obtained from integrated path measurements when an Abel inversion technique is applied [27].

In Figure 5.9, the influence of an additional coflow around the flame on the concentration of $\mathrm{NO}_{2}$ is shown. As can be seen, and as expected, the He coflow reduces the formation of $\mathrm{NO}_{2}$. The addition of a small amount of $\mathrm{N}_{2}$ to the gas mixture (1.3\%) immediately results in the formation of detectable levels of $\mathrm{NO}_{2}$. From the experimental results, an estimate of the detection limit in the $1000 \mathrm{ppb}$ range can be made $\left(\mathrm{S} / \mathrm{N}_{\mathrm{p}-\mathrm{p}}=1\right)$ using the mirror set with a lower reflectivity. The turbulent motion of the combustion gases and the stability of the flame are of influence on this value.

The results presented in this section show the applicability of the CRDS technique to detect reaction products in the combustion gas of an oxyacetylene flame. To draw more definite conclusions on $\mathrm{NO} / \mathrm{NO}_{2}$ formation from the quantitative results obtained for $\mathrm{NO}_{2}$, the total $\mathrm{NO}_{\mathrm{x}}$ concentration should be known. Of course, this can be calculated if the number density of NO is measured. This can be done with the same setup, as will be discussed in the next section, but has not been performed on this particular burner system.

\subsubsection{Diesel engine}

During initial CRDS experiments on the exhaust gas of a different, two-stroke diesel engine, molecular absorption was often obscured by the occurrence of larger or smaller soot particles. As Figure 5.3 shows, in the current experimental scheme the exhaust gas is led through a particle filter before flowing through the detection area to eliminate this adverse effect. A second important feature is the small absorption path length of $12 \mathrm{~mm}$ by performing the measurement at the exit of a small sampling tube. This reduced path length proved to be necessary to avoid saturation effects and non-single-exponential behaviour during the CRDS 


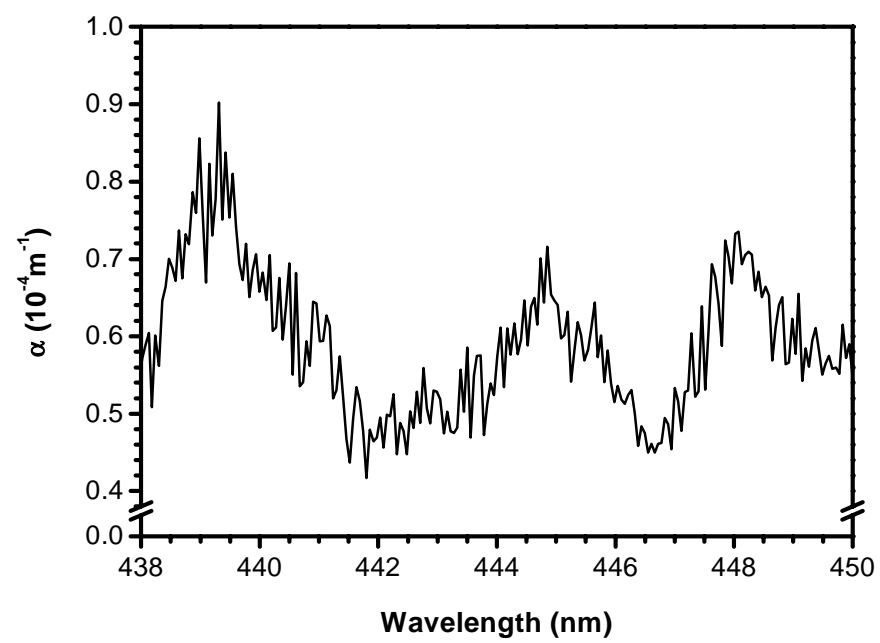

Figure 5.10: Part of the $\mathrm{NO}_{2}$ CRD spectrum measured in the exhaust gas of a diesel engine at $1360 \mathrm{rpm}, 35 \mathrm{Nm}$ load and $398 \mathrm{~K}$.

measurements. In addition, the use of a sampling tube offers the possibility to flush the cavity mirrors with nitrogen, and thus to avoid fouling of the mirror surfaces, without modifying or interfering with the absorption path length.

The densities measured at the sampling tube exit must be correlated with the densities inside the exhaust pipe. The air intake (and thus the throughput) of the three unmodified cylinders of the engine is $70 \mathrm{~g} / \mathrm{s}$, resulting in a maximum gas flow speed of $11 \mathrm{~m} / \mathrm{s}$ at the sampling point. This is still below the incompressibility limit of Mach 0.3 [28]. Therefore, the exhaust gas can be considered incompressible, i.e. density variations due to pressure changes - not temperature - can be neglected, and the species densities in the gas mixture, including $\mathrm{NO}_{2}$ and $\mathrm{NO}$, are independent of the flow speed. Pulsations in the output flow due to the strokes of the engine are dampened by the filter. Consequently, the relative densities inside the main exhaust pipe, in the sampling tube, and at the outlet of the sampling tube can be assumed to be equal. Thus, the measured data are directly representative of the concentrations inside the main exhaust gas flow.

Figure 5.10 shows an example of the $\mathrm{CRD}$ spectrum of $\mathrm{NO}_{2}$ taken with the current setup during operation of the engine at $1360 \mathrm{rpm}, 35 \mathrm{Nm}$ load and $398 \mathrm{~K}$. It clearly shows the three absorption features. A part of the experimental $\mathrm{A}^{2} \Sigma^{+} \leftarrow \mathrm{X}^{2} \Pi \mathrm{CRD}$ spectrum of $\mathrm{NO}$ at $1360 \mathrm{rpm}, 30 \mathrm{Nm}$ load and an exhaust gas temperature of $408 \mathrm{~K}$ at the tube exit is shown in Figure 5.11. In addition, it shows a scaled NO absorption spectrum in the same wavelength region simulated with LIFBASE [29]. A comparison between the two spectra shows a less intense $\mathrm{P}_{2}, \mathrm{Q}_{12}$ bandhead in the experimental spectrum, possibly due to saturation effects. To 


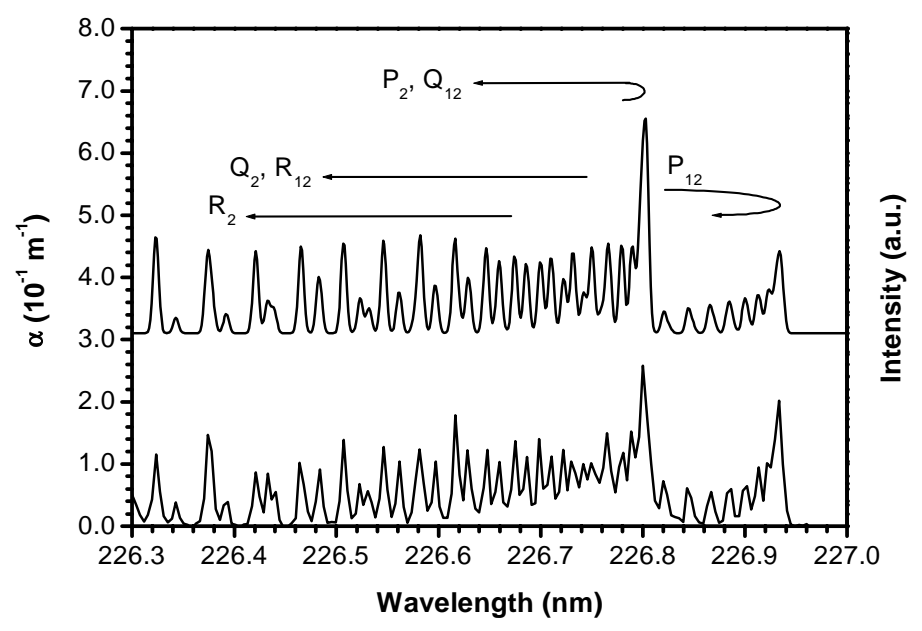

Figure 5.11: Part of the NO $A^{2} \Sigma^{+}-X^{2} \Pi$ CRD spectrum during $1360 \mathrm{rpm}$ and $30 \mathrm{Nm}$ load at $408 \mathrm{~K}$ (bottom) and the scaled absorption spectrum simulated with LIFBASE at $408 \mathrm{~K}$ given with an off-set for clarity (top) [29].

calculate accurate NO densities from the recorded spectra, weak absorption lines were selected to avoid saturation [30].

The quantitative results obtained in the exhaust gas of the diesel engine at $1360 \mathrm{rpm}$ and a load of $30 \mathrm{Nm}$ (NO measurement) or $35 \mathrm{Nm}$ ( $\mathrm{NO}_{2}$ measurement) are shown in Table 5.2. They are the result of an average over three spectral scans for each species, which took approx. 7 minutes per scan. Measurements were started after a 10 minutes warm up period for the engine after which a stable baseline was obtained. The temperature of the exhaust gas measured at the exit of the sampling tube is included in the table as well. The load is limited to about $4 \%$ of the normal full load of this type of engine, due to modifications made on other parts. Under normal working conditions the $\mathrm{NO}_{\mathrm{x}}$ emission levels for this type of engine are between 750 to $860 \mathrm{ppm}$ (1500 rpm, 50 to $100 \%$ load).

Table 5.2: Species concentration as a function of engine conditions

\begin{tabular}{lcccc}
\hline Species & $\begin{array}{c}\text { Speed } \\
(\mathrm{rpm})\end{array}$ & $\begin{array}{c}\text { Load } \\
(\mathrm{Nm})\end{array}$ & $\begin{array}{c}\text { Temperature } \\
(\mathrm{K})\end{array}$ & $\begin{array}{c}\text { Concentration } \\
(\mathrm{ppm})\end{array}$ \\
\hline $\mathrm{NO}_{2}$ & 1360 & 35 & 398 & $29 \pm 4$ \\
$\mathrm{NO}$ & 1360 & 30 & 408 & $212 \pm 22$ \\
\hline
\end{tabular}


For $\mathrm{NO}_{2}$, the total concentration $N_{\text {tot }}$ has been calculated from the relation between $\Delta \alpha$ and $N_{\text {tot }}$. With the data from the previous section, this resulted in $N_{t o t}=29 \pm 4 \mathrm{ppm}$. In this value, structureless broad-band background absorption, possibly caused by soot, is accounted for, because the difference in absorption $\Delta \alpha$ were used. The NO density was calculated from the coinciding $\mathrm{Q}_{1}(19.5)$ and $\mathrm{P}_{21}(19.5)$ lines at $225.806 \mathrm{~nm}$. The absorption cross-sections were obtained from the Einstein coefficients given by Luque et al. [29]. From the Boltzmann distribution and partition function at $408 \mathrm{~K}$ the concentration of NO could be calculated as $212 \pm 22 \mathrm{ppm}$. The errors are determined by the experimental noise and the accuracies of the values used for the absorption cross-section (3\% [29]).

In combination with the oxygen concentration at the sampling point (18.6\%) and the equilibrium constant $[31,32]$ for $\mathrm{NO}_{2} \Leftrightarrow \mathrm{NO}+1 / 2 \mathrm{O}_{2}$, it can be found that there is not yet an equilibrium and that the conversion of $\mathrm{NO}$ to $\mathrm{NO}_{2}$ is still expected to prevail.

Surprisingly, removal of the soot filter during the NO measurements did not result in a significant change of the experimental spectrum. Therefore, the production of soot particles in this engine under the current operating conditions is apparently low enough for not disturbing the CRDS measurements.

Sensitivities of $3 \mathrm{ppm}$ (for $\mathrm{NO}_{2}$ ) and $25 \mathrm{ppm}$ (for $\mathrm{NO}$ ) for a 12-mm absorption path length could be obtained. If necessary, sensitivities down to the low-ppb range may be reached by using the full absorption path length, mirrors with a higher reflectivity and by selecting the more intense R-branch for NO, provided interfering absorptions are not the limiting factor. Given the typical concentrations of $\mathrm{NO}$ and $\mathrm{NO}_{2}$ in engine exhausts, this maximum sensitivity will not be required in the present application. From the experimental results, a $\mathrm{NO}_{\mathrm{x}}$-level of $241 \pm 26 \mathrm{ppm}$ is found. Measurements with a chemical gas analyser (Signal Instruments, Camberley, UK, calibrated with an 800 ppm NO in $\mathrm{N}_{2}$ gas mixture) at an engine speed of $1360 \mathrm{rpm}$ and $30 \mathrm{Nm}$ load resulted in a total $\mathrm{NO}_{\mathrm{x}}$-level of $290 \mathrm{ppm}$, in reasonable agreement with the CRDS results. The obtained $\mathrm{NO}_{\mathrm{x}}$ levels are lower than specified for this type of engine under normal working conditions, due to the higher loads during normal operation. Examination of the experimental values and sensitivities shows that with this method the maximum emission levels of $\mathrm{NO}_{\mathrm{x}}$ required by the European Euro $\mathrm{V}$ standard directive on the emission of $\mathrm{NO}_{\mathrm{x}}(2008)$ can easily be determined.

The precision of the method can be increased by reducing the spectral range (to only two or three lines in case of NO) and increasing the number of spectral scans. A substantial reduction of the acquisition time can be attained by recording only the on- and off-resonance ring-down times. This will enable single cylinder, single stroke measurements, which is important for a detailed study of the combustion process in internal combustion engines. To achieve this, measurements should be conducted near the exit of the cylinder to prevent mixing. The pulsation of the flow should not impose an insuperable condition. Techniques based on gas analysis generally have a long response time and are unable to perform such measurements. The current method may provide a direct optical approach to measure both time averaged 
$\mathrm{NO}_{\mathrm{x}}$-emission levels as well as stroke-to-stroke fluctuations. Furthermore, since the wavelength for detection of $\mathrm{NO}$ is half the wavelength of $\mathrm{NO}_{2}$ absorption, it may be possible to monitor both species during the same experimental run using both the fundamental and the second harmonic of the laser source. A further improvement of the method can be the application of more sensitive, but slightly more complex, continuous wave absorption techniques (cw CRDS or CEA) [33] with the availability of blue laser diodes [34] and/or frequency doubling and quadrupling schemes [35-38]. In addition, CW and diode laser systems are also smaller, which makes a more compact, portable experimental setup possible that can easily be used in the field.

\subsection{Conclusions}

In this chapter, CRDS has been investigated for the quantitative detection of $\mathrm{NO}_{2}$ in various experimental environments. It has been used successfully to record absorption spectra of $\mathrm{NO}_{2}$ at different concentrations in dry air samples at atmospheric pressure. Thus, CRDS is shown to be a suitable tool for both the quantitative detection of this molecular pollutant and for molecular spectroscopic studies reaching low detection limits with a compact experimental setup. The obtained absorption cross-sections in the range 437 to $450 \mathrm{~nm}$ have been compared to literature values and show good agreement. The minimum detectable concentration for the present setup has been estimated to be $50 \mathrm{ppb}$.

The feasibility of CRDS for $\mathrm{NO}_{2}$ measurements in a laminar flame was demonstrated. The $\mathrm{NO}_{2}$ concentrations produced by a premixed oxyacetylene welding torch were in the low ppm-range. A simple experiment has shown the influence of a coflow on the formation of $\mathrm{NO}_{2}$. Sensitivities were estimated to be $1 \mathrm{ppm}\left(\mathrm{S} / \mathrm{N}_{\mathrm{p}-\mathrm{p}}=1\right)$.

Finally, a simple experimental setup to apply pulsed cavity ring-down spectroscopy to detect trace gases in the exhaust gas of a diesel engine was demonstrated. The setup was used to quantify the total $\mathrm{NO}_{\mathrm{x}}$ load under different conditions using $\mathrm{NO}$ absorption lines of the $\mathrm{X}^{2} \Pi$ to the $\mathrm{A}^{2} \Sigma^{+}$state at $226 \mathrm{~nm}$ and the spectral region between $438 \mathrm{~nm}$ to $450 \mathrm{~nm}$ for $\mathrm{NO}_{2}$. From the experimental results, a $\mathrm{NO}_{\mathrm{x}}$-level of $241 \pm 26 \mathrm{ppm}$ was found, in agreement with measurements using a chemical gas analyser. The CRDS method might enable single cylinder, single stroke measurements, which is important for a detailed study of the combustion process in internal combustion engines. 


\section{References}

1. Wennberg, P.O., Cohen, R.C., Stimpfle, R.M., Koplow, J.P., Anderson, J.G., Salawitch, R.J., Fahey, D.W., Woodbridge, E.L., Keim, E.R., Gao, R.S., Webster, C.R., May, R.D., Toohey, D.W., Avallone, L.M., Proffitt, M.H., Loewenstein, M., Podolske, J.R., Chan, K.R., Wofsy, S, Removal of stratospheric $\mathrm{O}_{3}$ by radicals: In situ measurements of $\mathrm{OH}, \mathrm{HO}_{2}, \mathrm{NO}, \mathrm{NO}_{2}, \mathrm{ClO}$, and $\mathrm{BrO}$. Science 266:398-404 (1994).

2. Plane, J.M.C.; Nien, C., Differential optical-absorption spectrometer for measuring atmospheric trace gases. Rev. Sci. Instrum. 63:1867-1876 (1992).

3. Toriumi, R.; Tai, H.; Takeuki, N., Tunable solid-state blue laser differential absorption lidar system for $\mathrm{NO}_{2}$ monitoring. Optic. Eng. 35:2371-2375 (1996).

4. Vandaelle, A.C.; Hermans, C.; Simon, P.C.; Van Roozendael, M.; Guilmot, J.M.; Carleer, M.; Colin, R., Fourier transform measurement of $\mathrm{NO}_{2}$ absorption cross-section in the visible range at room temperature. J. Atm. Chem. 25:289-305 (1996).

5. Patten, K.; Burley, J.D.; Johnston, H.S., Radiative lifetimes of nitrogen-dioxide for excitation wavelengths from 400nm to 750nm. J. Phys. Chem. 94:7960-7969 (1990).

6. Staicu, A., Evertsen, R., Dam, N.J., Ter Meulen, J.J., Cavity ring-down spectroscopy and laser induced fluorescence for $\mathrm{NO}_{2}$ detection. Proc. SPIE 4430:620-627 (2001).

7. Mann, B.A.; White, R.F.; Morrison, R.J.S., Detection and imaging of nitrogen dioxide with the degenerate four-wave-mixing and laser-induced-fluorescence techniques. Appl. Opt. 35:475-481 (1996).

8. Cattolica, R.J., Visualization of flame propagation by laser-fluorescence imaging of nitrogen-dioxide. Combust. Sci. Tech. 54:61-69 (1987).

9. Thornton, J.A., Wooldridge, P.J., Cohen, R.C., Atmospheric $\mathrm{NO}_{2}$ : In situ laser-induced fluorescence detection at parts per trillion mixing ratios. Anal. Chem. 72:528-539 (2000).

10. O'Keefe, A.; Scherer, J.J.; Paul, J.B.; Saykally, R.J., Chapter 6, in Cavity Ring Down Spectroscopy, Busch, K.W., Busch, M.A., eds., p. 71-92, American Chemical Society, Washington DC, 1999.

11. Romanini, D.; Kachanov, A.A.; Stoeckel, F., Diode laser cavity ring down spectroscopy. Chem. Phys. Lett. 270:538-545 (1997).

12. Romanini, D., Dupre, P., Jost, R., Non-linear efect by continuous wave cavity ringdown spectroscopy in jet-cooled $\mathrm{NO}_{2}$. Vib. Spectrosc. 19:93-106 (1999).

13. Dupre, P., Probing molecular species by cavity ringdown laser absorption spectroscopy, application to the spectroscopy and dynamics of jet-cooled $\mathrm{NO}_{2}$. C. R. Acad. Sci. Sr. IV 2:929-964 (2001).

14. Lauterbach, J., Kleine, D., Kleinermanns, K., Hering, P., Cavity ring-down spectroscopic studies of $\mathrm{NO}_{2}$ in the region around $612 \mathrm{~nm}$. Appl. Phys. B 71:873-876 (2000).

15. Lauterbach, J., Kleine, D., Kleinermanns, K., Hering, P., Erratum to Cavity ring-down spectroscopic studies of $\mathrm{NO}_{2}$ in the region around $612 \mathrm{~nm}$. Appl. Phys. B 72:631 (2001).

16. Harwood, M.H.; Jones, R.L., Temperature-dependent ultraviolet-visible absorption cross-sections of $\mathrm{NO} 2$ and $\mathrm{N}_{2} \mathrm{O}_{4}$ - low-temperature measurements of the equilibrium-constant for $2 \mathrm{NO}_{2}-\mathrm{N}_{2} \mathrm{O}_{4}$. J. Geophys. Res. 99:22955-22964 (1994).

17. Amoruso, A.; Crescentini, L.; Fiocco, G.; Volpe, M., New measurements of the $\mathrm{NO}_{2}$ absorption crosssection in the 440- $\mathrm{nm}$ to 460- $\mathrm{nm}$ region and estimates of the $\mathrm{NO}_{2}-\mathrm{N}_{2} \mathrm{O}_{4}$ equilibrium-constant. J. Geophys. Res. 98:16857-16863 (1993).

18. Kirmse, B.; Delon, A.; Jost, R., $\mathrm{NO}_{2}$ absorption cross section and its temperature dependence. J. Geophys. Res. 102:16089-16098 (1997). 
19. Davidson, J.A.; Cantrell, C.A.; Daniel, A.H.Mc.; Shetter, R.E.; Madronich, S.; Calvert, J.G., Visibleultraviolet absorption cross sections for $\mathrm{NO}_{2}$ as afunction of temperature. J. Geophys. Res. 93:71057112 (1988).

20. Warnatz, J., Maas, U., Dibble, R.W., Chapter 17, in Combustion, p. 219-236, Springer Verlag, Berlin, 1996.

21. Mokhov, A.V., Levinsky, H.B., A LIF and CARS investigation of upstream heat loss and flue-gas recirculation as $\mathrm{NO}_{x}$ control strategies for laminar, premixed natural-gas/air flames. Proc. Combust. Inst. 28:2467-2474 (2000).

22. Stoffels, G.G.M., Nitric oxide in a diesel engine: laser-based detection and interpretation, Ph.D. thesis, University of Nijmegen, Nijmegen, the Netherlands, 1999.

23. Van den Boom, H.L.G.J., Laser diagnostics in diesel engines, Ph.D. thesis, University of Nijmegen, Nijmegen, the Netherlands, 2000.

24. Pillier, L., Moreau, C., Mercier, X., Pauwels, J.F., Desgroux, P., Quantification of stable minor species in confined flames by cavity ring-down spectroscopy: application to NO. Appl. Phys. B 74:427-434 (2002).

25. Gaydon, A.G., Wolfhard, H.G.: Flames, their structure, radiation and temperature, Chapman and Hall, London, 1979.

26. Okkerse, R., Numerical simulation of an oxy-acetylene torch reacor for diamond CVD, Ph.D. thesis, Delft University of Technology, Delft, 2000.

27. Stolk, R.L., Ter Meulen, J.J., Laser diagnostics of CH in a diamond depositing flame. Diamond Relat. Mater. 8:1251-1255 (1999).

28. Kundu, P.: Fluid mechanics, Academic Press, San Diego, CA, 1990.

29. Luque, J., Crosley, D.R., LIFBASE: Database and Spectral Simulation Program (version 1.4), SRI International Report MP 96-001, 1998.

30. Zalicki, P., Zare, R.N., Cavity ring-down spectroscopy for quantitative absorption measurements. J. Chem. Phys. 102:2708-2717 (1995).

31. Chase, M.W., ed., NIST-JANAF thermochemical tables, American Institute of Physics, Woodbury, NY, 1998.

32. Giauque, W.F., Kemp, J.D., The equilibria $\mathrm{N}_{2} \mathrm{O}_{4}=2 \mathrm{NO}_{2}=2 \mathrm{NO}+\mathrm{O}_{2}$. J. Chem. Phys. 6:40-52 (1938).

33. Berden, G., Peeters, R., Meijer, G., Cavity ring down spectroscopy: experimental schemes and applications. Int. Rev. Phys. Chem. 19:565-607 (2000).

34. Nichia Corporation Japan. http://www.nichia.co.jp (2002).

35. Alnis, J., Gustafsson, U., Somesfalean, G., Svanberg, S., Sum-frequency generation with a blue diode laser for mercury spectroscopy at $254 \mathrm{~nm}$. Appl. Phys. Lett. 76:1234-1236 (2000).

36. Zimmerman, C., Vuletic, V., Hemmerich, A., Hansch, T.W., All solid state laser source for tunable blue and ultraviolet radiation. Appl. Phys. Lett. 66:2318-2320 (1995).

37. Goldberg, L., Kliner, D.A.V., Deep-UV generation by frequency quadrupling of a high-power GaAlAs semiconductor laser. Opt. Lett. 20:1145-1147 (1995).

38. Kliner, D.A.V., Koplowv, J.P., Goldberg, L., Narrow-band, tunable, semiconductor-laser-based source for deep-UV absorption spectroscopy. Opt. Lett. 22:1418-1420 (1997). 



\title{
CAVITY RING-Down SPECTROSCOPY OF A LOW-PRESSURE FLAT FLAME
}

\begin{abstract}
Initial studies on the structure of a flat flame at sub-atmospheric are presented. Cavity ringdown spectroscopy is applied to a premixed flat $\mathrm{CH}_{4} /$ air flame at $2 \cdot 10^{4} \mathrm{~Pa}$ (200 mbar) to determine absolute $\mathrm{OH}$ and $\mathrm{HCO}$ densities as a function of height above the burner surface. Two intensified CCD cameras are used to optimise alignment and spatial resolution. The HCO radicals are probed via the $\tilde{\mathrm{A}}^{2} \mathrm{~A}^{\prime}(0,9,0) \leftarrow \tilde{\mathrm{X}}^{2} \mathrm{~A}^{\prime \prime}(0,0,0)$ transition at $615 \mathrm{~nm}$. OH is excited via the $\mathrm{A}^{2} \Sigma \leftarrow \mathrm{X}^{2} \Pi$ transition at $308 \mathrm{~nm}$. Absolute $\mathrm{OH}$ number density distributions have been obtained for two different stoichiometries $(\phi=1.1$ and 1.2) in an optically flat burner-stabilised flame. The density profile of HCO was recorded for $\phi=1.2$. Signal-to-noise ratios indicate that $\mathrm{HCO}\left(\tilde{\mathrm{X}}^{2} \mathrm{~A} "\left(0,0^{1}, 0\right), \mathrm{J}=9\right)$ number densities down to $5 \cdot 10^{9} \mathrm{~cm}^{-3}$, corresponding to a concentration of $8 \mathrm{ppm}$ total $\mathrm{HCO}$ at $1600 \mathrm{~K}$, can be detected. The experimental results are compared to model calculations using GRI-Mech 2.11, showing reasonably good agreement for the $\mathrm{HCO}$ number density profile, but with the position of the maximum shifted further away from the burner surface. The calculated $\mathrm{OH}$ number densities were a factor of 2.4 lower than the experimentally obtained values. The $\mathrm{OH}$ profile for $\phi=1.2$ was also found shifted away from the surface as compared to the numerical results.
\end{abstract}




\subsection{Introduction}

Practical combustion applications normally operate at atmospheric or higher pressures. However, as we have seen in the previous chapters, this results in specific properties of the flames like a thin flame front, steep temperature gradients and thus steep index-of-refraction gradients, causing some practical experimental challenges in investigating these types of flames.

However, these properties can be changed in the positive sense by a reduction of the pressure. Decreasing the pressure leads to an expansion of the dimensions of the flame including the reaction zone. Laser-based combustion diagnostics can then be applied more easily to obtain detailed spatial information on species and structure at the flame front. At reduced pressures, the temperature gradient can be expected to be less steep and therefore less perturbing to the probe beam. However, a reduction of the pressure will also lead to lower number densities compared to the densities at atmospheric pressures. Assuming that the species in the combustion process behave as perfect gases, number density and pressure are related by the equation of state:

$$
p=\rho k T
$$

with $p$ the pressure, $\rho$ the number density, $k$ the Boltzmann constant and $T$ the temperature. The total molecular density is found to decrease on reduction of the pressure in the system, putting a more stringent demand on the sensitivity of the spectroscopic method.

To evaluate the influence of a change in pressure on the combustion process, the laminar flame structure and the burning velocity have to be considered. The pressure dependence of the burning velocity $S_{L}$, developed from thermal approaches, can be given by [1]:

$$
S_{L} \sim p^{(n / 2-1)}
$$

with $n$ the overall order of reaction. Thus, for second-order reactions the burning velocity is predicted to be independent of pressure. For hydrocarbon combustion the reaction $\mathrm{H}+\mathrm{O}_{2} \rightarrow$ $\mathrm{OH}+\mathrm{O}$ is a key chain-branching reaction largely governing the overall reaction rate. Any removal of $\mathrm{H}$ will reduce the overall reaction rate. It appears from sensitivity analyses that the most important reaction reducing the oxidation rate is $\mathrm{H}+\mathrm{O}_{2}+\mathrm{M} \rightarrow \mathrm{HO}_{2}+\mathrm{M}$ [2]. This is a third-order reaction. The chance of recombination through tri-molecular reactions decreases when the pressure is lowered. Consequently, their influence will decrease on reducing the pressure (especially below atmospheric pressures). 


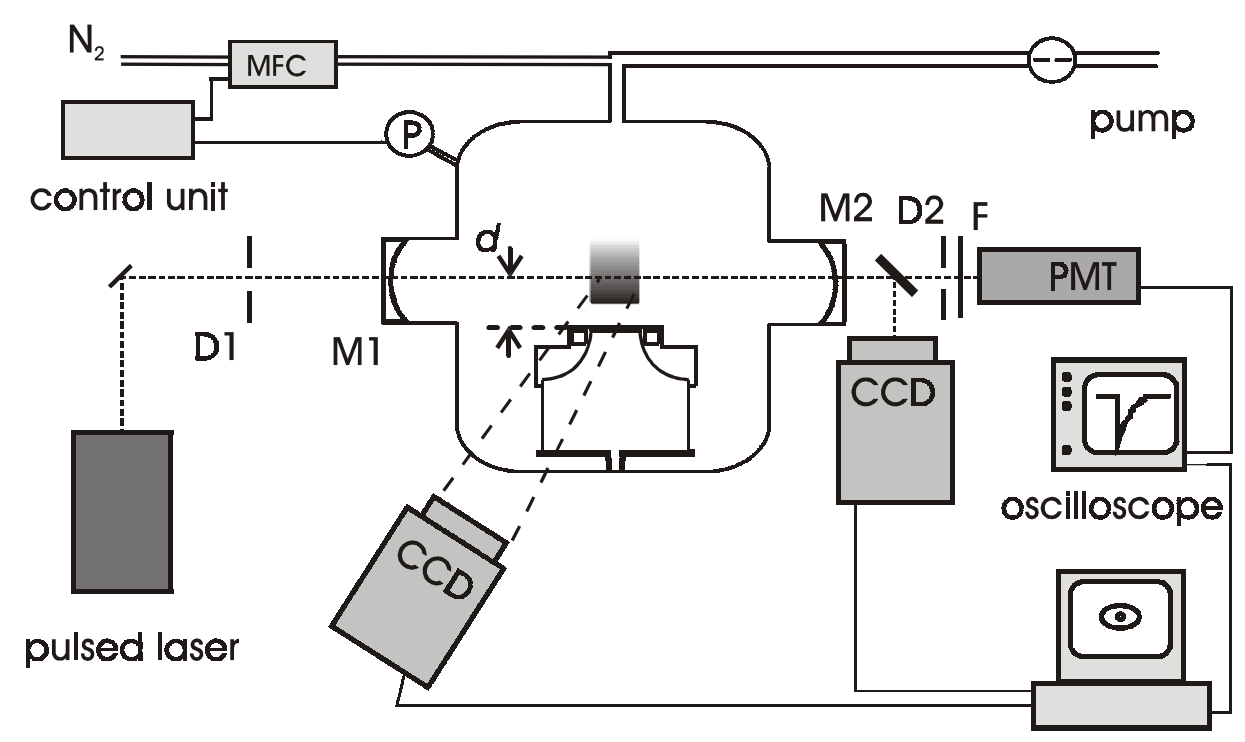

Figure 6.1: Schematic of the low-pressure CRDS flame setup. M1, M2: cavity mirrors; D1, D2: diaphragms; F: filter.

Therefore, the burning velocity of methane/air flames generally shows an increase with decreasing pressure [3, 4]. From Equations 6.1 and 6.2 it follows that the mass burning rate $m_{0, u}$ decreases with decreasing pressure, since

$$
m_{0, u}=\rho S_{L} \sim p^{n / 2}
$$

with $m_{0, u}$ the mass flow rate per unit area of unburned gases and the density $\rho=M N$ with $M$ the molecular mass and $N$ the number density. From the same thermal approach, it can be found that the thickness of the reaction zone $\delta$ depends on the pressure as [1]:

$$
\delta \sim D_{f} / S_{L} \sim \rho D_{f} / m_{0, u}
$$

with $D_{f}$ the thermal diffusivity. As an approximation $\rho D_{f}$ can be taken constant [1] and the flame thickness will scale with $p^{-n / 2}$. Therefore, a reduction of the pressure will result in a thicker reaction zone. Generally, at atmospheric pressure the reaction zone thickness for methane/air flames is in the order of a fraction of a millimeter. 


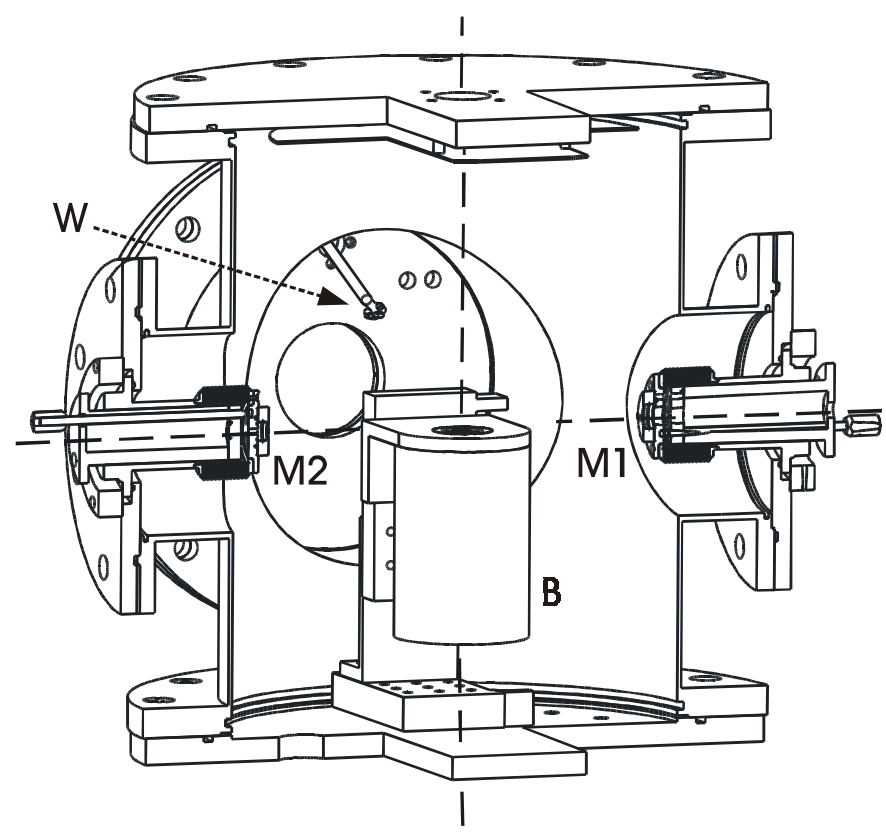

Figure 6.2: Cross-section of the low-pressure vacuum chamber including the flat flame burner. M1, M2: cavity mirrors; B: flat flame burner; W: hot-wire element.

\subsection{Experimental setup}

A scheme of the experimental setup is shown in Figure 6.1, which is comparable to the general setup presented in Chapter 2 of this thesis. A cross-section of the vacuum chamber including the burner system is shown in Figure 6.2. The cavity mirrors also form the entrance and exit windows of the vacuum chamber. A bellows construction enables adjustment of the cavity mirrors while maintaining a low pressure inside the chamber. The cavity length can be varied between $25 \mathrm{~cm}$ and $35 \mathrm{~cm}$. The other two side flanges of the vacuum chamber have $\varnothing 15 \mathrm{~cm}$ quartz windows to enable luminescence detection perpendicular to the cavity axis. The burner system [5] is placed in the center of the vacuum chamber and in the center of the cavity. The burner can be translated in the plane perpendicular to the cavity with submicrometer precision by two electronic translation stages (Newport). As a result, the distance $\mathrm{d}$ between the cavity axis and the burner surface can be varied from outside the chamber between $-2 \mathrm{~cm}$ and $+10 \mathrm{~cm}$. The flame can be ignited with a hot-wire element (kantal, $0.6 \mathrm{~mm}$ o.d., $7 \mathrm{~V}, 10 \mathrm{~A})$. The flame is stabilised with a mixture of $\mathrm{CH}_{4}(99.5 \%$ purity, Hoekloos) and air with calibrated MFC's (Bronckhorst HiTec) controlled by a homemade control unit (TUE, Eindhoven). Burner deck and mantle are thermostated by two separate water-circulation units. The stainless steel vacuum chamber is pumped by a rotary pump (AEG). The chamber pressure is controlled using a feedback-loop with an absolute pressure 
transducer coupled to a control unit regulating a nitrogen-gas MFC (Bronckhorst HiTec), supplying a nitrogen gas load to the rotary-pump. Pressure stability was better than 0.05 mbar ( $5 \mathrm{~Pa}$ ). The combustion gases pass two water-cooling units before reaching the rotary-pump. The experiments were conducted with fuel equivalence ratios of $\phi=1.2$ and 1.1 , at flow velocities of $u=44.5 \mathrm{~cm} / \mathrm{s}$ and $46.5 \mathrm{~cm} / \mathrm{s}$ and at a pressure of $p=2 \cdot 10^{4} \mathrm{~Pa}$. The temperature of the cooling water for cooling the burner head was around $350 \mathrm{~K}$ in all cases. A CCD camera is used to check the parallel alignment of the burner plate to the laser beam axis. Errors in the alignment were typically smaller than $0.075 \mathrm{~mm}$ over a length of $30 \mathrm{~mm}$.

The $\mathrm{OH}$ radicals are probed via the $\mathrm{A}^{2} \Sigma^{+} \leftarrow \mathrm{X}^{2} \Pi$ transition at $308 \mathrm{~nm}$, the HCO radicals via the $\tilde{\mathrm{A}}^{2} \mathrm{~A}^{\prime}(0,9,0) \leftarrow \tilde{\mathrm{X}}^{2} \mathrm{~A}^{\prime \prime}(0,0,0)$ transition at $615 \mathrm{~nm}$. Two different sets of cavity mirrors were used with a reflectivity $\geq 0.998$ at $615 \mathrm{~nm}$ (Laser Optik) and a reflectivity $\geq 0.998$ at $308 \mathrm{~nm}$ (REO), respectively, and a radius of curvature of $250 \mathrm{~mm}$. The distance between the two mirrors was $301 \mathrm{~mm}$. The second harmonic of a Nd:YAG laser (Quantel TDL-50), operated at a repetition rate of $10 \mathrm{~Hz}$ with a pulse duration of $7 \mathrm{~ns}$, is used to pump a dye laser using a mixture of rhodamine 640 and sulforhodamine $640\left(0.06 \mathrm{~cm}^{-1}\right.$ bandwidth, checked on the $\mathrm{Q}_{1}(1)$ transition of $\mathrm{OH}$ in a jet-cooled molecular beam). The wavelength scale of the dye laser system was calibrated using the frequency doubled output of the dye laser by comparing the CRDS absorption spectrum of the $\mathrm{OH}$ radical using reference data [6, 7]. The waist of the $308 \mathrm{~nm}$ beam in the centre of the cavity was $0.9 \pm 0.2 \mathrm{~mm}$ FWHM as derived from OH LIF detection of the $\mathrm{R}_{2}(4)$ transition at $307.5 \mathrm{~nm}$. The cavity output is detected with both a gated intensified CCD camera (LaVision Flamestar or Princeton Instruments 512-T) and a fast redor UV-sensitive photomultiplier tube (Thorn-EMI) with a ns-risetime and a wide linear dynamic range. In order to reduce the background signal, caused mainly by chemiluminescence, a diaphragm of $\varnothing 15 \mathrm{~mm}$ and a spectral filter were mounted in front of a quartz diffuser plate at the entrance of the photomultiplier tube. For the $\mathrm{OH}$ measurements a band pass filter $(\lambda=325 \pm 25 \mathrm{~nm}$ ) was used, and for the HCO measurements a long pass filter (cut-off at $\lambda=590 \mathrm{~nm}$ ). The PMT-signal is coupled to a computer via an 8 bits, $100 \mathrm{Msamples/s}$ digital oscilloscope (Lecroy 9361). In all results presented below, each data point represents an average over 32 laser pulses. Data are analysed with specially designed software containing weighted fitting algorithms to determine ring-down times. The single exponential behaviour of the transients was checked whenever any experimental parameters were changed. Single exponential decay was shown over at least 2.5 times the ring-down time. The cavity alignment was continuously optimised using the CCD image recorded directly behind the second mirror. The $\mathrm{HCO}$ and $\mathrm{OH}$ densities were measured at different distances $d$ between burner surface and laser beam. For the data processing, the temperature is assumed to be constant over the total path above the cylindrically symmetric burner [8]. 


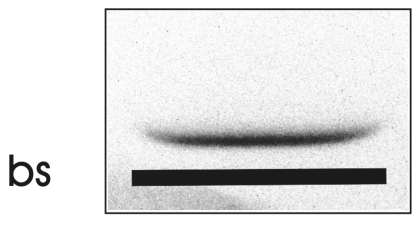

a

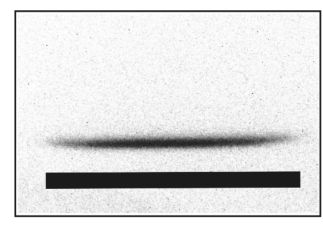

b

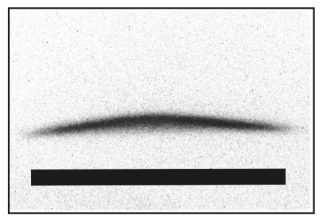

C

Figure 6.3: Chemiluminescence of $\mathrm{CH}$ in a low-pressure methane/air flat flame with $\phi=1.2$ at $p=2 \cdot 10^{4} \mathrm{~Pa}, T_{\text {deck }}=347 \mathrm{~K}$ and $u=25 \mathrm{~cm} / \mathrm{s}(a), 45 \mathrm{~cm} / \mathrm{s}(\mathrm{b}), 55 \mathrm{~cm} / \mathrm{s}(\mathrm{c})$. bs indicates the burner surface.

\subsection{Flame behaviour}

The flame curvature was studied by recording the chemiluminescence of $\mathrm{CH}$ with the intensified CCD camera through a narrow bandpass filter $(\lambda=430 \pm 5 \mathrm{~nm})$. Figure 6.3 shows the results for three different flow speeds at $\phi=1.2$, at $p=2 \cdot 10^{4} \mathrm{~Pa}$. It can be seen that at high flows the flame can still stabilise at the edges of the burner. The curvature of the flame at low flows is expected to be the result of a non-uniform exit flow profile of the gas mixture or flame non-uniformity, which is also present, but less visible, at atmospheric pressures. Experimentally it could be observed that the regime in which a stable flame could be obtained was progressively smaller and more difficult to attain when going to lower pressures. From Figure 6.3 , it can also be concluded that there is a case in which the flame front has a minimum curvature. This is most probably under adiabatic conditions and close to the situation depicted in Figure 6.3b. In case of CRDS, line-integrated absorption is recorded and any deviation from a flat flame front will influence the results [9]. In the experiments presented below, the conditions for optically flat flames have been selected using chemiluminescence images at different flows.

The influence of the flame on the off-resonant cavity ring-down time due to scattering processes can be a measure for position of the flame structure relative to the burner surface. Figure 6.4 shows the off-resonant cavity losses in case of a flat flame with $\phi=1.2$ and $44.5 \mathrm{~cm} / \mathrm{s}$ at $p=2 \cdot 10^{4} \mathrm{~Pa}$ and $\lambda=307.3 \mathrm{~nm}$ as a function of height above the burner surface. Starting high above the burner surface, it is clear from the figure that the ring-down time decreases when approaching the flame front. The position of the flame front was found by imaging of the chemiluminescence of $\mathrm{CH}$, the maximum of which was at $3.1 \mathrm{~mm}$ above the burner surface. Below the flame front, the ring-down time is shown to increase before losses resulting from scattering at the burner surface will disrupt the ring-down signals. From a systematic study of this kind of off-resonance effects, it should be possible to predict the exact position of the flame front. 


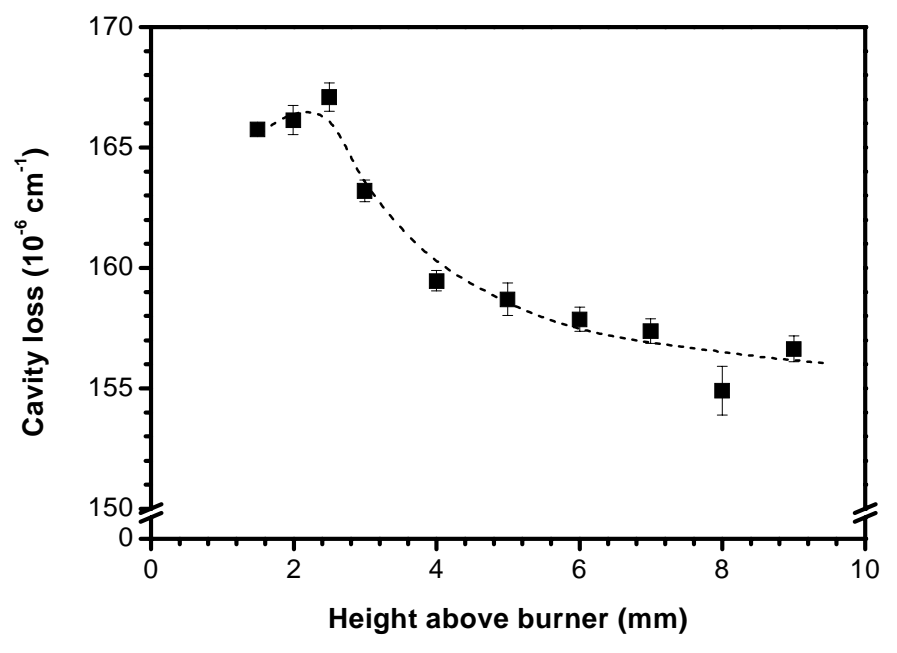

Figure 6.4: Off-resonant cavity losses at $\lambda=307.3 \mathrm{~nm}$ as a function of height above the burner surface. Flame conditions: $\phi=1.2,44.5 \mathrm{~cm} / \mathrm{s}, \mathrm{p}=2 \cdot 10^{4} \mathrm{~Pa}, \mathrm{~T}_{\text {deck }}=347 \mathrm{~K}$. Dashed line is plotted as a guide to the eye.

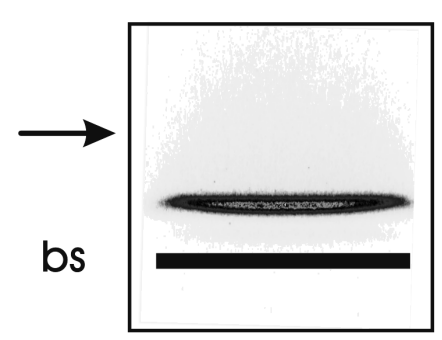

a

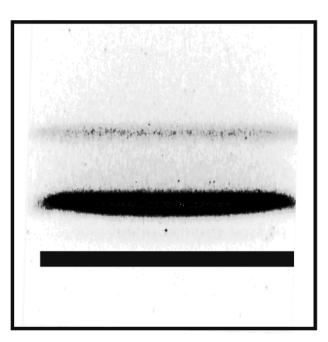

b

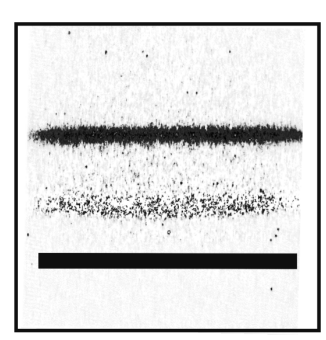

C

Figure 6.5: $O H$ LIF images resulting from excitation via the $R_{2}(4)$ transition at $307.526 \mathrm{~nm}$ in the ring-down cavity; (a) off-resonant laser showing background luminescence from the flame front, (b) resonant excitation, (c) corrected fluorescence image (b-a). Flame conditions: $\phi=1.2,44.5 \mathrm{~cm} / \mathrm{s}, p=2 \cdot 10^{4} \mathrm{~Pa}$ with the laser beam at $d=8.0 \mathrm{~mm}$ above the burner surface. The arrow indicates the laser beam direction and position; bs: the burner surface. The images are scaled individually for a good contrast. 
The width of the probe beam was estimated from OH LIF measurements while the ring-down resonator was aligned for CRDS experiments. The $\mathrm{OH}$ radicals were excited via the $\mathrm{R}_{2}(4)$ transition at $307.526 \mathrm{~nm}$ at $d=8.0 \mathrm{~mm}$ above the burner surface. LIF was recorded with a gated iCCD camera perpendicular to the cavity through a bandpass filter $(\lambda=325 \pm 25 \mathrm{~nm})$. Background images were recorded in the same way, but with the laser tuned off-resonance. Part of the recorded images is presented in Figure 6.5. By subtracting the on- and offresonance images, the strong intensity of the background luminescence is largely removed. From the results, the waist of the laser beam could be estimated to be $0.9 \mathrm{~mm}$ FWHM in a setup without mode matching optics or spatial filtering.

\subsection{Hydroxyl}

The $\mathrm{OH}$ number density profile at two different flame conditions was recorded as a function of height above the burner surface and is presented in Figure 6.6. The figure shows the $\mathrm{OH}$ $\mathrm{F}_{1}\left(\mathrm{~N}^{\prime \prime}=16\right)$ number density obtained from the measured cavity losses on the $\mathrm{R}_{21}(16)$ transition using the Einstein B coefficient of $6.917 \cdot 10^{7} \mathrm{~m}^{2} \mathrm{~J}^{-1} \mathrm{~s}^{-1}$ given by Luque and Crosley [7]. The increased experimental error bars on the results of the $\phi=1.1$ flame can be attributed to fouling of the mirrors during the progress of the experiments. The experimental maximum densities are $(2.2 \pm 0.1) \cdot 10^{13} \mathrm{~cm}^{-3}$ and $(2.7 \pm 0.2) \cdot 10^{13} \mathrm{~cm}^{-3}$ around $5 \mathrm{~mm}$ above the burner surface at $\phi=1.2$ and $\phi=1.1$, respectively.

In the numerical calculations, an adiabatic 1D flame was simulated with $\mathrm{x}=0$ at the (experimental) burner surface temperature using GRI-Mech 2.11 [10] and mixture-averaged transport data [11]. To be able to compare the experimental results with these results, the numerical $\mathrm{OH} \mathrm{F}_{1}\left(\mathrm{~N}^{\prime \prime}=16\right)$ number density profile was calculated from the numerical $\mathrm{OH}$ and temperature profiles. The resulting numerical $\mathrm{OH} \mathrm{F}_{1}\left(\mathrm{~N}^{\prime \prime}=16\right)$ number density profiles are also presented in Figure 6.6. The numerical values in the figure are multiplied by 2.5 for clarity.

A comparison of the experimental and numerical values shows that changes in the number density and the positions of the experimental profiles are qualitatively in agreement with the variation of the numerical values when changing the stoichiometry from $\phi=1.2$ to $\phi=1.1$. The absolute values differ by a factor of 2.4. The position of the experimental $\mathrm{OH}$ profile for $\phi=1.1$ is found to agree with the position of the numerical profile. However, it can be seen from the figure that the experimental $\mathrm{OH}$ profile for $\phi=1.2$ is shifted $1.2 \mathrm{~mm}$ away from the burner surface, derived from the point of inflection, as compared to the numerical values. The experimental error in the determination of the position is estimated to be less than $0.1 \mathrm{~mm}$.

The cause for the differences in position may be found in the experimental burner surface temperature profile, which is assumed to be the same as the cooling water temperature. In addition, the flame can be super-adiabatic when it is optically flat [12]. A super-adiabatic flame has a high burning velocity tending to blow off, resulting in a flame front position that 


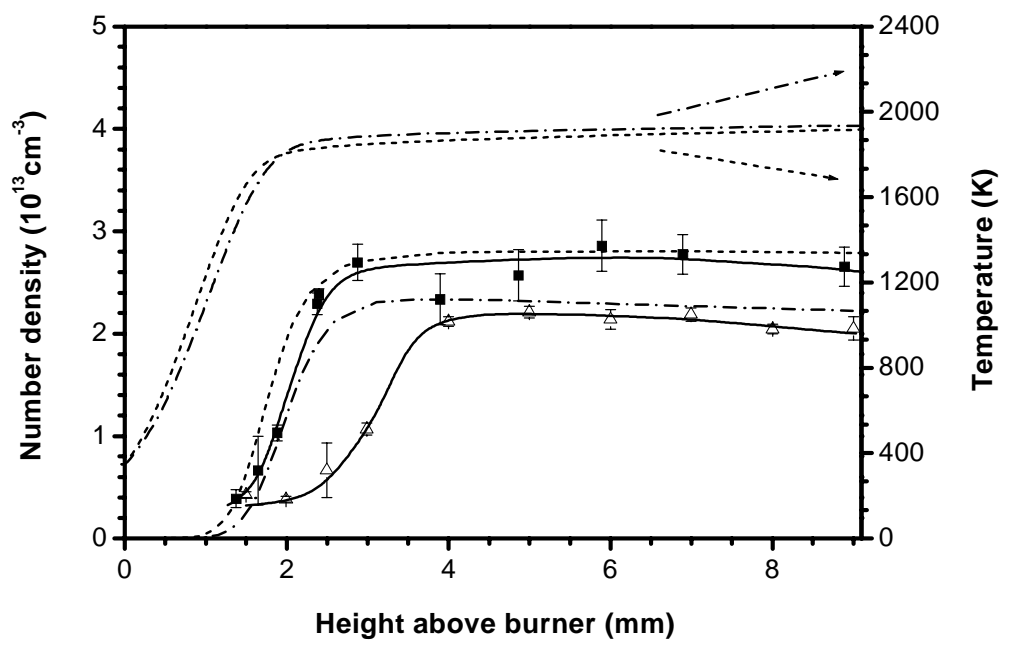

Figure 6.6: Experimental and calculated (GRI-Mech 2.11) number density profiles of $\mathrm{OH}$ in the $F_{1}\left(N^{\prime \prime}=16\right)$ state as a function of height above the burner surface. Numerical number densities are multiplied by 2.5 for clarity. $\Delta$ experimental data at $\phi=1.2$, $\boldsymbol{\text { experimental }}$ data at $\phi=1.1$, ---- numerical $O H$ curve and numerical temperature profile at $\phi=1.1$, - - numerical $\mathrm{OH}$ curve and numerical temperature profile at $\phi=1.2$. Conditions: $\phi=1.2$ : $44.5 \mathrm{~cm} / \mathrm{s}, T_{\text {burner }}=348 \mathrm{~K}$, and $\phi=1.1: 46.5 \mathrm{~cm} / \mathrm{s}, T_{\text {burner }}=348 \mathrm{~K}$ at $\mathrm{p}=2 \cdot 10^{4} \mathrm{~Pa}$. The solid lines through the data points are plotted as a guide to the eye.

is very susceptible to small experimental disturbances. Numerical calculations show that a rise of the burner surface temperature with $20 \mathrm{~K}$ results in a shift of the $\mathrm{OH}$ profile by less than 75 $\mu \mathrm{m}$ further away from the burner surface, without significant changes in the absolute number density or temperature profile. To eliminate the uncertainty of the experimental temperature, the burner surface should be equipped with thermocouples. The difference in absolute number densities should be more thoroughly investigated, especially since the ratio between the experimental and numerical values is opposite to the results found at atmospheric pressure, as presented in Chapter 2. The validity of the numerical results including the current reaction mechanism can be established from a systematic study in which more parameters, like the temperature, and different species are examined. The experimental curves can be corrected for the spatial width of the probe beam as outlined in Chapter 4. When such a procedure is followed, it can be expected that this results in more steeply rising profiles and a shift of the profile with about one mm away from the burner surface.

The sensitivity limit can be estimated from the experimental spectra and the corresponding absolute number densities. With a $\mathrm{S} / \mathrm{N}=1$ on the $\mathrm{R}_{21}(16)$ transition, this results in a detection limit of $5.5 \cdot 10^{11} \mathrm{~cm}^{-3}$ for $\mathrm{OH}$ in the $\mathrm{F}_{1}\left(\mathrm{~N}^{\prime \prime}=16\right)$ state. However, the detection limit can easily be improved by at least a factor of 500 by selecting a more intense Q- or R-branch transition. 


\subsection{Formyl}

Presented in Figure 6.7 is the CRDS absorption spectrum of the $\widetilde{\mathrm{A}}^{2} \mathrm{~A}^{\prime}(0,9,0) \leftarrow \tilde{\mathrm{X}}^{2} \mathrm{~A}$ ( $(0,0,0)$ band system of $\mathrm{HCO}$ in the low-pressure flat flame at $\phi=1.2,44.5 \mathrm{~cm} / \mathrm{s}$ and a pressure $p=2 \cdot 10^{4} \mathrm{~Pa}$. The different branches of the transition can easily be assigned. The signal-to-noise ratio is comparable to the results obtained for the atmospheric, burner-stabilised flat flame presented in Chapter 4.

To obtain the HCO number density as a function of height, the $\left(0,9^{0}, 0-0,0^{1}, 0\right) \mathrm{P}(9)$ line at $615.95 \mathrm{~nm}$ was probed. The absorption cross-section of this line is known from literature to be $1.1 \cdot 10^{-18} \mathrm{~cm}^{-2}$ at room temperature with an uncertainty of $\pm 60 \%$ [13]. The cavity losses for this line were recorded as a function of height above the burner surface. From the integrated losses the HCO number density in the $\tilde{X}^{2} A^{\prime \prime}\left(0,0^{1}, 0\right), J "=9$ state could be derived. The results are shown in Figure 6.8. The experimental error in the data is the result of an average over three spectral scans. The systematic error in the absorption cross-section is not included in the figure. The maximum HCO number density is $(4.6 \pm 1.0) \cdot 10^{10} \mathrm{~cm}^{-3}$ at $2.2 \mathrm{~mm}$ above the burner surface.

To compare the numerical simulations directly with the experimental data, the HCO number density in the state probed was calculated from the numerical density and temperature profiles [11]. These were calculated for a 1D flame using GRI-Mech 2.11 [10] and mixture-averaged transport data. The numerical result is also included in Figure 6.8. The maximum numerical HCO number density is $6.1 \cdot 10^{10} \mathrm{~cm}^{-3}$ at $1.4 \mathrm{~mm}$ above the burner surface.

The absolute number densities of both the experimental and the numerical results are in quantitative agreement, though the large systematic error in the absorption cross-section has to be considered. The experimental result presented here is not corrected for the spatial width of the probe beam. It can be expected that such a correction would lead to a higher experimental maximum number density, and a smaller width of the profile. Assuming a width of the probe laser of $0.7 \mathrm{~mm}$, the width of the deconvoluted HCO profile will be $\sim 25 \%$ smaller and the maximum $\sim 35 \%$ higher. The experimental HCO profile is found about 0.8 $\mathrm{mm}$ further away from the burner surface than the profile resulting from the numerical simulations. This shift is smaller than the shift of the experimental $\mathrm{OH}$ profile measured under the same experimental conditions, but in the same direction. As stated in the previous section, the experimental burner surface temperature profile, which is assumed the same as the cooling water temperature, is not known. In addition, the flame tends to be super-adiabatic [12] with a flame front position that is very susceptible to small experimental disturbances. Numerical calculations, in which an adiabatic flame is assumed, show that a rise of the burner surface temperature with $20 \mathrm{~K}$ results in a shift of the HCO profile with $60 \mu \mathrm{m}$ further away from the burner surface. The results show no significant changes in absolute number densities or the temperature profile. A definite conclusion about can only be drawn when the temperature at the burner surface is accurately known, for example by using thermocouples. 


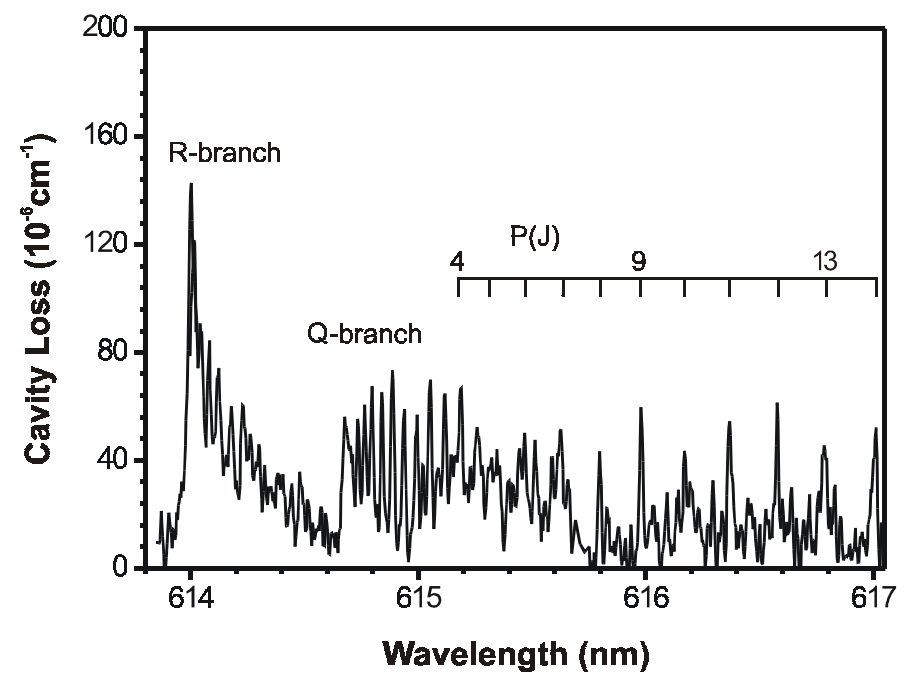

Figure 6.7: CRDS spectrum of the $\tilde{A}^{2} A^{\prime}(0,9,0) \leftarrow \tilde{X}^{2} A^{\prime \prime}(0,0,0)$ band system of HCO in a lowpressure flat flame. Conditions $\phi=1.2,44.5 \mathrm{~cm} / \mathrm{s}, T_{\text {burner }}=348 \mathrm{~K}, p=2 \cdot 10^{4} \mathrm{~Pa}$ at $d=2.0 \mathrm{~mm}$ above the burner surface.

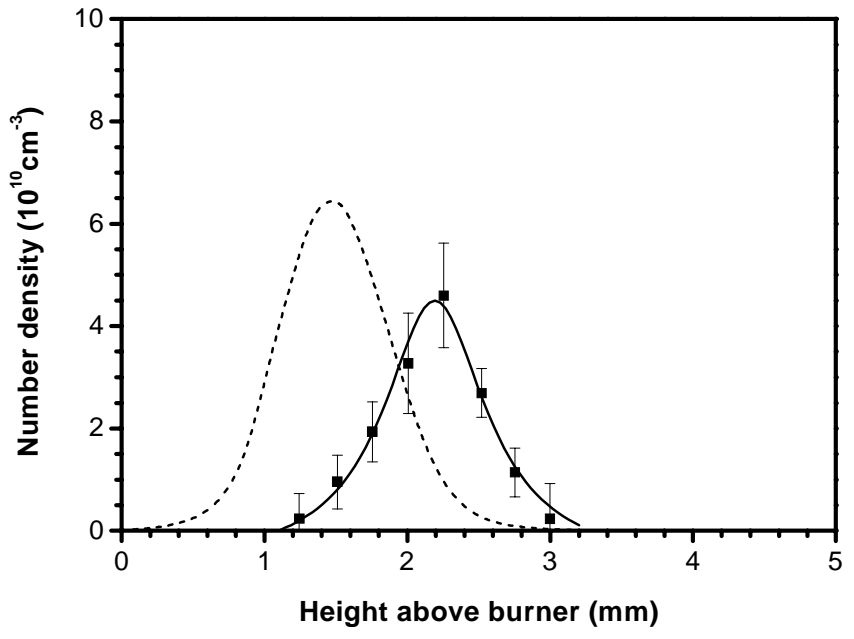

Figure 6.8: Experimental and numerical HCO $\left(\tilde{X}^{2} A^{\prime \prime}\left(0,0^{1}, 0\right), J^{\prime \prime}=9\right)$ number densities in a low-pressure flat flame at $\phi=1.2, u=44.5 \mathrm{~cm} / \mathrm{s}, T_{\text {burner }}=348 \mathrm{~K}$, as a function of height above the burner surface. - measured data, --- numerical curve (GRI-Mech 2.11). 
The sensitivity can be estimated from the signal to noise in the experimental spectra and the corresponding absolute number densities. With a $\mathrm{S} / \mathrm{N}=1$, this results for $\mathrm{HCO}$ radicals in the $\tilde{X}^{2} A "\left(0,0^{1}, 0\right), J "=9$ state in a minimum detectable concentration of $5 \cdot 10^{9} \mathrm{~cm}^{-3}$, corresponding to $8 \mathrm{ppm}$ total $\mathrm{HCO}$ at $1600 \mathrm{~K}$.

\subsection{Summary and outlook}

In this chapter, CRDS studies on an optically flat low-pressure methane/air flame are presented. The results show that detailed spatial data on flat flame structures can be more easily obtained at lower pressures than at atmospheric pressure, e.g. compare Figure 6.8 to Figure 4.7. With respect to the numerical data, the experimental $\mathrm{OH}$ profiles recorded at two different flame stoichiometries show a difference in absolute number densities. The experimental $\mathrm{OH}$ profile at $\phi=1.2$ is shifted $1.2 \mathrm{~mm}$ further away from the burner surface. The experimental and numerical HCO number densities are in quantitative agreement. However, the position of the experimental $\mathrm{HCO}$ maximum is shifted $0.8 \mathrm{~mm}$ further away from the burner. To further evaluate the origin of the differences found between the experimental and numerical results, the burner should be equipped with thermocouples to record the temperature profile of the burner surface. In this way, the flame conditions can be more accurately controlled and the heat exchange between flame and burner surface can be measured. When the experimental profiles of several radicals, like $\mathrm{CH}, \mathrm{HCO}$ and ${ }^{1} \mathrm{CH}_{2}$ are recorded, the validity of the reaction mechanism can be investigated more thoroughly. Further developments of the experimental setup include the addition of a coflow for additional stabilisation of the flame, nitrogen purging to avoid fouling of the mirrors and a setup for simultaneous CRDS and (P)LIF measurements. 


\section{References}

1. Glassman, I.: Combustion, Academic Press, San Diego, CA, 1996.

2. Warnatz, J., Maas, U., Dibble, R.W.: Combustion, Springer Verlag, Berlin, 1996.

3. $\quad$ Egolfopoulos, F.N., Cho, P., Law, K.C., Laminar flame speeds of methane-air mixtures under reduced and elevated pressures. Combust. Flame 76:375-391 (1989).

4. Iijima, T., Takeno, T., Effects of temperature and pressure on burning velocity. Combust. Flame 65:3543 (1986).

5. Van Maaren, A., Thung, D.S., De Goey, L.P.H., Measurement of flame temperature and adiabatic burning velocity of methane/air mixtures. Combust. Sci. Technol. 96:327-344 (1994).

6. Dieke, G.H., Crosswhite, H.M., The ultraviolet bands of $O H$. J. Quant. Spectrosc. Radiat. Transfer. 2:97-199 (1962).

7. Luque, J., Crosley, D.R., LIFBASE: Database and Spectral Simulation Program (version 1.4), SRI International Report MP 96-001, 1998.

8. Bosschaart, K.J., Versluis, M., Knikker, R., Van der Meer, Th. H., Schreel, K.R.A.M., De Goey, L.P.H., Van Steenhoven, A.A., The heat flux method for producing burner stabilized adiabatic flames: an evaluation with CARS thermometry. Combust. Sci. Techn. 168:1-19 (2001).

9. Luque, J., Jeffries, J.B., Smith, G.P., Crosley, D.R., Scherer, J.J., Combined cavity ringdown absorption and laser-induced fluorescence imaging measurements of $C N(B-X)$ and $C H(B-X)$ in low-pressure $\mathrm{CH}_{4}-\mathrm{O}_{2}-\mathrm{N}_{2}$ and $\mathrm{CH}_{4}-\mathrm{NO}-\mathrm{O}_{2}-\mathrm{N}_{2}$ flames. Combust. Flame 126:1725-1735 (2001).

10. Bowman, C.T., Hanson, R.K., Davidson, D.F., Gardiner, W.C., Lissianski, V., Smith, G.P., Golden, D.M., Frenklach, H., GRI-Mech 2.11. http://www.me.berbeley. edu/gri_mech/(1995).

11. Somers, L.M.T., The simulation of flat flames with detailed and reduced chemical models, Ph.D. thesis, Eindhoven University of Technology, Eindhoven, the Netherlands, http://www.tue.nl/bib/, 1994.

12. Bosschaart, K.J., personal communication, (2002).

13. Lozovsky, V.A., Derzy, I., Cheskis, S., Radical concentration profiles in a low-pressure methane-air flame measured by intracavity laser absorption and cavity ring-down spectroscopy. Proc. Combust. Inst. 27:445-452 (1998). 



\section{Chapter 7}

\section{SUMMARY AND OUTLOOK}

\subsection{Summary}

This thesis gives an introduction to pulsed cavity ring-down spectroscopy and its application in combustion research and presents a number of experiments which show the potential and drawbacks of the method in the study of flames and combustion products. Experimental results have been compared to numerical simulations, providing a means to validate reaction mechanisms and numerical approaches.

Pulsed cavity ring-down spectroscopy (CRDS) is a sensitive absorption technique based on the time-dependent attenuation of the intensity of a laser pulse. It is a relatively simple method, and quantitative data on minority species can, apart from the careful consideration of the bandwidth, be easily obtained. Applications of the technique range from the field of trace gas detection, molecular beam studies and spectroscopic studies to combustion research. Up to now, the application of CRDS in the field of combustion research has been focused mainly on sub-atmospheric flames and quantitative investigations of atmospheric flames have been very limited. In the previous chapters, experimental results have been presented obtained from the application of CRDS to study atmospheric and sub-atmospheric flames and combustion gases.

Pulsed cavity ring-down spectroscopy has been applied to study $\mathrm{OH}$ and $\mathrm{CH}$ radicals in the flame of a premixed methane/air flat flame burner at atmospheric pressure. Spectral lines from the absorption spectrum of $\mathrm{OH}$ have been used successfully to obtain flame temperatures. In addition, it has been used to study the effect of the laser bandwidth on the experimental results. The $\mathrm{CH}$ radical is often used as an indicator of the flame front and it plays an important role in the formation of prompt NO. At atmospheric pressure the radical has been found present in a thin layer less than $0.6 \mathrm{~mm}$ wide with a maximum at about $0.5 \mathrm{~mm}$ above the burner surface. Due to these small dimensions, special attention has to be given to the cavity setup and the parallel alignment of the laser beam with respect to the burner surface. An intensified CCD camera can be used as an aid for the alignment and can be used to determine the spatial laser beam profile. Because the spatial laser beam profile has a width that is comparable to the width of the $\mathrm{CH}$ density profile, statistical and analytical methods have been used to correct the measured $\mathrm{CH}$ density distribution for this. An Abel inversion technique has been used to extract the radial $\mathrm{CH}$ density profile from a set of measurements as 
a function of the radial distance to the flame axis. The comparison of the experimental data with the numerical values showed a lower maximum $\mathrm{CH}$ concentration at a position closer to the burner surface and at a lower temperature for two different stoichiometries. These differences might be attributed to incompleteness of the reaction mechanisms in the models. In addition to the $\mathrm{CH}$ radical, the singlet methylene radical ${ }^{1} \mathrm{CH}_{2}$ and the formyl radical $\mathrm{HCO}$ have been studied as well. HCO plays an essential role in the oxidation of hydrocarbons in combustion processes. The metastable ${ }^{1} \mathrm{CH}_{2}$ participates in the pathways leading to the formation and reduction of nitrogen oxides and in the formation of higher hydrocarbons which may ultimately lead to the formation of soot. Because the density profiles of both radicals are positioned very close to the burner surface at atmospheric pressures, it is difficult to obtain complete density distributions for both radicals. The numerical simulations show a qualitative and quantitative good agreement with the experimental ${ }^{1} \mathrm{CH}_{2}$ and $\mathrm{HCO}$ density profiles and the numerical simulations. To circumvent the problems arising at atmospheric pressure due to the small dimensions of the flame front, a low-pressure burner setup has been constructed. The dimensions of the flame front scale inversely proportional with pressure. However, a reduction of the pressure also results in lower absolute number densities. The complete $\mathrm{HCO}$ density profile as a function of height above the burner surface has been

recorded at $2 \cdot 10^{4} \mathrm{~Pa}$ (200 mbar). Apart from a shifted position of the profile, which might be the result of the flame conditions and the temperature of the burner surface, the experimental result showed a good quantitative agreement with the numerical simulations. In addition, the absolute $\mathrm{OH}$ density profile has been measured to determine the position of the flame structure and for comparison to numerical simulations as well.

Pulsed cavity ring-down spectroscopy has also been successfully applied for trace gas detection of $\mathrm{NO}$ and $\mathrm{NO}_{2}$. $\mathrm{NO}$ and $\mathrm{NO}_{2}$, collectively called $\mathrm{NO}_{\mathrm{x}}$, are well-known pollutants of the atmosphere, being responsible for acid rain and playing a role in the destruction of ozone. The absorption cross-section of $\mathrm{NO}_{2}$ has been studied by CRDS as a function of concentration and temperature and has been compared to literature values showing a good agreement. As an example, CRDS has been applied to the burned gas region of an oxyacetylene flame showing the dependence on entrained air for the formation of $\mathrm{NO}_{2}$. Both $\mathrm{NO}$ and $\mathrm{NO}_{2}$ have been detected in situ in the exhaust gas of a diesel engine running on commercial fuel. The CRDS results agreed well with separate chemical gas analysis. The experiments showed that CRDS provides a direct optical method to determine $\mathrm{NO}_{\mathrm{x}}$ in exhaust gases, which amply meets the sensitivity requirements stated in the European standard directives on the emission of $\mathrm{NO}_{\mathrm{x}}$.

\subsection{Outlook}

The results show that pulsed cavity ring-down spectroscopy can be successfully applied in combustion research. As stated in Chapter 1, the experimental scheme employed in the work 
in this thesis may suffer from a limited bandwidth resolution but this can be substantially increased by using narrow band pulsed or continuous wave lasers. Continuous wave cavity ring-down spectroscopy (cw CRDS) with diode laser sources provides a high resolution and high duty cycles. A drawback might be the limited wavelength range which is available compared to other laser sources. $\mathrm{Cw}$ CRDS can be performed in different ways. One way is to scan the cavity to match the frequency of the laser source with the modes of the cavity to enable light to couple into the cavity, and after sufficient build-up of intensity inside the cavity, the laser is switched off and the transient is recorded [1, 2]. A different, but more complex scheme locks the mode of the cavity to the laser frequency, increasing the efficiency of coupling light into the cavity and enhancing the sensitivity [3]. Different cw CRDS schemes have shown to achieve several orders higher sensitivities than conventional pulsed CRDS, though at the expense of instrumental complexity. Reported sensitivities are typically $10^{-9}$ to $10^{-12} \mathrm{~cm}^{-1}$. However, the small light sources in $\mathrm{cw}$ techniques make a compact experimental setup possible with the option of field measurements.

In addition to the experimental pulsed cavity ring-down scheme presented in this thesis, a number of different experimental schemes and enhancements have been developed based on the same cavity ring-down principle. These schemes include phase shift CRDS [4], Fourier transform CRDS [5], polarization dependent CRDS [6], evanescent wave CRDS [7], CRDS on solid thin films [8], and cavity enhanced spectroscopy (CEA) [9]. All these methods have unique advantages over pulsed CRDS and convential absorption methods and might be employed in spectroscopic combustion research.

The research presented in this thesis is focused on a burner which produces a cylindrically symmetric flat flame. Clearly, the method can also be applied to other flame geometries, including laminar flames on slot burners and counterflow flames. In this case, interaction of the laser beam with the burner surface can be largely eliminated which enables the study of the complete reaction layer, including species like $\mathrm{HCO}$ and ${ }^{1} \mathrm{CH}_{2}$. Recent CRDS studies show the possibility to obtain absolute number densities of excited state minority species [10], which is of great interest for the development of reaction schemes and optical emission models [11]. Future combustion research may focus on other species like $\mathrm{C}_{2} \mathrm{H}$ or species with higher carbon content such as $\mathrm{C}_{6} \mathrm{H}_{6}$ [12] or other PAHS, which are of environmental interest, or on the monitoring of soot and particle formation $[13,14]$.

The technological advancements in laser systems and optical equipment, such as high repetition laser systems for the simultaneous detection of several species [15] and the development of high speed cameras [16] will support the progress of both experimental and numerical combustion research. In future, research will also be directed towards the combination of CRDS with different optical techniques, as has been shown for the combination of CRDS and LIF [17]. This may lead to the development of fast detection methods for different species and temperature at small time scales, which could make it possible to study non-symmetric, turbulent, combustion processes quantitatively. 


\section{References}

1. Romanini, D., Dupre, P., Jost, R., Non-linear efect by continuous wave cavity ringdown spectroscopy in jet-cooled $\mathrm{NO}_{2}$. Vib. Spectrosc. 19:9-106 (1999).

2. Romanini, D., Lehmann, K.K., Ring-down cavity absorption spectroscopy of the very weak HCN overtone bands with six, seven, and eight stretching quanta. J. Chem. Phys. 99:6287-6301 (1993).

3. Paldus, B.A., Harb, C.C., Spence, T.G., Wilke, B., Xie, J., Harris, J.S., Zare, R.N., Cavity-locked ringdown spectroscopy. J. Appl. Phys. 83:3991-3997 (1998).

4. Engeln, R., Von Helden, G., Berden, G., Meijer, G., Phase shift cavity ring-down absorption spectroscopy. Chem. Phys. Lett. 262:105-109 (1996).

5. $\quad$ Engeln, R., Meijer, G., A fourier transform cavity ring-down spectrometer. Rev. Sci. Instrum. 67:27082713 (1996).

6. Engeln, R., Berden, G., Van den Berg, E., Meijer, G., Polarization dependent cavity ring-down spectroscopy. J. Chem. Phys. 107:4458-4467 (1997).

7. Pipino, A.C.R., Hudgens, J.W., Huie, R.E., Evanescent wave cavity ring-down spectroscopy for probing surface processes. Chem. Phys. Lett. 280:104-112 (1997).

8. $\quad$ Engeln, R., Von Helden, G., Van Roij, A.J.A., Meijer, G., Cavity ring down spectroscopy on solid C60. J. Chem. Phys. 110:2732-2733 (1999).

9. $\quad$ Engeln, R., Berden, G., Peeters, R., Meijer, G., Cavity enhanced absorption and cavity enhanced magnetic rotation spectroscopy. Rev. Sci. Instrum. 69:3763-3769 (1998).

10. Staicu, A., Stolk, R.L., Ter Meulen, J.J., Absolute concentrations of the $C_{2}$ radical in the $A^{1} \Pi_{u}$ state measured by cavity ring down spectroscopy in an atmospheric oxyacetylene flame. J. Appl. Phys. 91:969-974 (2002).

11. Luque, J., Jeffries, J.B., Smith, G.P., Crosley, D.R., Walsh, K.T., Long, M.B., Smooke, M.D., CH(A-X) and $\mathrm{OH}(\mathrm{A}-\mathrm{X})$ optical emission in an axisymmetric laminar diffusion flame. Combust. Flame 122:172175 (2000).

12. Kleine, D., Stry, S., Lauterbach, J., Kleinermanns, K., Hering, P., Measurement of the absolute intensity of the fifth $\mathrm{CH}$ stretching overtone of benzene using cavity ring-down spectroscopy. Chem. Phys. Lett. 312:185-190 (1999).

13. Vander Wal, R. L., Ticich, T. M., Cavity ringdown and laser-induced incandescence measurements of soot. Appl. Opt. 38:1444-1451 (1999).

14. Thompson, J.E., Smith, B.W., Winefordner, J.D., Monitoring atmospheric particulate matter through cavity ring-down spectroscopy. Anal. Chem. 74:1962-1967 (2002).

15. Bockle, S., Kazenwadel, J., Kunzelmann, T., Shin, D.-I., Schulz, C., Wolfrum, J., Siumultaneous single -shot laser-based imaging of formaldehyde, $\mathrm{OH}$, and temperature in turbulent flames. Proc. Combust. Inst. 28:279-286 (2000).

16. Kaminski, C.F., Hult, J., Alden, M., Lindenmaier, S., Dreizler, A., Maas, U., Baum, M., Spark ignition of turbulent methane/air mixtures revealed by time-resolved planar laser-induced fluorescence and direct numerical simulations. Proc. Combust. Inst. 28:399-405 (2000).

17. Luque, J., Jeffries, J.B., Smith, G.P., Crosley, D.R., Scherer, J.J., Combined cavity ringdown absorption and laser-induced fluorescence imaging measurements of $C N(B-X)$ and $C H(B-X)$ in low-pressure $\mathrm{CH}_{4}-\mathrm{O}_{2}-\mathrm{N}_{2}$ and $\mathrm{CH}_{4}-\mathrm{NO}-\mathrm{O}_{2}-\mathrm{N}_{2}$ flames. Combust. Flame 126:1725-1735 (2001). 


\section{SAMENVATTING}

\section{Cavity ring-down spectroscopie aan verbrandingsprocessen}

Verbranding van fossiele brandstoffen speelt een belangrijke rol in de opwekking van energie en zal dit naar verwachting ook de komende vijftig jaar blijven doen ondanks de ontwikkeling van duurzame energiebronnen. Om aan de toegenemende wettelijke eisen met betrekking tot de uitstoot vanschadelijke stoffen te kunnen voldoen en om tot schonere en efficiëntere verbrandingstechnologieën te kunnen komen is meer fundamentele kennis van de achterliggende fysische en chemische processen nodig. Voor het onderzoeken van verbrandingsprocessen staan ons verschillende op lasers gebaseerde optische technieken ter beschikking. Deze hebben het voordeel dat ze het verbrandingsproces niet of slechts heel weinig verstoren, vaak molecuulspecifiek en gevoelig zijn en dichtheids- en temperatuursinformatie kunnen leveren. Een aantal verschillende op lasers gebaseerde detectietechnieken wordt toegepast in verbrandingsonderzoek. Hierbij kan onderscheid gemaakt worden tussen methoden die de verstrooiing van licht detecteren en methoden die de absorptie van laserstraling meten. De laser-geïnduceerde fluorescentietechniek LIF behoort tot de eerste groep. Deze wordt vaak toegepast vanwege de hoge gevoeligheid. Het is echter moeilijk om de meetresultaten om te zetten in absolute dichtheden. Daarentegen bieden absorptietechnieken de mogelijkheid om direct kwantitatieve informatie te verkrijgen. Eén van deze absorptie-technieken is cavity ring-down spectroscopie (CRDS), de methode die gebruikt is bij het experimentele werk beschreven in dit proefschrift.

Het aantal toepassingen van en publicaties over cavity ring-down spectroscopie zijn sinds de introductie van de methode in 1988 bijna exponentieel toegenomen, ook in het veld van verbrandingsonderzoek. De eenvoudigste toepassing van het principe is de gepulste CRDS waarbij de opstelling bestaat uit een gepulste laser die fungeert als lichtbron, een resonator bestaande uit twee concave spiegels en een snelle, gevoelige photomultiplier die gekoppeld is aan een digitale oscilloscoop voor detectie en verwerking. Bij gepulste CRDS wordt de tijdsafhankelijkheid van de intensiteit van een laserpuls die geïnjecteerd wordt in de optische resonator gemeten. Afhankelijk van de reflectiviteit van de spiegels, de absorptie van het licht door de aanwezige stoffen en verstrooiingsverliezen in de cavity vertoont het signaal een exponentieel verval in de tijd, gekenmerkt door de cavity ring-down tijd $\tau$. Deze $\tau$ kan direct gecorreleerd worden aan de eigenschappen van de resonator, zoals de reflectiviteit van de 
spiegels en de absolute dichtheid van de stoffen in de resonator die het laserlicht absorberen. Aangezien het licht vele malen tussen de spiegels heen- en weer beweegt, zijn lange absoptieweglengtes te behalen waardoor hoge gevoeligheden bereikt kunnen worden. Kort samengevat koppelt de methode een eenvoudige experimentele opstelling aan een hoge gevoeligheid en levert het directe, kwantitatieve informatie.

De techniek is onder andere toegepast op een voorgemengde methaan/lucht-brander die een dunne, vlakke, cilinder-vormige vlam produceert. Het branderontwerp en zijn specifieke eigenschappen worden besproken in Hoofdstuk 2. Dit type vlakke vlam is met de huidige computers snel te simuleren en de numerieke resultaten kunnen vrijwel direct vergeleken worden met de experimentele data. Op deze manier kan de kwaliteit en de betrouwbaarheid van een verbrandingsmodel, waaronder ook het reactiemechanisme, getest worden. Hiervoor is betrouwbare kwantitatieve data van moleculaire dichtheidsverdelingen in de vlam nodig. In dit geval kunnen absorptiemetingen zoals CRDS de data leveren.

Bij de toepassing van CRDS op atmosferische vlammen treden echter een aantal complicaties op die de metingen uitdagender maken. Bij atmosferische druk zijn de afmetingen van het vlamfront, het gebied van een vlam waar de meeste, interessante, (tussen)producten gevormd en afgebroken worden, in de orde van één millimeter. Aangezien dit in dezelfde grootteorde ligt als de dimensies van de laserbundel, moet bij het opzetten van het experiment extra aandacht gegeven worden aan de uitlijning van de laserbundel ten opzichte van het branderoppervlak (parallelliteit) en moet getracht worden door het inkoppelen van een goed gedefiniëerde bundel een kleine bundeldiameter te bereiken in de resonator om een hoge spatiële resolutie te bereiken. Metingen met een CCD camera kunnen hierbij de informatie leveren over de afstand tussen de laserbundel en het branderoppervlak en over de bundeldiameter binnenin de resonator, onder andere door het registreren van Rayleigh/Mie verstrooiing. Ook de uitlijning van de resonator en de invloed van de vlam na de ontsteking van het brandstof/lucht mengsel op de lichtbundel kan gevolgd worden met de camera. Doordat de vlam een temperatuurgradiënt veroorzaakt die loopt van ongeveer $350 \mathrm{~K}$ aan het branderdek tot circa $2000 \mathrm{~K}$ slechts enkele millimeters hoger, ontstaat door het verband met de dichtheid ook een brekingsindexgradiënt in dezelfde richting. Deze brekingsindexgradiënt veroorzaakt een afbuiging van de laserbundel wanneer deze door de vlam heengeschoten wordt. In de resultaten moet deze afbuiging, die in de orde van enkele tientallen micrometers kan zijn, meegenomen worden.

Het methylidyne radicaal, $\mathrm{CH}$ is een kortlevend tussenproduct dat voorkomt in het vlamfront, het gebied van een vlam waar de meeste reacties zich afspelen. De blauwkleurige, 430-nm, spontane emissie straling afkomstig van $\mathrm{CH}$ is zichtbaar in een gebiedje van minder dan $1 \mathrm{~mm}$ dikte en geeft de positie van het vlamfront in goede benadering aan. Het radicaal levert een belangrijk aandeel in de vorming van prompt NO. Doordat $\mathrm{CH}$ slechts in lage dichtheden voorkomt, is het bij simulaties gevoelig voor kleine veranderingen in de reaktieschema's en is het een goede indicator van de betrouwbaarheid van reaktieschema's. De absorptieovergang 
van de $\mathrm{X}^{2} \Pi$ naar de $\mathrm{A}^{2} \Delta$ toestand bij $430 \mathrm{~nm}$ is gebruikt om absolute $\mathrm{CH}$ dichtheden in een voorgemende, atmosferische vlakke vlam te bepalen bij twee verschillende stoichiometriën ( $\phi=1.1$ en 1.2) in een brandergestabiliseerde vlam. De experimenten staan beschreven in Hoofdstuk 3. Signaal/ruis verhoudingen geven aan dat $\mathrm{CH}$ dichtheden van $1110^{10} \mathrm{~cm}^{-3}$, wat correspondeert met $0.4 \mathrm{ppb}$ bij atmosferische druk, nog eenvoudig gedetecteerd kunnen worden. Door gebruikt te maken van de symmetrie van de vlam is met behulp van de Abelse inversie-methode, waarbij metingen als functie van de radiële afstand tot de as van de vlam verricht zijn het radiële $\mathrm{CH}$ dichtheidsprofiel bepaald. Het gemeten dichtheidsprofiel als functie van de hoogte boven het branderoppervlak is gecorrigeerd voor de grootte van de lichtbundel in de resonator via een analytische en een statistisch-mathematische benadering. De resulterende profielen en de gemeten rotationele vlamtemperatuur ter plaatse van het dichtheids-maximum zijn vergeleken met 1D vlamsimulaties, gebruikmakend van de reaktieschema's GRI-Mech 2.11 en 3.0. De experimentele resultaten tonen een lagere maximale $\mathrm{CH}$ concentratie, dichter bij het vlamoppervlak en bij een lagere temperatuur. Dit is geverifiëerd met $\mathrm{CH}$-chemiluminiscentie metingen en door de bepaling van het $\mathrm{OH}$ dichtheidsprofiel gemeten met directe absorptie. Hierdoor kon vastgesteld worden dat de positie van het $\mathrm{CH}$ dichtheidsmaximum niet het resultaat is van een verschuiving van de totale vlamstructuur. De verschillen voor $\mathrm{CH}$ kunnen waarschijnlijk toegeschreven worden aan het reaktiemechanisme.

In Hoofdstuk 4 staat het onderzoek naar ${ }^{1} \mathrm{CH}_{2}$ en $\mathrm{HCO}$ centraal. Het singlet methyleen radicaal ${ }^{1} \mathrm{CH}_{2}$ speelt onder andere een rol bij de vorming van stikstofoxides en roet en het formyl radicaal $\mathrm{HCO}$ heeft een centrale rol bij de oxidatie van koolwaterstoffen. Beide radicalen vertonen absorptie in hetzelfde golflengtegebied rond $620 \mathrm{~nm}$, wat detectie met dezelfde experimentele CRDS opstelling mogelijk maakt. De absorptie door ${ }^{1} \mathrm{CH}_{2}$ vond plaats via de $\tilde{\mathrm{b}}^{1} \mathrm{~B}_{1}(0,13,0) \leftarrow \tilde{\mathrm{a}}^{1} \mathrm{~A}_{1}(0,0,0)$ band bij $622 \mathrm{~nm}$ en door HCO via de $\tilde{\mathrm{A}}^{2} \mathrm{~A}^{\prime}(0,9,0)$ $\leftarrow \tilde{\mathrm{X}}^{2} \mathrm{~A} "(0,0,0)$ band rond $615 \mathrm{~nm}$. De gemeten absolute ${ }^{1} \mathrm{CH}_{2}$ en $\mathrm{HCO}$ dichtheden als functie van de hoogte boven het branderoppervlak zijn vergeleken met numerieke simulaties gebruikmakend van de GRI-Mech 2.11 en 3.0 mechanismes. De vergelijking is bemoeilijkt doordat de dichtheidsprofielen van beide radicalen dicht op het branderoppervlak liggen. De meetresultaten lijken kwalitatief en kwantitatief goed overeen te komen met de numerieke resultaten. De posities van de ${ }^{1} \mathrm{CH}_{2}$ en $\mathrm{HCO}$ dichtheidsprofielen verschuiven in overeenstemming met de berekende trend dichter naar het branderoppervlak wanneer de stoichiometrie verandert van $\phi=1.2$ naar $\phi=1.1$. Detectiegrenzen liggen rond de $16 \mathrm{ppm}$ voor ${ }^{1} \mathrm{CH}_{2}$ en $72 \mathrm{ppm}$ voor $\mathrm{HCO}$ bij een temperatuur van $1600 \mathrm{~K}\left(\mathrm{~S} / \mathrm{N}_{\mathrm{p}-\mathrm{p}}=1\right)$.

Om de problemen die zich bij atmosferisch vlamonderzoek voordoen te verminderen, is een lage-druk branderopstelling opgezet zoals beschreven in Hoofdstuk 6. Doordat de afmetingen van de vlamstructuren omgekeerd evenredig schalen met de druk, kunnen dichtheidsprofielen, die dicht bij het branderoppervlak liggen, bij lagere drukken eenvoudiger bestudeerd worden (ten koste van een verlaging van de dichtheid). CRDS is toegepast op de voorgemengde 
$\mathrm{CH}_{4}$ /air vlakke vlam bij $2 \cdot 10^{4} \mathrm{~Pa}(200 \mathrm{mbar}$ ) om de absolute dichtheden van $\mathrm{OH}$ en $\mathrm{HCO}$ te bepalen als functie van de hoogte boven het branderoppervlak. Twee CCD camera's zijn gebruikt om de uitlijning van de resonator en de ruimtelijke resolutie te optimaliseren. Absorptie door $\mathrm{OH}$ vindt plaats via de $\mathrm{A}^{2} \Sigma \leftarrow \mathrm{X}^{2} \Pi$ overgang rond $308 \mathrm{~nm}$. Absolute $\mathrm{OH}$ dichtheidsprofielen zijn gemeten voor twee verschillende stoichiometrieën ( $\phi=1.1$ en 1.2) in een optisch vlakke, brander-gestabiliseerde vlam. Het dichtheidsprofiel van HCO is gemeten voor $\phi=1.2$. Doordat bij een lagere druk gemeten is, kon in tegenstelling tot de metingen bij atmosferische druk, het complete dichtheidsprofiel gemeten worden. Uit de signaal/ruis verhouding volgt een gevoeligheid van $5 \cdot 10^{9} \mathrm{~cm}^{-3} \mathrm{HCO}\left(\tilde{\mathrm{X}}^{2} \mathrm{~A} "\left(0,0^{1}, 0\right), \mathrm{J}=9\right)$, overeenkomend met een concentratie van 8 ppm HCO bij $1600 \mathrm{~K}$. Een vergelijking van de experimentele resultaten met numerieke simulaties gebruikmakende van GRI-Mech 2.11 toont een redelijke goede kwantitatieve overeenkomst voor het HCO dichtheidsprofiel, maar een verschuiving van de positie van het maximum ten opzichte van de experimentele waarde van $0.8 \mathrm{~mm}$ weg van het branderoppervlak. De berekende $\mathrm{OH}$ dichtheden zijn een factor 2.4 lager dan de experimentele waarden. Het berekende $\mathrm{OH}$ profiel met $\phi=1.2$ is ook verschoven naar een positie verder gelegen ten opzichte van het branderdek.

Naast de toepassing van CRDS direct in vlammen om de dichtheidsprofielen van (kortlevende) radicalen te meten, is het ook goed mogelijk om de techniek toe te passen voor het detecteren en kwantificeren van verschillende verbrandingsproducten. Hoofdstuk 5 beschrijft de detectie van stikstofoxide en stikstofdioxide in de verbrandingsgassen van een oxy-acetyleenvlam en in de uitlaatgassen van een dieselmotor. Allereerst zijn $\mathrm{NO}_{2}$ concentraties varieërend van $0.1 \mathrm{ppm}$ tot $15 \mathrm{ppm}$ in een gascel gemeten om de absorptiecrosssecties in het gebied tussen $437 \mathrm{~nm}$ en $450 \mathrm{~nm}$ te bepalen. De gevoeligheid lag in de orde van 50 ppb. Daarna is CRDS toegepast op de detectie van $\mathrm{NO}_{2}$ in de verbrandingsgassen van een oxyacetyleen vlam. Tenslotte is CRDS toegepast voor de detectie van $\mathrm{NO}$ en $\mathrm{NO}_{2}$ in de uitlaatgassen van de dieselmotor van een truck. Op dit moment worden bepalingen van stikstofoxides in uitlaatgas via een chemische stap gedaan waarbij alle $\mathrm{NO}_{2}$ omgezet wordt in NO en detectie van fluorescentie van NO plaats vindt. Eenvoudiger en daardoor minder onderhevig aan fouten is de directe optische detectie van stikstofoxides met behulp van een gevoelige absorptietechniek als CRDS. Doordat de frequenties van de gebruikte elektronische overgangen van $\mathrm{NO}$ precies het dubbele is van een sterke overgang van $\mathrm{NO}_{2}$, is detectie met hetzelfde lasersysteem mogelijk en zijn slechts kleine veranderingen nodig bij omschakeling van het ene naar het andere deeltje. NO is gedetecteerd door excitatie van de $\mathrm{X}^{2} \Pi$ grondtoestand naar de $\mathrm{A}^{2} \Sigma^{+}$aangeslagen toestand bij $226 \mathrm{~nm}$ en $\mathrm{NO}_{2}$ door de absorptie van licht in het gebied tussen $438 \mathrm{~nm}$ en $450 \mathrm{~nm}$. De concentraties die in situ gemeten zijn in de verbrandingsgassen van de motor liggen op $212 \pm 22$ ppm en $29 \pm 4$ ppm voor $\mathrm{NO}$ en $\mathrm{NO}_{2}$ en komen goed overeen met de resultaten van een geautomatiseerde chemische gasanalyse. De detectiegevoeligheden liggen rond de 500 ppb voor $\mathrm{NO}$ en 30 ppb voor $\mathrm{NO}_{2}$ en bieden de 
mogelijkheid tot de ontwikkeling van een eenvoudige, handzame optische detector van stikstofoxides.

Naar verwachting zullen in de toekomst door de voortdurende ontwikkeling van (vaste-stof) lasersystemen en de verdere verbetering van optische componenten zoals spiegelcoatings, zeer gevoelige, compacte detectoren gebaseerd op optische absorptie en het CRDS principe beschikbaar komen. Hierdoor kunnen bijvoorbeeld metingen aan de uitlaatgassen van één enkele cylinder en één enkele slag mogelijk zijn. De ontwikkelingen in het veld van verbrandingsonderzoek zal zich nog meer richten op de combinatie met andere optische technieken zoals LIF om sneller een compleet beeld van de verbranding te kunnen vormen en om naar kleinere tijdsschalen te kunnen gaan, zodat wellicht ook turbulentere verbrandingsprocessen kwantitatief in kaart gebracht kunnen worden. 



\section{Curriculum Vitae}

\section{Personal Information}
Full Name:
Rogier Evertsen
Place and date of birth:
Haarlem, 1-VIII-1972

\section{Education}

$1984-1990$

Gymnasium B, Spaarne Scholengemeenschap, Haarlem

1990 - 1996 Chemistry, Free University of Amsterdam (VUA)

Major: General and Analytical Chemistry: Spectroscopy

Fluorescence line-narrowing for the identification and quantification of B[a]P-DNA adducts on PEI-cellulose TLC plates

Paper: On-line coupled techniques with capillary zone electrophoresis

Minor: Physical and Theoretical Chemistry: Physical Chemistry

LIF and bolometric detection of the IR-spectrum of $\mathrm{NO}_{2}$

Minor: Faculty of Chemistry, Bates College, Lewiston, USA

Development of a solid phase lanthanide luminescence detector

1997 - 2001 PhD research project, Applied Physics, University of Nijmegen (KUN)

Laser techniques for quantitative measurements in combustion processes

\section{Research and Teaching Tasks}

1996

Student assistant at General and Analytical Chemistry, VUA

$1996-1997$

Junior research scientist chemistry, VUA

$1997-2001$

Supervision of students and visiting PhD students, KUN

Supervision of practical courses for physics students, KUN

Tutor of the course on quantum mechanics for chemists , KUN 



\section{Publications}

Evertsen, R., Van Oijen, J.A., De Goey, L.P.H., Ter Meulen, J.J.; Absolute ${ }^{1} \mathrm{CH}_{2}$ and HCO concentration measurements in a premixed atmospheric flat flame by cavity ring-down spectroscopy, Combust. Flame, in preparation.

Evertsen, R., Van Oijen, J.A., De Goey, L.P.H., Ter Meulen, J.J.; Absolute CH concentration measurements in a premixed atmospheric flat flame by cavity ring-down spectroscopy, Combust. Flame, accepted.

Evertsen, R., Ter Meulen, J.J.: Vlammen in vacuüm: laserdiagnostiek voor een beter begrip van verbranding, NEVACBLAD, May 2002.

Evertsen, R., Staicu, A., Dam, N., Van Vliet, A., Ter Meulen, J.J.; Pulsed cavity ring-down spectroscopy of $\mathrm{NO}$ and $\mathrm{NO}_{2}$ in the exhaust of a running diesel engine, Appl. Phys. B 74: 465-468, 2002.

Staicu, A., Evertsen, R., Dam, N.J., Ter Meulen, J.J.; Cavity ring-down spectroscopy and laser induced fluorescence for $\mathrm{NO}_{2}$ detection, ROMOPTO 2000: Sixth conference on optics, Proc. SPIE, 4430, 620-627, 2001.

Evertsen, R., Peeters, R.; Een vuiltje aan de lucht, De Ingenieur, 1: 24-25 2000.

Kok, S.J., Evertsen, R., Velthorst, N.H., Brinkman, U.A.T., Gooijer, C.; On the coupling of fluorescence line-narrowing spectroscopy and poly(ethylene)imine-cellulose thin-layer chromatography, Anal. Chim. Acta 405: 1-7 2000.

Evertsen, R., Stolk, R.L., Ter Meulen, J.J.; Investigations of cavity ring down spectroscopy applied to the detection of $\mathrm{CH}$ in atmospheric flames; Combust. Sci. Technol. 149: 19-34 1999; 157: 341-342 2000.

Wenzel, T.J., Evertsen, R., Perrins, B.E., Light, T.B., Bean, A.C.; Solid phase lanthanide luminescence detection in liquid chromatography, Anal. Chem. 70: 2085-2091 1998. 


